\title{
An Exploration of How University Development Officers Can Cultivate Year 0 Alums
}

\author{
Lily McKnight \\ West Virginia University, Imm0026@mix.wvu.edu
}

Follow this and additional works at: https://researchrepository.wvu.edu/etd

Part of the Communication Technology and New Media Commons, Journalism Studies Commons, and the Social Media Commons

\section{Recommended Citation}

McKnight, Lily, "An Exploration of How University Development Officers Can Cultivate Year 0 Alums" (2021). Graduate Theses, Dissertations, and Problem Reports. 8052.

https://researchrepository.wvu.edu/etd/8052

This Problem/Project Report is protected by copyright and/or related rights. It has been brought to you by the The Research Repository @WVU with permission from the rights-holder(s). You are free to use this Problem/Project Report in any way that is permitted by the copyright and related rights legislation that applies to your use. For other uses you must obtain permission from the rights-holder(s) directly, unless additional rights are indicated by a Creative Commons license in the record and/ or on the work itself. This Problem/Project Report has been accepted for inclusion in WVU Graduate Theses, Dissertations, and Problem Reports collection by an authorized administrator of The Research Repository @ WVU. For more information, please contact researchrepository@mail.wvu.edu. 
Graduate Theses, Dissertations, and Problem Reports

2021

\section{An Exploration of How University Development Officers Can Cultivate Year 0 Alums}

Lily McKnight

Follow this and additional works at: https://researchrepository.wvu.edu/etd

Part of the Communication Technology and New Media Commons, Journalism Studies Commons, and the Social Media Commons 
An Exploration of How University Development Officers Can Cultivate Year 0 Alums

\author{
Project submitted \\ to the Reed College of Media \\ at West Virginia University \\ in partial fulfillment of the requirements for the degree of \\ Master of Science in \\ Journalism
}

Geah Pressgrove, Ph.D., Chair

Steve Urbanski, Ph.D.

Julia Daisy Fraustino, Ph.D.

Kirsten Barnicle, Ph.D.

Department of Journalism

Morgantown, WV

2021

Keywords: donor relations, higher education, participatory action research, humancentered design, stewardship, fundraising and Year 0 Alumni 


\section{ABSTRACT \\ An Exploration of How University Development Officers Can Cultivate Year 0 Alums}

Lily McKnight

As higher education in West Virginia continues to lose state funding, students' tuition is increasing to fill the gap. These tuition increases have led to an increased reliance on private funding and a need to creatively approach engaging new potential donors. Year 0 Alumni are an ignored group of stakeholders when it comes to university fundraising, likely due to their limited potential to make large gifts. However, cultivating these relationships demonstrates the long view necessary for future planning, while providing a novel approach for smaller gifts that can accumulate to meaningful support to address the current emerging need.

To this end, this professional project explores new strategies to cultivate Year 0 Alumni as future university donors. By employing a Participatory Action Research (PAR) and Human-Centered Design approach, the author aims to understand the factors that might lead to increased postgraduation engagement. Drawing on fundraising, public relations and stewardship scholarship, the author conducted workshops with student ambassadors that are part of a small unit at a large land-grant flagship state university. As these students did not have extensive experience with financial giving, the author incorporated photovoice to provide these students a pathway for illustrating the strengths of their current relationship and the potential for a future commitment to the college. The project resulted in two key outcomes: a participant-created photo exhibit and a co-created strategic plan for the college's development officer. In so doing, the project informs future campaign planning in terms of appeal, message and visual 


\section{Acknowledgments}

This project would not have come to together without the support of many. The most thanks is to my chair Dr. Pressgrove who must've read this a thousand times. Thank you for helping me through this entire process. Also thanks to my committee members for offering me guidance and support during this virtual time. Thank you to Whitney Godwin for providing me with a Graduate Assistantship that allowed me to pursue this degree and project. Another round of thanks goes to my friends and family for the endless love-especially my grandparents who funded my college education. 


\section{Table of Contents}

Chapter 1: Introduction..............................................

Chapter 2: Literature Review..................................... 3

Research Questions.................................................. 9

Chapter 3: Methods.............................................. 15

Chapter 4: Part One................................................. 18

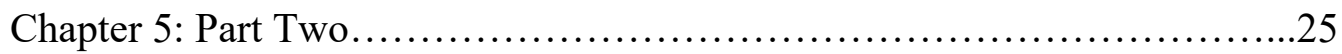

Chapter 6: Discussion and Conclusion..................................34

Chapter 7: Limitations..............................................41

References........................................................43

Appendices........................................................... 51 


\section{Chapter 1: Introduction}

Development officers, responsible for raising funds for higher education institutions, are ignoring a key group of stakeholders - Generation Z. Instead, higher-ed development officers have looked towards older, established alumni for financial gifts. Trends, however, have shown that Gen Z (90 million people in the United States' population) like to donate and get involved (Gen Z Donors, 2019). In fact, 44\% percent of this age group (representing 9.3 million people) gave an average of $\$ 341$ in 2017 to 4.6 charities, for a total of $\$ 3.2$ billion (Giving by Generation, 2019). Further, for this generation of new alums, higher education is of the utmost importance. In fact, recent research indicates that individuals with bachelor's degrees earn on average $\$ 32,000$ more than those with just high school diplomas (Edelson, 2020). Recognizing the potential of this confluence of factors, this project will focus on donor development of Gen $\mathrm{Z}$ alums at a land grant institution in a state with significant economic challenges. Further, the focus will look not at a large campus unit, but instead a small college within the larger institution.

In the state of West Virginia, the reality is that some students are not given the opportunity to gain the competitive life advantage afforded by a college degree due to financial circumstances. According to the 2019 U.S. Census, West Virginia ranked as the poorest state with a median household income of $\$ 44,921$ and a $16 \%$ poverty rate. Additionally, in 2018 , the State of West Virginia cut the budgets for their higher education institutions by $\$ 16$ million (McElhinny, 2017). To make up this financial gap, tuition and fees have grown. This increase in expenses for students translates to post-graduation debt of more than $\$ 19,000$ (WVU Foundation, n.d.). This has resulted in increased competition among the state's institutions of higher learning for donor dollars that would support student scholarships. 
The need for donor support for scholarships is particularly evident at the state's land grant institution, West Virginia University (WVU), where one in eight students are the first in their family to seek a higher education. For many of the students aspiring to become a Mountaineer, pursuing a college degree is directly connected to the institution's ability to provide scholarships. These scholarships are often funded by private gifts from donors; yet, the number of donors and financial gifts from the same established donors has its limits. To this end, this proposal will explore the opportunity to cultivate relationships with a new segment of donors, recent graduates who are also known as Year 0 alums.

To gain perspective, this project will focus on the 750 undergraduate and 260 graduate students in the WVU Reed College of Media. Given its comparatively small size and familial feel, this college provides an ideal case study for this research. For many of the College's students, privately funded merit is crucial to providing the financial resources they need to be successful. In fact, according to the Dean of Advising, there are 70 privately funded scholarships through the Reed College of Media (T. Petty, personal communication, October 22, 2020). Scholarship and philanthropy conducted by the WVU Reed College is an investment not only in the students attending but also one in the state's future.

Simply put, more private philanthropy is needed in the Reed College of Media. This will lead to more scholarships and college degrees for media students. To better inform opportunities to engage a new generation of donors, this research project will explore what might compel Year 0 alums of the Reed College of Media to become higher education donors. To accomplish this, the author employed participatory action research (PAR) and human-centered design (HCD) to co-create a donor relations strategy for the college's development professionals. As part of the project, photovoice methods were used and resulted in a student-created photo-narrative exhibit. 
Ultimately, this photo-narrative exhibit will give a voice to those Year 0 alums who may not have words when it comes to their future commitment to the Reed College of Media and help inform a better understanding of their views on financial giving to the college. This project, upon its conclusion, can also serve as a template for other organizations who also rely heavily on funding for their functionality.

\section{Chapter 2: Literature Review}

In this research proposal, it is vital to organize key concepts and synthesize what has been previously found. To be in conversation with other existing literature, this literature review will explore other work on fundraising and donor relations, Year 0 alumni, stewardship, participatory action research and human-centered design.

\section{Fundraising \& Donor Relations}

Fundraising can be viewed as a systematic activity aimed primarily at raising financial resources for an organization or institution (Hommerová \& Severová, 2019). Kelly (1998) defines fundraising as: "the management of relationships between a charitable organization and its donor publics," (p. 8). Further, when it comes to goals of fundraising, Edles (1993) indicates that successful fundraising campaigns must be specific, attractive, people-oriented and have a sense of urgency. Wedgeworth (2002) says that in terms of goals, fundraising should convey a sense of how the institution or organization sees itself in the future. These principles and goals provide a foundation for the approach to this project exploring the cultivation of relationships with Year 0 donors in higher education.

In developing the approach for this project, it was important to acknowledge nonprofit scholarship that has stressed the importance of communications and public relations in

fundraising (e.g., Waters, 2009 \& 2013; Worley \& Little, 2001; Grunig \& Hunt, 1984). Grunig 
and Hunt (1984) define public relations as, "the management of communication between an organization and its public (p. 6). Given this definition, Wedgeworth (2000) says that the management of donor relationships is a specialized form of public relations. In previous research, scholars have stressed the importance of relationships in fundraising and how they can result in increased donor loyalty to the organization, especially by dedicating more time to these donor relationships (O’Neil, 2007; Worth 2002). Waters (2013) says that the field of public relations has a large impact on fundraising due to the similar processes and strategies that both public relations and fundraising practitioners use when it comes to relationship management. In fact, some scholars have argued that these fields are interconnected because of the way they both rely on establishing, cultivating and maintaining relationships with donors (Worley \& Little, 2001). Thus, donor relations and public relations scholarship will inform the planning for the project.

Donor relations is a set of strategies that are in place to help an organization build its relationships with those who contribute to that organization (Hendrick, 2009). Previously, donor relations has been studied and used in athletic giving (Wanless, Pierce, Martinez, LawrenceBenedict \& Kopka, 2017) disaster relief (Caviola, Schubert \& Nemirow, 2020) and higher education (Harrison, 1995; Tindall, 2007; Lara \& Johnson, 2013). Donor relationships especially play a major role in higher education as tuition in higher education across the country rises due to decreased funding from the government (Pew, 2019). Hendrick (2009) says donor relations strategies include specific aspects such as acknowledgement, recognition and stewardship (p. 4). These strategies are particularly important concepts that guide this work.

Furthermore, in higher education donor relations, each individual alumnus and alumna's reaction to the institutional solicitation is unique, based on factors such as the student's own 
experience attending the institution (Button Renz, 2010). Further, the likelihood of giving postgraduation has been linked to factors such as sociodemographic characteristics, current financial support, and college encounters/experiences (Freeland, Spenner \& McCalmon, 2015). In other recent studies, scholars have found that some factors are more important than others when it comes to donor relations in higher education. Some of these factors include religion (Cascione, 2003; Wuthnow \& Hodgkinson, 1990; Gallo, 2013), identity (Drezner, 2018), ethnicity and race (Tindall, 2007) and morals (Drezner, 2010). Although this literature discusses the factors that scholars found to be most important in donor relations, to the author's knowledge, this body of scholarship does not consider the giving potential and fundraising opportunities for new graduates. The unique attributes of this demographic will be discussed later in the literature review.

\section{Stewardship}

Due to the uniqueness of Year 0 alumni, cultivating relationships best practices in public relations and donor relations are central. As stated by Hendrick (2009), stewardship is an essential aspect of the relationship management process. As defined by Kelly (2001) stewardship is the fifth step in public relations. In fact, she posits that the popular ROPE model of public relations, composed of research, objectives, programming, and evaluation (ROPE), is made cyclical by the addition of stewardship (Kelly, 1998). As explained by Greenfield (1999), the purpose of stewardship is to "establish the means for continued communication that will help to preserve their interest and attention to the organization" (p. 148). Thus, the project's aims of cultivating Year 0 alumni will be guided by an understanding of this approach to relationship cultivation. 
In Kelly’s conceptualization, stewardship has four dimensions: reciprocity, responsibility, reporting, and relationship nurturing (Kelly, 1998, 2001). Building on this work, Pressgrove, McKeever and Collins (2015) defined these stewardship dimensions as follows. First, responsibility is the general overarching statements related to mission fulfillment including stories and human-interest pieces that showcase mission fulfillment. Similarly, Reporting is also related to sharing information related to how the mission is fulfilled, but instead relies on specific quantifiable statements of success. Considering the importance of thanking donors, reciprocity focuses on visible signs of listening to different publics; the process of thanking donors, volunteers, and other organizational supporters for their contribution to the organization. The process of engaging donors is captured by the dimension of relationship nurturing which focuses on opportunities for initiating and/or participating in dialogue with existing and potential stakeholders and the opportunity for publics to do something for/with the organization.

In recent years, Pressgrove (2017) advanced our understanding of stewardship by developing a comprehensive way to measure perceptions of stewardship quantitatively. In this work, she found that reciprocity actually represents two dimensions she calls regard and recognition. The researcher says that the dimension of regard is more about personalized/individual acknowledgements and recognition is a more public affair as organizations publicly shine a spotlight on donors. Understanding all five dimensions of stewardship is important as scholars have demonstrated that they are key factors in effective relationship management in nonprofit public relations and further different dimensions of stewardship lead to varying outcomes (Hon \& Grunig 1999; Greenfield, 1991; Pressgrove, 2017). 
As the concept of stewardship has evolved, scholars have studied it in the context of nonprofit fundraising (Worley \& Little 2002; Whitchurch \& Comer, 2016); cultivating online relationships (Waters, 2011) and tourism (Melvin, 2020). In this work, scholars have approached their work both quantitatively and qualitatively. For example, scholars like Li, Men \& Yue (2020) found additional evidence of the utility of the four stewardship strategies as they conducted in-depth interviews with fundraising professionals. In a case study exploring The Coaches Vs. Cancer Campaign, Worley \& Little (2002) traced campaign shortcomings back to a failure to carry out the responsibility dimension and failure to properly identify audience expectations (Worley \& Little, 2002). These studies and the reviewed literature will guide this project approach.

\section{Year 0 Alumni}

In recent years, scholars have lauded the importance of engaging Year 0 alumni as they begin to graduate college and begin the next chapter of their lives (Singh \& Dangmei, 2016; Schwieger \& Ladwig, 2018; Francis \& Hoefel, 2018). Currently, this generation is mostly composed of Generation Z, the first digital natives. Following the Millennial generation, Generation $\mathrm{Z}$ has their own set of characteristics unique to them that are important to understand when fundraising and targeting them as potential donors.

According to the U.S. Census Bureau, this generation is considered to be the most diverse generation, with more than half of the population coming from different minority groups (Wang, 2018). Due to their upbringings, Generation $Z$ does truly believe that they have the power to change the world; therefore, a special approach is needed to create a strong relationship for postgraduation support. When building this relationship, it is important that when engaging Generation Z, they feel in control (Kizuk, 2015). Previous research has also shown that 
Generation $\mathrm{Z}$ have never known a world where they could not instantly connect, communicate or get answers instantly (Schwieger \& Ladwig, 2018). Year 0 alumni are best engaged through flexibility as they need options to choose from (Rothman, 2016).

Previous research on young collegiate alumni also has shown that new graduates are heavily influenced by peer pressure when it comes to giving post-graduation (Meer \& Rosen, 2018). Other scholars in this field, like Seltzer (2016) highlighted that young alumni are attracted through social media, texting and crowdfunding, particularly as crowdfunding supports smaller donations. When studying this group as potential donors, it is also important to take into consideration Meer and Rosen's (2012) annoyance effect where young alumni are less likely to give back to their institution due to their accumulation of student loan debt. While this literature review aims to understand how to best approach Year 0 alumni through donor strategies, it is vital to expand on what could affect this group in the unique socio-cultural context of the target university.

Generation $\mathrm{Z}$ has been shaped by the advancement of technology, issues of violence, a volatile economy and different social justice movements after witnessing historical moments like the legalization of same-sex marriage and the beginning of the Black Lives Matter movement (Seemiller \& Grace, 2017). Seeing these pivotal moments in history has had an influence on Gen $\mathrm{Z}$, as a recent study found that $32 \%$ have donated their own money or allowances (Goldstraw, 2019). Their demonstration of support for things that matter to them doesn't just include money; $77 \%$ of Generation Z are extremely interested in volunteering opportunities (Classy, 2018).

These characteristics should also influence the way Gen $\mathrm{Z}$ is being approached through donor relations strategies. Further, recognizing that Gen $\mathrm{Z}$ likes to feel in charge, receive instant feedback and is tech savvy will be instrumental in developing this project. 


\section{Research Questions}

Based on the reviewed literature the following research question is advanced to guide this project's development and execution.

RQ1: What might compel Year 0 alums of a small college within a larger university to become a donor?

To answer this research question, this professional project will proceed drawing on the best practices of participatory action research and human-centered design. As part of the data collection and analysis, photovoice will be employed to give Year 0 alums a voice in donor relations approaches that target them. The dimensions of stewardship will be used to guide data collection and analysis. Each of the approaches are detailed below.

\section{Participatory Action Research}

Participatory action research (PAR) is a methodology that seeks to understand and improve the world (Baum, MacDougall \& Smith, 2006). To accomplish this, PAR allows researchers to actively engage and collaborate with members of the study population on all phases of a project (Gershon, Rubin, Qureshi, Canton \& Matzner, 2018). This method creates a shared language between researcher and participants that allows researchers to participate in and develop the forms of action that will be used to meet the needs of changing times and circumstances (Kemmis, McTaggart \& Nixon, 2013). The primary aim of this approach is to engage community members as co-researchers to guide personal and social change and give those previously marginalized a voice (Cargo \& Mercer, 2008; Minkler, 2010; Kidd \& Kral, 2005).

In recent years, this approach has been used to explore advocacy opportunities (Bell, 2007; \& Becker, Reiser, Lambert, \& Covello, 2014), disaster research (Gershon et al., 2008; 
Lykes \& Scheib, 2016; Jones, Hob, Kunc, Milsomd, Shakpehe, Ratnayakea \& Loewensonf, 2018) community change (Accoe, Marchal, Gnokane, Abdellahi, Bossyns \& Criel, 2020) and public health research (Ritterbusch, 2016 \& Ahari, Habibzadeh, Yousefi, Amani \& Abdi, 2012). Building on this work, scholars also have used this approach to engage younger audiences through youth participatory action research (YPAR) (Wilson, Dasho, Martin, Wallerstein, Wang, \& Minkler, 2007; Zenkov \& Harmon, 2009; Kohfeldt, Chhun, Grace \& Langhout, 2010). Discussed by Burke \& Hadley (2018), YPAR practices include collaborative dialogue, participatory decision-making and the maximal participation and representation of all relevant parties. YPAR reflects both the needs of research focused on Gen Z and the project aim of cocreating donor relations strategies that cultivate relationships with them.

In reviewing the PAR methodology, numerous approaches were found. For example, PAR has been used as an approach by scholars to understand public health case studies through community interviews (Accoe et al., 2020), to promote the inclusion of disadvantaged adolescent girls in decision-making and action related to the reduction of vulnerability and risk through focus group discussions (Forbes-Genade \& van Niekerk, 2019), and to understand communitybased needs in urban areas through questionnaires and face-to-face interviews (Ahari et al., 2012). In fact, unlike other methodological approaches in the communication field, there seems to be no consistent mold. For example, Ahari et al. (2012) used surveys and questionnaires along with face-to-face interviews, Van der Riet \& Boettiger (2009) used group interviews and Adams, Burns \& Liebzeit (2012) used Photovoice.

The different ways scholars have conducted PAR research have also varied in terms of sampling methods. A review of the literature found that convenience sampling is quite prevalent (Morrison, Akter, Jennings, Nahar, Kuddus, Shaha, Ahmed, King, Haghparast-Bidgoli, Costello, 
Khan, Azad \& Fottrell, 2019). Similarly, Budig, Diez, Conde, Sastre, Hernán \& Franco (2018) also took a nonprobability sampling approach, using purposive sampling based on residence locations. Consistent across all approaches, as scholars like Ahari et al. (2012) found, a participatory action approach assures a community's viewpoint is considered so that trust can be built and action plans developed collaboratively. The highly engaged nature of this type of work necessitates a flexible sampling approach to accommodate for the needs of the research, the desired outcomes and community impact, as well as the time commitment necessary. As Baum, MacDougall \& Smith (2006) define, "PAR advocates that those being researched should be involved in the process actively" (p. 854).

\section{User \& Human-Centered Design}

Reflecting a desire to develop a project based on a successful methodology, the author explored the related methodological approach known as User-Centered Design (UCD). UCD is a design philosophy that places the needs, wants, and desires of users at the center of the process, allowing these needs and desires to drive the development of a product, system, or service (Dorrington, Wilkinson, Tasker, \& Walters, 2016). UCD takes into consideration end-users' influences and experiences when designing solutions and allows users' contributions at every stage (Dorrington et al., 2016; Abras, Maloney-Krichmar \& Preece, 2004). In terms of data collection and analysis, UCD uses many different approaches, such as journey mapping, participatory design, rapid prototyping and usability testing (Cornet, Toscos, Bolchini, Ghahari, Ahmed, Daley, Mirro \& Holden, 2020). These tools go beyond just a traditional interview or questionnaire because they unleash participants' creativity and help researchers arrive at more innovative solutions (Design Kit, n.d.). 
Often used synonymous with UCD, human-centered design (HCD) is also a creative approach to problem solving specifically pioneered by the design firm IDEO (Design Kit, n.d.). It is an approach that starts with the people needing designed for and produces solutions best suited to their needs (Design Kit, n.d.). HCD has a well-defined approach composed of three phases: the Inspiration phase, the Ideation phase and the Implementation phase (Design Kit, n.d.). In the Inspiration phase, researchers can learn directly from the people they're designing for (Design Kit, n.d.). During the Inspiration phase, common tools researchers use to understand their participants include interviews, observation and photo journaling (Design Kit, n.d.). In the Ideation phase, researchers make a sense of what they learned and start to identify opportunities for designing prototypes for solutions (Design Kit, n.d.). Tools in this phase can include brainstorming, storyboards, role play and journey maps (Design Kit, n.d.). Lastly, in the Implementation Phase researchers implement a solution to help the community they are working with (Design Kit, n.d.). This phase can include tools such as live prototyping, piloting, scalability and funding strategies (Design Kit, n.d.).

While largely considered a practitioner approach rather than academic approach, HCD has been used by scholars in public health (Sedlmayr, 2018), art history and design (Goransdotter \& Redstrom, 2018) and technology accessibility and development (Dorrington et al., 2016 \& Morgan, 2016). In the professional world, the HCD approach has benefited groups like Ghanaians without in-home toilets through Ideo.org's Clean Team project that used the Inspiration, Ideation and Implementation phases to develop a comprehensive sanitation system, (Design Kit, n.d.). In Chicago's public high schools HCD was used to develop a mentoring program called Moneythink (Design Kit, n.d.). Further, other groups like regional dancers have used HCD to create multimedia educational platforms (Sitorus \& Allwine, 2020). 
There are many similarities and differences between PAR and HCD. As stated above, PAR is typically used in academic settings to give a voice to marginalized audiences and $\mathrm{UCD} / \mathrm{HCD}$ is all about co-creating solutions in the professional setting. Collectively, these approaches provide the foundation for this professional project. Given that Year 0 donors have historically been overlooked in donor relations (since they are not always seen as viable for large gifts) this approach will provide a space for their marginalized voices to be heard. Further, PAR and UCD are an essential pairing to fill this gap because together, these methods have kept a balance between enjoyment and learning (Guo \& Goh, 2016) — an approach necessary to properly engage this generation.

\section{Photo Journaling \& Photovoice}

While PAR and $\mathrm{UCD} / \mathrm{HCD}$ provide a framework for addressing this project's research question, photo journaling and photovoice provide a pathway for the data collection, analysis and co-creation of solutions. In previous work, photovoice has been used as a tool in PAR work, while photo journaling has been advanced as a potential approach to the Inspiration phase of HCD. This image-based approach goes beyond an in-person interview or focus group, and will provide Year 0 alumni a way to visualize and explore their potential future monetary commitment to the Reed College of Media. As Ideo.org's Design Kit discusses, with just a prompt, or minimal instructions, participants can capture images that provide researchers a view into someone's life that they wouldn't find through traditional methods (Design Kit, n.d.).

While different terms have been used to describe this approach, they are very similar. Photo journaling is used in the Inspiration phase of HCD as a visual way to get a glimpse into people's lives and empower them to tell their own stories (Design Kit, n.d.). Photovoice is a qualitative method of inquiry used to actively engage participants who may have difficulty 
verbally articulating their thoughts (Annang et al., 2016; Wang, 2004). Reinforcing the similarities, Heffron et al. (2018) defined the goal of photovoice as a tool to ultimately help those in communities who have previously been marginalized have a voice in their community. Given these similarities, both approaches inform this professional project.

In recent scholarship, photovoice has been used to explore and better understand mental health advocacy (Becker et al., 2014), public health (Jones et al., 2018) and disaster relief (Annang et al., 2016; Gershon et al., 2008; Lykes \& Scheib, 2016). Scholars have found that using photovoice allows participants to embrace creativity (Simmonds, Roux \& Avast, 2015), record and vivify their community's strengths and concerns (Wang, 2006) and is a tool in helping enable participants to reflect on their own cities (Ronzi, Pope, Orton \& Bruce, 2016). Building on these studies and further informing the design of this professional project, photovoice was used in the 2007 Cabin Creek Project. In this project, photovoice was a tool for organizing for change in Central Appalachia by the creation of a community-made photo exhibit (Bell, 2007).

To begin the process of photovoice, a PAR approach is taken as participants who have been marginalized are chosen through the researcher's inclusion criteria and briefed on the project. Participants are then given a prompt that should inspire their picture taking and a means by which they can take these pictures. Participants are given a timeframe and a set number of photos and then begin capturing. In a lot of recent work, HCD methods have also been incorporated as participants are then interviewed via focus group or in-depth interviews (Heffron, Spassiani, Angell \& Hammel, 2018). Consistent in all approaches, once photos are captured, they are shared with others to encourage reflection and dialogue (Weinronk et al., 2018). In some instances, these photos are put together as a photo narrative piece (Lykes \& 
Scheib, 2016) or projects like Bell (2007) used participants' photos to create a photo exhibit for the community.

Photovoice can act as a successful method for this project since Year 0 alums don't have a history of giving. Because of this lack of history, finding words to describe their views on fundraising and donor relations would be difficult; however, this generation likes to visually document their life and always has a phone handy. So handy, that a recent report found that Gen $\mathrm{Z}$ spend an average 4 hours and 15 minutes per day on mobile with $95 \%$ of them owning a smartphone (Freier, 2019). Therefore, using this approach allows for deeper dialogue and an investigation of their perceptions of stewardship approaches.

\section{Chapter 3: Methods}

In this section, the approach for this professional project is reviewed. First, the approach to developing and recruiting the sample is discussed. Then, the two-part procedure for data collection and analysis is reviewed.

\section{Sampling}

Similar to past PAR work reviewed above, this project also used a convenience sample. For the purposes of this work, student ambassadors in the Reed College of Media were selected as the participant pool. Student ambassadors are selected by the Reed College's recruitment specialist through an application process during the end of the spring semester each year. Each candidate for the ambassador position interviewed to determine their willingness and ability to proudly represent their college as leaders in media. During their time as ambassadors, they help with social media initiatives for the college, create content and served on student panels for potential students. 
Ten out of the 20 student ambassadors were selected to participate in this project based on their graduation year, major and availability. The author selected students with a variety of Reed College majors including advertising and public relations, journalism, interactive media design and sports and adventure media. The author currently works in the student services center as a graduate assistant and works closely with these students. This relationship allowed for selection of participants that represent varying backgrounds, interests and perspectives. Further, the author already knew their contact information, work ethic, majors and general schedules, which helped to facilitate the execution of the proposed approach. Ultimately, five students were able to participate in both parts.

Given the COVID-19 pandemic, student ambassadors who were not currently on campus were still given the option to be participants, thus allowing a mixture of both in-state and out-ofstate students. Selected student ambassadors were asked to participate via email (see Appendix A). This project received IRB Flex approval in the Spring 2021 semester (see Appendix J).

\section{Overview of Procedure}

After student ambassadors were selected, one meeting and two workshops were scheduled. Both the meeting and workshop times were arranged via email using a Doodle Poll. The meeting lasted approximately one hour, and workshops lasted approximately two hours. The meeting was held via Zoom, as were the workshops. The workshops also included the interactive platform Google Jamboard. This platform was compatible with students' university emails and was user-friendly.

In Part One, the first meeting was held via Zoom in mid-February to provide students with an overview of the project and tutorial on how to use Google Jamboard. During the meeting, participants were also given their first prompt (outlined in more detail below). The first 
workshop also took place virtually approximately two weeks later in early March (outlined in more detail below). Before the meeting, in accordance with IRB approval, student ambassadors received a letter via email that outlined their rights as participants (see Appendix B) and gave their verbal consent for recording before beginning the workshop. The aim of the workshop was to understand how these students visualize their connection to the College of Media and were also used to develop the photo exhibit component of this project.

To kick off Part Two, participants received an email in late March explaining the next phase of the project (see Appendix E). Then, participants were briefed for participation in the second part of the project (outlined in more detail below) (see Appendix F). In this email, participants were informed of the definitions of the five stewardship dimensions (see Appendix F). The second workshop was held virtually approximately two weeks later in early April for roughly two hours. The objective of this workshop was to understand how the College of Media could cultivate a relationship with these individuals by exploring the dimensions of stewardship. Based on this workshop, recommendations for a strategic plan were developed and proposed to the College of Media development officer in mid-April.

Findings from this phased approach allowed the author to explore the research question guiding this study: What would compel Year 0 alums of a small college within a larger university to become a donor? In Part One, the participants helped to identify visual cues that exemplify their relationship with the College of Media. In Part Two, they helped to identify the messages, strategies and tactics that provided a foundation to the strategic plan recommendations. All meetings were recorded via Zoom. Transcripts were used to identify key insights (see Appendix N \& P), as were the field notes the author compiled during the workshop (see Appendix M \& O). 


\section{Chapter 4: Part One}

\section{Detailed Review of Part One}

Building on the above brief synopsis, the following provides a detailed description of how participants were guided through the PAR/HCD process in the Part One workshop.

\section{Inspiration Phase:}

Upon returning to campus in January, participants were sent an email containing a Doodle Poll that determined the group's first Zoom meeting. This meeting took place in midFebruary. During the meeting, participants were briefed on the project as a whole, the workshops, the planned photo exhibit and provided their first photovoice prompt of "What makes you proud to be in the Reed College family?" During the meeting, participants were also given a brief tutorial on the platform Google Jamboard. Students were taught how to access the Jamboard through their university emails and upload their future photos to the board. Students were given two weeks to gather three pictures that responded to the prompt. Participants were allowed to curate existing pictures from their past experiences and/or take new photos in response to the prompt. This meeting lasted approximately an hour.

Following the meeting, participants were sent a follow-up email (see Appendix C) recapping the project and reminding them of their prompt. This email contained another Doodle Poll containing times for the HCD Part One workshop outlined below in the Ideation Phase. This workshop was held virtually and lasted approximately two hours. The workshop was held in early March (two weeks after the meeting).

\section{Ideation Phase:}

During the Part One workshop, five participants met via Zoom and Google Jamboard to carry out the above outlined procedure. The workshop lasted approximately an two hours and 
was recorded and transcribed via Zoom (see Appendix N). The group was moderated by the author based on the Moderator Guide One (see Appendix D). Each ambassador was given their own Jamboard that was labeled with their name where they were instructed to upload their prompt response photos. Students then collaborated with their peers to carry out the Ideation Phase of HCD by deciding on narratives for their chosen photos. See the process outlined below.

1. Make a list/Icebreaker. To warm up, the moderator asked participants to talk about some of the places they visited to capture their photos whether they were taken during the twoweek period or prior.

2. Share stories. Students then shared the stories behind the photos they uploaded to the Jamboard one by one. They also discussed why they chose them. Each student took approximately five minutes to discuss their photos with the group.

3. Cluster into themes. Once all the photos were discussed, students then found the "gems." One by one, students picked three photos that they felt were most interesting or insightful. The selection did not have to be their own photo, it could be one they identified with for some reason. As a group, ambassadors clustered photos on the Jamboard into themes. In other words, they reviewed the "gems" and organized them into similar groupings and categories. Students then wrote headlines for each cluster they created.

4. Create insight statements. Students worked together to draft a concise sentence for each headline that explained why the theme they identified describes the prompt. Then, the students worked with each other to revise and rewrite the insight statements until the group had captured the most unique and compelling points related to each theme. 
5. Map the exhibit. Ambassadors then curated the photo exhibit. Led by the moderator, ambassadors mapped out the order of images to correspond with the visual narrative they felt best represented their response to the prompt.

\section{Implementation Phase:}

In the Implementation Phase of $\mathrm{HCD}$, the selected images will be printed by the author at the library's poster printing services for the exhibit in the Reed College of Media's Media Innovation Center. Given the limited access to the Center during the pandemic, the exhibit is expected to be part of the reopening following the Summer of 2021. After the Center's reopening, students will be able to walk through the exhibit and enjoy the photos and captions. Further, when prospective students, alums and others visit the Center they will be exposed to this story of why the Reed College is so unique. The exhibit will also be featured on the College's Instagram account in late April, allowing students to virtually visit the exhibit. This campaign will be featured via Instagram Story and be archived in the account's highlights section for other users to see. The images and corresponding quotes are located in the Outcome section below.

\section{Outcome Part One}

Part One of this project had some noteworthy outcomes that will be synthesized below. Most notable was the participants' idea to split the photos into two themes: nature and people. After a brief discussion, students realized that their nature theme was really broader than just capturing the beauty of West Virginia, but really the environment around them that encapsulated the different places and opportunities that are part of being a part of the College. As one participant stated, "I guess my theme for like talking about the college is the people, the places, and the opportunities." 


\section{Theme 1: Environment}

To represent the idea of the environment, participants wanted to include more than the natural beauty of the state, but also to also include the beauty of the college and campus infrastructure. One participant said, "I toured WVU and literally touring Martin and touring the Media Innovation Center, I was like oh wait yeah I want to come here. It felt like Google. Like it felt like such a modern and collaborative space and I feel like this space is only representational of the people here."

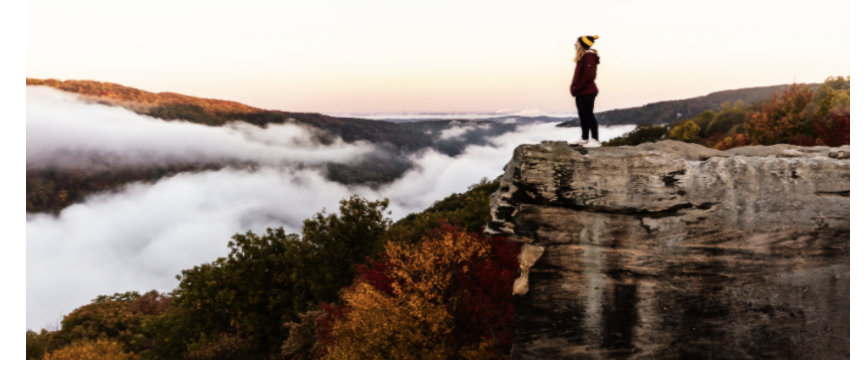

Dark and dusty, painted on the sky
To introduce this theme, the first photo in the exhibit was one taken by the youngest of the group. The image shows Raven's Rock, a natural prize of West Virginia. To participants, this picture encapsulated the environment theme of the photo exhibit and was captioned "Dark and dusty, painted on the sky" to honor the song Take Me Home Country Roads, the anthem of WVU. As illustration of how seamlessly participants converged on this idea, one advertising student said: “...Country Roads lyrics, I like that.”

The hat photo to the right showcases the beauty and the nature of the state. Featuring the Mountaineer on the hat, the story behind the photo incorporates both of the themes picked by participants, as one participant shot this photo while on a trip to Spruce Knob with classmates. Participants chose this photos as a

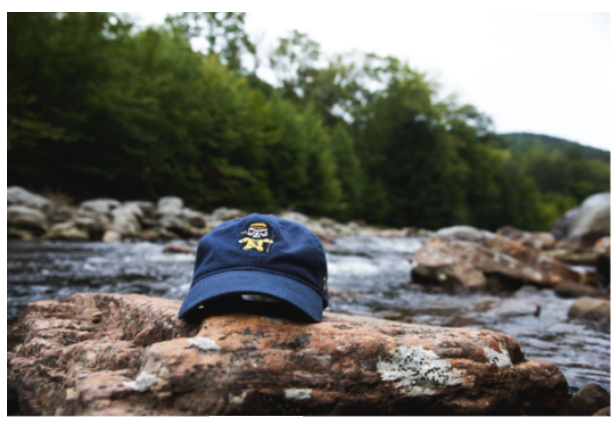
"hats off to West Virginia." This photo was a crowd favorite and led into the next photo. 
Serving as a gateway into the next theme of people, the doors of Martin Hall were important to participants to include because of the amount of time they spend in this College of Media space. Although the photo appears to just be a set of doors, it has a lot more weight than just that. One said: "It's a very dramatic photo." Choosing a more serious caption, participants wanted to acknowledge the college's history and show how long Martin Hall has been serving students just like them. Representing how the caption emerged as a nod to the legacy of those people, one participant said: "Inside Martin Hall is where we spend a lot of our time." Another participant

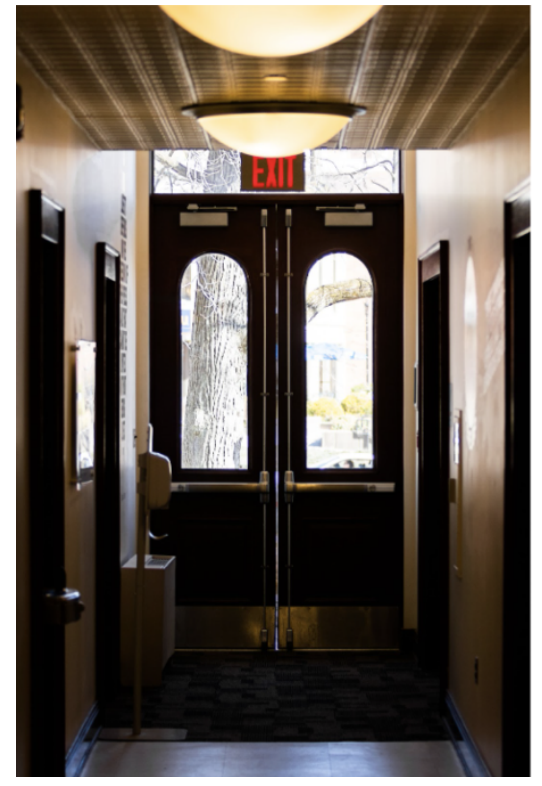

Since 1870 , these doors have served as the gateway to excellence for generations of creators. echoed that these doors have seen "generations of creativity."

\section{Theme 2: People}

Moving into the next theme, participants felt that the College's people were a significant part of what made it home. As an example, to the right is a photo of a photoshoot for Mirage Magazine which is a student-run magazine in the Reed College. Participants chose to include this photo because they are all heavily involved in WVU and the college. One of the most common ways

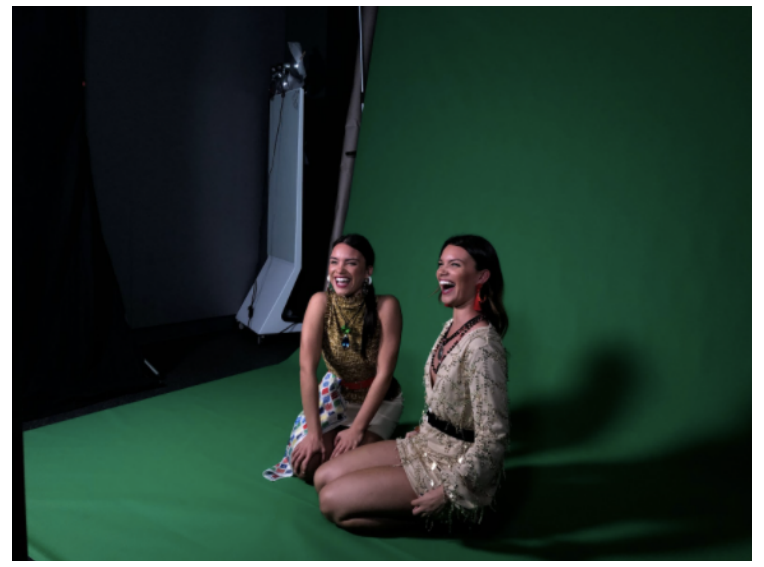

making magazines $\&$ inspiring smiles 
for students to be involved is through student organizations. As one participant said, "I feel like a

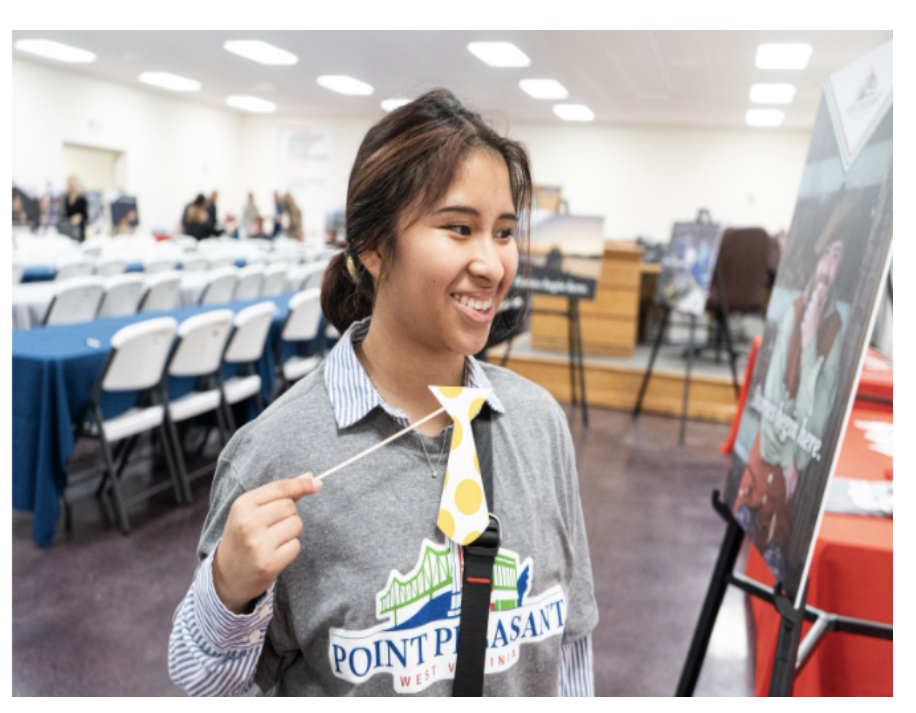

OUTFIT ON POINT lot of like the best connections I've made have been through my student organizations."

Another representation of the people theme, the photo to the left shows a Reed College student at a Brand Journey event in Point Pleasant, West Virginia. Brand Journey was a project aimed at revitalizing

West Virginia communities and also a

college capstone course. Almost combining both themes, one participant captured their friend with a photo prop while they worked together at the program event. It shows the passion that the participant had for the cause. In this environment, students came together with their Reed College Family and helped to story tell in a way that favors place over product. Showing the fun and joking friendship between the photographer and the person in the photo, the photo shows the people it takes to achieve success along the way. "It's really nice to have so many people that I have a lot of things in common with," said one participant. Echoing the commonalities among Reed College students, one sports and adventure media student brought up making friends so easily in class saying, "That was like the biggest thing, like the small class aspects like you have you have to like talk to other people like you can't go for years, like not meeting anyone or being friends with anybody so that's really cool." 
The next photo in the exhibit also falls under both themes and was the most difficult for participants to develop a creative statement for. Best shown in the photo caption "Just hangin' out" it captures a time some students went on a trip together. Hanging out outside of class is just another aspect of being a Reed College student. Choosing a puny caption to compliment the photo, participants laughed together during this photo's conversation as they brought up other memories they shared together with Reed College

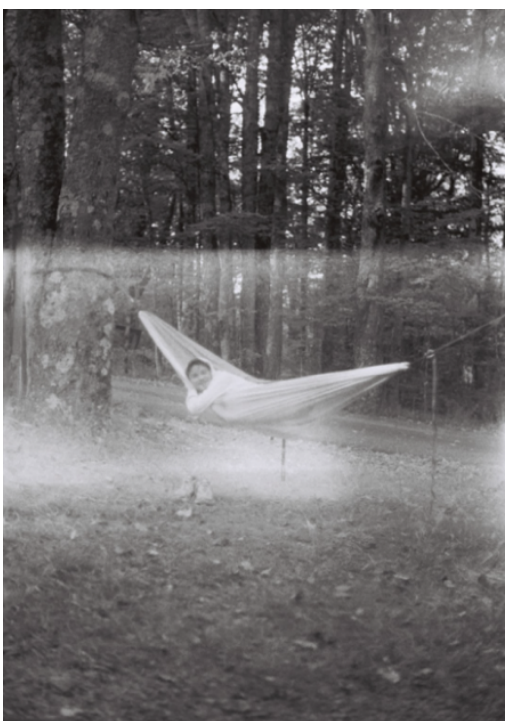

Just hangin' out people. One participant said: "But it's just really cool to have like those people who are obviously not related to you at all, but be able to talk to them like they're your brother or sister that kind of thing." Simultaneously, another participant echoed and wrapped up this portion saying, "These people are a group of people that I really care about and that I hope care about me."

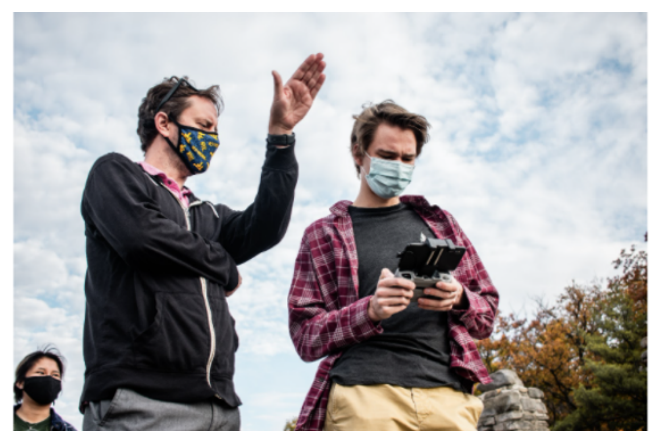

Reed College of Media professor

David Smith and student Connor

Taylor create visual storytelling journalism from both on the ground and in the air.
The final photo in in the exhibit pictures Reed College professor David Smith helping student Connor Taylor capture images from the college's drone course. This last photo shows that it's not just people who are college-aged that are important to the Reed College family; it is the staff and faculty who are always willing to help, participate and teach each other. As the youngest participant put it, "Everyone in the college always says yes.

Without hesitation like it doesn't matter what it is, doesn't matter who you are. Like if you want 
something or like you asked like a favor or someone or like you need information, it doesn't matter who you talk to like you're always going to get a yes."

\section{Chapter 5: Part Two}

\section{Detailed Review of Part Two}

Once more building on the brief synopsis in Chapter 3, the following provides a more detailed description of how participants were guided through the PAR/HCD process in the Part Two workshop.

\section{Inspiration Phase:}

Two weeks following the Part One HCD workshop students received another email briefing them on the next part of the project (see Appendix E \& Appendix F). In this email, participants were informed of the five dimensions of stewardship and provided a graphic that shared the definition and examples. Then, students were given five prompts for their next photovoice session. Participants needed to think of a time they donated to something or witnessed the outcomes of a campaign or fundraiser. These prompts were focused on the five dimensions of stewardship and were:

- Show an organization demonstrating responsibility

- Show an organization demonstrating reporting

- Capture an organization showing regard

- Show an organization displaying recognition

- Show an organization nurturing a relationship

Students were again given two weeks to respond to the five prompts and again given the option to take photos or use previously taken photos because of the COVID-19 pandemic. Participants only needed to respond with one photo per prompt. The workshop email also 
contained another Doodle Poll with times for the HCD Part Two workshop outlined below in the Ideation Phase.

This workshop, held in early April, was also hosted virtually and lasted approximately two hours. For this session, the Jamboard had five different sections labeled responsibility, reporting, regard, recognition and relationship nurturing. Participants had the option to go into the Jamboard on their own time and uploaded their designated photos to the corresponding stewardship dimension section. One participant did so and the other four took the first 10 minutes to do so during the Zoom workshop.

\section{Ideation Phase:}

Students met via Zoom again on a date decided ahead of time and participated in a similar Ideation process as the one they carried out in Part 1 (see Moderator Guide for Part Two in Appendix G).

1. Make a list/Icebreaker. To start, students discussed the places they visited to capture their photos whether they were taken in the two-week period or prior. Most students chose stock photos from the internet. For example, one participant used photos from Bill \& Melinda Gates Foundation and another included their photos from the GetMoving! Day of Play (a College of Media based nonprofit dedicated to promoting physical activity and healthy lifestyles).

2. Share stories. Students then shared the stories behind their photos they uploaded dimension by dimension. They also discussed why they chose them. After students were done talking about their photos, other students were free to comment or ask questions. A brief recap of highlights from the discussions follows with more in-depth findings reviewed in the Outcomes section of this chapter. 
Responsibility- Students seemed to understand this dimension of the Jamboard. Being a dimension that creates awareness of issues related to the organization's value, students chose very progressive photos. For example, one graduate student uploaded a photo from Nike's recent “\#StopAsianHate and another from the Patagonia website showing information on the " $1 \%$ For the Planet" campaign. Reporting- This dimension did not seem to particularly evoke response from participants, implying the more fact and statistics-based nature of this stewardship dimension was less resonate with participants. For example, one advertising student uploaded a graphic from the Patagonia website where shoppers could view and read about various environmental causes which led to little follow-up discussion.

Regard- This dimension related to personal demonstrations of appreciation, seemed to resonate with students. Interestingly, a lot of these images included aspects of teamwork. For example, one ADPR student uploaded a stock image of an office team fist bumping at work.

Recognition- This dimension related to public acknowledgement was understood contextually well by students; however, the images were not necessarily insightful to this project's end goals. No photos from this Jamboard slide were chosen as gems.

Relationship Nurturing- This dimension was well received by participants in the next step of the HCD process. Students uploaded images that did not necessarily reflect their visualization of this dimension. While this dimension later served as 
extremely vital to this project's goals for Part Two, none of this photos were chosen as gems.

3. Group discussion. Following the sharing of stories, students began discussing what their new knowledge of stewardship means to them and what their future commitment to the Reed College could look like. This was facilitated by the author. Again, students found the gems during this time. As a group, ambassadors clustered chosen photos (gems) into themes. These themes emerged as teamwork, eye contact and change.

4. Create insight statements. Students again worked together to draft a concise sentence for each headline that explained why the theme they have identified describes the prompt. Then, students worked with the others to revise and rewrite the insight statements until the group had captured the most unique and compelling points related to each theme. They discussed that urgent posts discourage them from donating so the group wanted to keep creative statements fun and lighthearted.

5. Group discussion revisited and continued: Recognizing that the insights from the photovoice process were somewhat limited, the author pivoted the conversation to a dialogue more deeply rooted in the HCD philosophy of co-creation. This allowed participants to focus on their insights and recommendations, rather than trying to visualize their thoughts on donations behaviors and relationship cultivation.

\section{Implementation Phase:}

After the group discussion, based on what the author learned, strategic recommendations were developed. These recommendations were then shared with the college's development officer Joshua Walters as he is the college's overseer of fundraising and alumni relations. As reviewed in the methods, the author sent Waters an email during the middle of the Spring 2021 
semester briefing him on the project (see Appendix H). Then, in April, after the completion of the Part Two HCD workshop, the author reached out again via email to schedule a meeting (see Appendix I). During this meeting, the author explained what was found during the Part One and Part Two workshop. The author saved the Jamboards from both phases to share during the meeting. The author also discussed how the visuals help to explain the participants' connections to the college and how the stories behind their photos could help cultivate a relationships with Year 0 alums.

\section{Outcome Part Two}

As referenced above, participants chose to split the photos from this phase into three themes: teamwork, eye contact and change. While participants did decide on these themes, they were not an integral part in answering this research question. At this point in the workshop, the conversation started to become unproductive. Participants understood the definitions of the stewardship dimensions, but were having a difficult time connecting them to the images in the Jamboard. Thus, the moderator pivoted the dialogue to a more conversational tone to avoid limited contributions to the recommendations. The following insights are a merging of the photovoice and dialogue-based approaches used in the workshop.

\section{Theme 1: Teamwork}

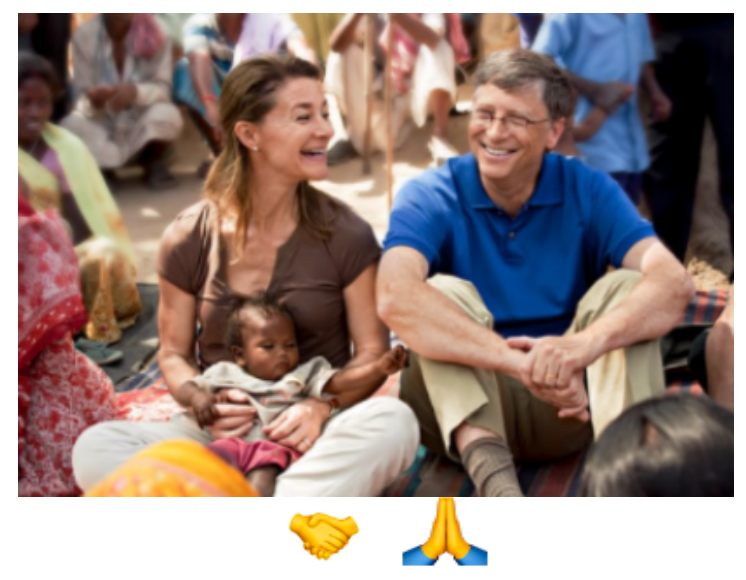

This first photo was placed in the Regard Jamboard slide because of its missionary roots. A student pulled this photo from the Bill \& Melinda Gates Foundation's website. The implication is that great fortune provides an opportunity to demonstrate personal appreciation for what life has afforded you. 
Due to impact of Bill and Melinda Gates' deeply rooted history with charity, the participants wanted to include this photo as a gem and it was placed under the group's teamwork theme. To capture the impact of the missionary work done by their foundation, the participants wanted to include an emoji caption like last time. In the students' words, this captures the teamwork element behind organizations' regard.

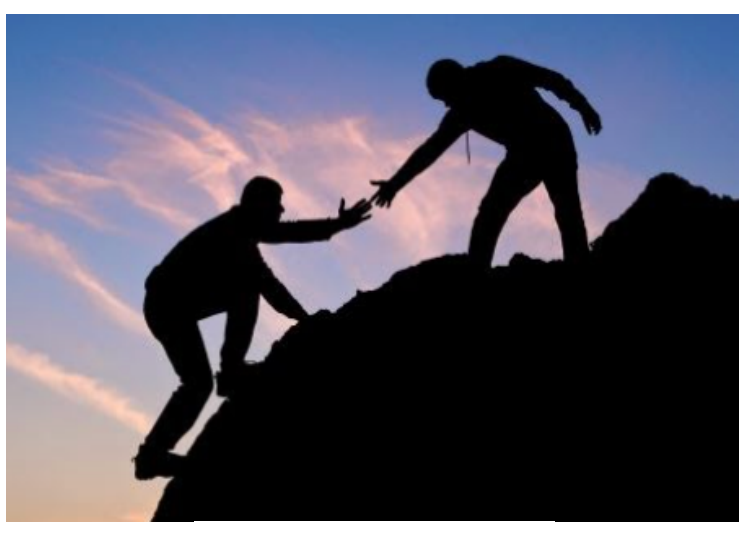

Trust the climb

The second photo is a stock photo that was also uploaded to Regard Jamboard and focused on lending a helping hand. This image was one of the pictures placed the teamwork theme. Again, participants wanted to demonstrate the importance of reaching back and acknowledging personal gratitude, but also aligning with the them they highlight view of regard as an intersection of personal gratitude and the teamwork it takes to achieve success. Originally wanting to build on their lighthearted captions, one participant first wanted hone in on the teamwork theme and caption the photo "teamwork makes the dreamwork." Then, the final caption came again from a graduate student because it reminded them of WVU and their slogan "Trust the Climb."

While these photos and creative statements only directly provide limited insights, there were key insights from the following group discussion that are applicable to this theme and these gems. Most notably would be the group's association between Regard and the theme "teamwork." It is important to note that Year 0 alums might be more inclined to participate in stewardship efforts if it involved being on a team. For example, this could look like crowdsourcing for a college-specific initiative. See the Professional Implications sections for specific recommendations. 
Moreover, most participants had not had many experiences donating money to organizations or WVU, so it makes sense why students would feel better embarking on their future commitments as a team. Participants felt if they were going to make a monetary gift, it needed to align with their personal convictions and values. When asked about organizations they value, one participant said they prefer donating to causes such as a political candidates over businesses. Another participant echoed that they'd much prefer donating to a business or company that's politically involved. This graduate student used the example of her parents avoiding spending money at places like Hobby Lobby or Chick-Fil-A because their owners' values.

From the discussion, the author could also infer that alongside teamwork and value alignment, participants wanted to donate a small sum for something very specific or original to the Reed College. In fact, when asked about best stewarding them, generally, participants wanted to donate to something specific - they didn't want to just make a general donation. One ADPR student used the example of a Martin Hall Agency fundraiser from last year since they were passionate about that organization in their undergraduate time at the Reed College. Another ADPR participant said "I think if it were for something specific. Like wanting to like fund a trip, or like build some new building or get some new gear...," they continued "It would be easier to donate rather than just like $\$ 30$ to the college just because." 


\section{Theme 2: Eye Contact}

The photo to the left was uploaded by a student to the Reporting Jamboard slide. Taken during from the Day of Play last year, this photo shows a university photographer capturing the event. One student thought this photo should be a gem because of its camera element. Another participant, the photographer of this image, appreciated how deeply others saw into their work. An ADPR student said: "I think this could be under eye contact as well, especially with the camera because it's like

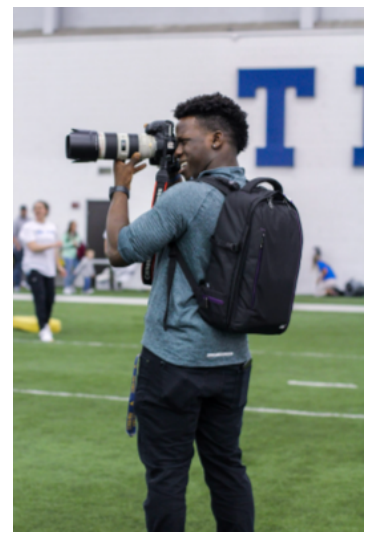

WoRth A ShOt perception and focus." While sticking with their cheesy theme for creative statements, participants decided to take a spin on the saying "it's worth a shot" and incorporate it with the shot of the camera.

While there was not much group discussion revolving around this photo, nor much talk surrounding its selection as a gem, students did understood the definition of reporting in itself as a stewardship dimension. In the end, the group discussion surrounding this topic provided many important messages for development officers. Specifically, emerging from this discussion of reporting, came some important findings on Year 0 alumni's opinions on WVU's Day of Giving. When thinking about reporting, students brought up past Day of Giving efforts from the university. Overall, participants were in agreement on their dislike of WVU's Day of Giving. One journalism participant said "WVU Day of Giving like that annoys me so much because it's like you take all my money. I'm out-of-state. Like I give you thousands upon thousands of dollars, and now you want my donation. Like really, you're kind of like already sucking me dry." Although participants felt it annoying that WVU would ask students for donations, although they did understand its overall importance. Another said "Yeah it's like a little annoying but it's also 
necessary." Building on the scholarly definition of reporting as a means to share concrete data related to impact, perhaps students were hinting that Day of Giving would be a time to share with them the impact of others' gifts, rather than simply dollars accumulated, as a means to prime them for contributions once their financial situation allowed.

\section{Theme 3: Change}

The photo to the right was initially uploaded to the Responsibility slide in the Jamboard. Capturing a sweet moment at the Day of Play event, this photo was clusted as part of the change theme. Due to the nature of GetMoving! participants thought this photo was best served under this theme. This photo's caption came from a play on the quote "live, laugh, love" after participants wanted to continue their lighthearted approach to developing captions.

While this photo did not seem to illustrate participants'

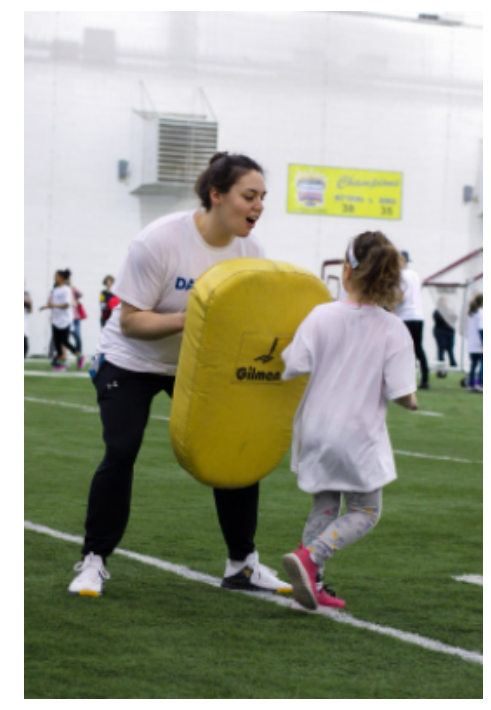

live laugh play understandings of the responsibility dimension of stewardship, participants did understand and put value on this dimension. One participant shared that Responsibility is the dimension that the college should be prioritizing the most. They said: "If an organization isn't showing responsibility or like doing the right thing then you're not going to be inclined to."

Interestingly enough, this discussion of the "right thing" sparked some further discussion among graduate participants. Specifically tying in Relationship Nurturing, two students were in agreement that the college has the responsibility to change their level of relationship nurturing for those students continuing their graduate schooling here. The college also has the responsibility to inform Year 0 alums on initiatives that aren't just monetary. 
The lack of relationship nurturing the graduate level participants felt was prevalent throughout the group discussion. Applicable to a donation setting, two participants discussed the differences between their graduate degrees and their previous degrees. The students had felt that they lacked the same support and guidance from the college they'd received during their undergraduate careers. Specifically, one journalism participant said "I think the college could have done a little bit better of a job maintaining that relationship...especially during COVID times...We need more guidance..."

Alongside this responsibility to nurture, participants overall also said if they were going into professions that were notoriously higher paying, they would consider monetary donations. As of now, participants feel as though their time and efforts are more impactful than money for students. One junior participant reflected on a time that they reached out to WVU alums on LinkedIn and asked for their networking help and received an answer from a NYC agency. They said, "You know, a couple minutes out of his day to do something nice for a current student. So, if I could provide that same type of resource down the line for current WVU student, because it was super nice and reassuring."

\section{Chapter 6: Discussion \& Conclusion}

After successful completion of two HCD and photovoice workshops, findings from this project emerged in two areas. The first is related to the process used, including the utility of photovoice and Google Jamboard. The second area includes implications for the practice of cultivating relationships with Year 0 alums. Reflections, evaluation and implications for each area are detailed below in turn. 


\section{Process Evaluation}

To start, the author will review the utility of Google Jamboard and Zoom as PAR/HCD tools for this project. Overall, Google Jamboard worked well as a platform, particularly given the existing access by students and the platform similarities to other Google products that they regularly use. There were only five participants able to attend each workshop, so this allowed for sufficient space for participants to upload their photos; however, if there would have been full participant occupancy (eight to 10), Google Jamboard would not have provided enough space for photos. With the smaller group, the Jamboard pages were not overcrowded and students didn't seem to feel that this method was cumbersome or chaotic. They each took their own sliver of the page and uploaded their own photos. Further, the author did not need to provide much guidance as these students were already familiar with each other and the stories behind their photos. Further demonstrating the utility of Zoom and Jamboard, for the creative statements, students used both their voice and the chat feature for suggestions and ideas allowing even the quietest students to make meaningful contributions to the outcome. Combined, these factors led the author to conclude that, while in-person sessions would have been ideal, given the pandemic, Zoom and Google Jamboard were appropriate compliments to achieve the project's goals.

Next, the author believed that the PAR/HCD process was effective for both workshops. The process may have been more effective given that participants knew one another and had an existing rapport. As an illustration of this harmony, in Parts One \& Two the participants picked their gem photos quite quickly and a few of the students even picked the same gems. This part only took approximately five minutes each time. When deciding on gems, participants didn't really use either of the worksheets the author shared to influence creativity; they preferred talking among themselves. There weren't any disagreements on gems and the process seemed 
quite natural for participants. When it came to mapping the exhibit in Part One, participants instantly knew they wanted to separate the photos into the themes of environment and people. One participant suggested using the doors to Martin Hall as a separator between the two and all participants eagerly agreed. This portion of the workshop only took a few minutes. Further, participants joked with each other a lot during the creative process making the co-creation environment welcoming for all.

Photovoice was a very successful method in Part One; however, it wasn't as helpful in Part Two. While it very much helped participants visualize their existing connection to the Reed College, using photovoice to try to visualize a potential connection was not as effective. In Part One, many students used photos that they had previously taken, while in Part Two a lot of participants used screenshots from Google or social media indicating a lack of personal connection to the prompt. As a result, the photos did not seem to evoke as much response or emotions from participants. Instead, participants in Part Two had a lot more insights on the questions from the moderator rather than the discussions revolving around their photos.

Further, the participants found it most difficult to develop creative statements in Part One because they all had so many ideas. This part took approximately 20 minutes both times. The hammock photo seemed to be the hardest when it came to the creative statements while the photo of Raven's Rock photo was the easiest to caption. Wanting to keep the creative statements the same for both the Instagram exhibit and the physical exhibit, the participants ultimately decided to have a mixture of caption types as the author mentioned in Outcome Part One. However, when it came to Part Two, the creative statements did not seem to flow naturally, nor did they highlight the key takeaways from each photo as much as it did reflect the good time the participants were 
having with the discussion. To this end, the captions from Part Two were not as informative to the project's overall goals.

In the end, participants seemed to enjoy participating in the workshops. The author found that four out of seven of those who were able to participate in this part of the project were photographers at the professional level, likely contributing to the overall success of the endeavor. In sum, participants with an existing rapport, comfort capturing photos and familiarity with the subject seemed to produce the best results. In the future, if replicating the Part Two workshop, the author believes that the photovoice aspect may not have been as useful as the more traditional focus group approach with a guided discussion. For example, a charrette style meeting with participants being provided with the problem and guided through a process to map a solution may have resulted in more strategic and meaningful insights.

\section{Professional Implications}

Findings from this project, indicate that this generation's understanding of stewardship manifests in different way than previous academic literature. Below, the author will draw on findings from both Part One and Part Two to explain this deviation from previous operationalizations and offer professional implications based on the five stewardship dimensions. These professional implications aim to answer this project's research question and were presented to Reed College development officer on April 15 (see Appendix Q). Recommendations were also shared with the WVU Foundation's Director of Donor Relations.

Relationship Nurturing: Students approaching Year 0 placed the highest emphasis on Relationship Nurturing as a stewardship dimension. Their understandings of the dimension were similar to scholarly definitions, but added the insight that the process must be continuous and not narrowly focused on the needs of the university to raise capital funds. In particular, Part Two 
showed that successfully nurturing relationships requires communications efforts to inform Year 0 alumni on how they can get involved in mentoring and sharing their professional passions. A key insight here is that this gradual process of relationship cultivation will establish an ongoing connection, rather than allowing for the relationship to go quiet only to come back with a funding request once the student has reached financial maturity. Further, leading into the next set of findings, relationship nurturing should make alumni feel as though they are valued and appreciated even without monetary contributions.

Responsibility \& Reporting: Next in importance came from the discussions related to responsibility and reporting, which intersect to provide meaningful insights related to both campaign messaging and channel. It was apparent though that the participants' ideas of responsibility and reporting seem to differ from a scholarly standpoint. In current literature, responsibility would be the act of creating awareness on how a donation was used through narrative storytelling and reporting would be describing how the mission was fulfilled in more concrete quantitative terms. This group, however, seemed to perceive these dimensions as associated with awareness of issues facing the organization either through progressive advocacy type content or factually-based issues awareness.

Understanding how students perceive responsibility and reporting, the author can draw from Part One and Two for recommendations related to relationship cultivation. This generation enjoys knowing how lives are impacted (i.e. the love for student organizations' impacts in Part One and the want for more alumni involvement in Part Two) and also how they can impact the lives of others. Based on the creative statements developed from Part One and Two, it is also crucial that the messaging for stewarding this generation should carry lighthearted tones. This messaging should also include images of both the environment and people - the themes 
developed from the student-made photo exhibit. This relates to the responsibility dimension of stewardship and highlights the importance of a people-centered narrative focused in messaging.

Another example of how these insights could lead to campaign recommendations might include a Day of Giving Facebook campaign that would target Year 0 alumni with narratives focused on impacts (rather than solicitation). From Part Two, the author learned that students were comfortable with Facebook fundraisers. Connecting to the people theme that emerged in Part One, such a Facebook campaign should include student-made testimonials, feature stories of those students impacted by Day of Giving efforts from previous years, and challenge explanation videos in real time from Reed College professors. Based on the photo captions created by students, messaging should seem fun and lighthearted instead of the urgent timebound approach common with past giving challenges.

Recognition: Participants' perceptions of regard as a stewardship dimension also did not match the scholarly definition. While the academic literature indicates recognition should show public appreciation, the participants here focused on publicly displaying the role each person plays in achieving success overall. Emerging from Part Two but connecting with elements from Part One, in terms of recognition, the author thus recommends publicly creating a team-based crowdfunding project for a college-specific need such as travel funds for professional conferences, media equipment for a class or capstone course experience fundraiser. One example of how this might look, could include creating a senior class fund to encourage the teamwork aspect of stewardship learned from Part Two's research. Each year, the Reed College development officer could coordinate a meeting with upperclassmen college ambassadors. The college development officer can work with Whitney Godwin, college recruiter, to get connected with this sample. These ambassadors would work with the college development officer to decide 
on a senior class crowdfunding initiative and the timing of such giving. Once executed, the fund would be named after the class and promoted to alums through social media and the eNewsletter the college distributes.

As an example of a specific project, we saw in Part One participants really enjoy the nature and beauty surrounding the university. Then the graduating class could work together to create a scholarship for a student in Sports and Adventure media or fund a student to attend an adventure media camp. Due to the nature of this target group, the graduating senior class could create a strategic plan and promotional materials for this depending on what they decide to pursue. This could even be partnered with student organizations or alumni that could mentor the team. This would create the mentorship opportunities that were so valued in the discussion outlined above. Further, this approach begins to create a legacy for future Year 0 alums to be primed for crafting their own targeted campaign in future years. Over time, competitions between different graduation years could be established.

Regard: In academic terms, regard would usually focus around personalized or individual acknowledgment for donors; however, participants from this project actually perceived regard as being a part of a team or family. Further, from Part One and Two, the author also learned that this generation wants to give back and that environment is an important part of being in the Reed College family. To turn these insights into actionable recommendations, the authors recommends the Reed College development officer should host an annual alumni and donor dinner to invite these groups back to the Reed College campuses. This will both retain the connection between alumni and the college while also connecting and networking those who embody what it means to be a part of the Reed College family. 
Specifically, professors, staff, graduate students and Reed College alumni could attend this event to enjoy an evening of free food, drinks and a presentation on alumni/development initiatives from existing Reed College students. This presentation will not only give these stakeholders a free networking dinner, but will also provide them with a chance to learn about ways to get involved with the college that aren't just a monetary solicitation.

In summary, findings from this project provide insight into potential ways to cultivate a relationship with a new generation of potential donors. To realize this relationship, solicitations should go beyond the monetary ask and include opportunities for person-to-person engagement. This makes sense as it aligns with current literature such as Schwieger \& Ladwig (2018). When funding requests are made, they should include narratives of their potential impact and include the voices of those served by the fund. When possible new graduates should have the opportunity to collaborate to create greater impact in the lives of new and existing students - especially through acts like crowdfunding like Seltzer (2016) suggested. The graduates should also have a voice in selecting the specific initiatives that their efforts fund. Finally, the relationship with these emerging graduates should be initiated before graduation with a collaborative senior year project and sustained over the years through the annual tradition of returning to their beloved college environment to meet with new students, reconnect with former professors and learn about the projects going on at the college.

\section{Chapter 7: Limitations}

There were several noteworthy limitations to this project. As this project took place, the COVID-19 pandemic was affecting in-person campus activities. This ultimately limited participants' abilities to commit to both parts of the project. Due to the level the participants are involved in the university, scheduling was a major limitation. Since the pandemic affected the 
scheduling with WVU Athletics, many of the media students were unable to commit to the workshops because of potential conflicts that they could not plan for. To overcome this, the author oversampled and included additional participants. These participants are not Reed College ambassadors; however, they display the same characteristics as one due to their heavy involvement with the college. Two of these oversampled students are at the graduate level. They both work graduate assistantships and offer a similar perspective as the ambassadors and highlighted the unique perspectives of students who had completed their undergraduate degree. It is notable to point out that full capacity at ten participants in this project might yield different results.

Another limitation to this research was the success of photovoice as a PAR tool for Year 0 Alumni in the Part Two workshop. The majority of the insights from Part Two's research and the understandings of participants' perceptions on stewardship came from the group discussions - not the photos. For future duplication of this project, the author would recommend a focus group or charrette instead of an HCD workshop using photovoice in Part Two. This would provide a deeper more conversational dialogue. 


\section{References}

Abras, C., Maloney-Krichmar, D., \& Preece, J. (2004). User-centered design. Bainbridge, $W$. Encyclopedia of Human-Computer Interaction. Thousand Oaks: Sage Publications, 37(4), 445-456.

Accoe, K., Marchal, B., Gnokane, Y., Abdellahi, D., Bossyns, P., \& Criel, B. (2020). Action research and health system strengthening: the case of the health sector support programme in Mauritania, West Africa. Health research policy and systems, 18(1), 1-13.

Adams, K., Burns, C., Liebzeit, A., Ryschka, J., Thorpe, S., \& Browne, J. (2012). Use of participatory research and photo-voice to support urban Aboriginal healthy eating. Health \& Social Care in the Community, 20(5), 497-505.

Ahari, S. S., Habibzadeh, S., Yousefi, M., Amani, F., \& Abdi, R. (2012). Community based needs assessment in an urban area; A participatory action research project. BMC Public Health, 12(1), 161.

Annang, L., Wilson, S., Tinago, C., Wright Sanders, L., Bevington, T., Carlos, B., ... \& Svendsen, E. (2016). Photovoice: Assessing the long-term impact of a disaster on a community's quality of life. Qualitative Health Research, 26(2), 241-251.

Baum, F., MacDougall, C., \& Smith, D. (2006). Participatory action research. Journal of epidemiology and community health, 60(10), 854.

Becker, K., Reiser, M., Lambert, S., \& Covello, C. (2014). Photovoice: Conducting communitybased participatory research and advocacy in mental health. Journal of Creativity in Mental Health, 9(2), 188-209.

Bell, S. E. (2008). Photovoice as a strategy for community organizing in the central Appalachian coalfields. Journal of Appalachian Studies, 34-48.

Bureau, U. (2019, October 29). U.S. Median Household Income Up in 2018 From 2017. Retrieved October 19, 2020, from https://www.census.gov/library/stories/2019/09/usmedian-household-income-up-in-2018-from-2017.html

Burke, K. J., \& Hadley, H. L. (2018). I'm Empowered by a Better Connection. The High School Journal, 101(4), 217-235. 
Button Renz, A. (2010). How to build the bridge between students and alumni. In J. A. Feudo (Ed.): Alumni relations: A newcomer's guide to success (2nd ed., pp. 123-129). Washington, DC: Council for the Advancement and Support of Education.

Cargo, M., \& Mercer, S. L. (2008). The value and challenges of participatory research: strengthening its practice. Annu. Rev. Public Health, 29, 325-350.

Cascione, G. L. (2003). Philanthropists in higher education: Institutional, biographical, and religious motivations for giving. Psychology Press.

Caviola, L., Schubert, S., \& Nemirow, J. (2020). The many obstacles to effective giving. Judgment and Decision Making, 15(2), 159.

Cornet, V. P., Toscos, T., Bolchini, D., Ghahari, R. R., Ahmed, R., Daley, C., ... \& Holden, R. J. (2020). Untold Stories in User-Centered Design of Mobile Health: Practical Challenges and Strategies Learned From the Design and Evaluation of an App for Older Adults with Heart Failure. JMIR mHealth and uHealth, 8(7), e17703.

Design Kit: The Human-Centered Design Toolkit. (n.d.). Retrieved from https://www.ideo.com/post/design-kit

Dorrington, P., Wilkinson, C., Tasker, L., \& Walters, A. (2016). User-centered design method for the design of assistive switch devices to improve user experience, accessibility, and independence. Journal of Usability Studies, 11(2), 66-82.

D. Morgan, J. (2016). A User-centered Design for the Addition of Interactive Masking Capability within an existing Web GIS. Transactions in GIS, 20(5), 807-816.

Drezner, N. D. (2018). Philanthropic mirroring: Exploring identity-based fundraising in higher education. The Journal of Higher Education, 89(3), 261-293.

Drezner, N. D. (2010). Private Black colleges' encouragement of student giving and volunteerism: An examination of prosocial behavior development. International Journal of Educational Advancement, 10(3), 126-147.

Edles, P. (1993). Fundraising: Hands-on tactics for non-profit groups. New York: McGraw-Hill. 
Edelson, D. (2020, February 27). How does a college degree improve graduates' employment and earnings potential? Retrieved October 26, 2020, from https://www.aplu.org/projectsandinitiatives/collegecoststuitionandfinancialaid/publicuval ues/employment-earnings.html

Francis, T., \& Hoefel, F. (2018). True Gen': Generation Z and its implications for companies. McKinsey \& Company.

Forbes-Genade, K., \& Van Niekerk, D. (2019). GIRRL power! Participatory Action Research for building girl-led community resilience in South Africa. Action Research, 17(2), 237-257.

Freeland, R. E., Spenner, K. I., \& McCalmon, G. (2015). I gave at the campus: Exploring student giving and its link to young alumni donations after graduation. Nonprofit and Voluntary Sector Quarterly, 44(4), 755-774.

Freier, A. (2019, June 19). A look at Gen Z mobile behaviours - 64\% of mobile users are always connected. Retrieved October 26, 2020, from https://www.businessofapps.com/news/alook-at-gen-z-mobile-behaviours-64-of-mobile-users-are-always-connected/

Gallo, M. (2013). A third master? Examining the road to alumni philanthropic giving at an Irish catholic college. Christian Higher Education, 12(4), 266-281.

Gershon, R. R., Rubin, M. S., Qureshi, K. A., Canton, A. N., \& Matzner, F. J. (2008). Participatory action research methodology in disaster research: results from the World TradE Center evacuation study. Disaster Medicine and Public Health Preparedness, 2(3), 142-149.

Gen Z: The Next Generation of Donors. (2018, February 13). Classy. Retrieved October 19, 2020, from https://www.classy.org/blog/gen-z-next-generation-donors/

Gen Z Donors: What You Need To Know About The Newest Generation Of Philanthropists. (2019, June 25). Retrieved November 12, 2020, from https://www.givingcompass.org/article/gen-z-donors-what-you-need-to-know-about-thenewest-generation-of-philanthropists/

Giving by Generation - Different giving preferences by generation. (2019, March 28). Retrieved November 12, 2020, from https://www.lasallenonprofitcenter.org/generational-charitablegiving/

Goldstraw, C. (2019, November 22). Cherish Goldstraw. Retrieved October 19, 2020, from https://home.givepenny.com/2019/11/22/why-your-charity-needs-generation-z/ 
Göransdotter, M., \& Redström, J. (2018). Design Methods and Critical Historiography: An Example from Swedish User-Centered Design. Design Issues, 34(2), 20-30.

Greenfield, J. M. (1999). Fund Raising: Evaluating and Managing the Fund Development Process (AFP/Wiley Fund Development Series). John Wiley \& Sons.

Grunig, J. E., \& Hunt, T. T. (1984). Managing public relations. Holt, Rinehart and Winston.

Guo, Y. R., \& Goh, D. H. L. (2016). Library Escape: User-Centered design of an information literacy game. The Library Quarterly, 86(3), 330-355.

Harrison, W. B. (1995). College relations and fund-raising expenditures: Influencing the probability of alumni giving to higher education. Economics of Education Review, 14(1), 73-84.

Heffron, J. L., Spassiani, N. A., Angell, A. M., \& Hammel, J. (2018). Using photovoice as a participatory method to identify and strategize community participation with people with intellectual and developmental disabilities. Scandinavian Journal of Occupational Therapy, 25(5), 382-395.

Hedrick, J. L. (2009). Effective donor relations (Vol. 169). John Wiley \& Sons.

Hommerová, D., \& Severová, L. (2019). Fundraising of nonprofit organizations: specifics and new possibilities. Journal of Social Service Research, 45(2), 181-192.

Hon, L. C., Grunig, J. E. (1999). Guidelines for measuring relationships in public relations. Gainesville, FL: Institute for Public Relations.

Jones, T., Ho, L., Kun, K. K., Milsom, P., Shakpeh, J., Ratnayake, R., \& Loewenson, R. (2018). Rebuilding people-centred maternal health services in post-Ebola Liberia through participatory action research. Global Public Health, 13(11), 1650-1669.

Kelly, K. S. (1998). Effective fund-raising management. Mahwah, NJ: Lawrence Erlbaum Associates.

Kelly, K. S. (2001). Stewardship: The fifth step in the public relations process. Sage.

Kemmis, S., McTaggart, R., \& Nixon, R. (2013). The action research planner: Doing critical participatory action research. Springer Science \& Business Media. 
Kidd, S., Davidson, L., Frederick, T., \& Kral, M. J. (2018). Reflecting on participatory, actionoriented research methods in community psychology: Progress, problems, and paths forward

Kohfeldt, D., Chhun, L., Grace, S., \& Langhout, R. D. (2011). Youth empowerment in context: Exploring tensions in school-based yPAR. American journal of community psychology, 47(1-2), 28-45.

Lara, C., \& Johnson, D. (2014). The anatomy of a likely donor: econometric evidence on philanthropy to higher education. Education Economics, 22(3), 293-304.

Li, P., Men, L. R., \& Yue, C. A. (2020). An exploratory study of stewardship for Chinese nonprofit organizations. International Journal of Nonprofit and Voluntary Sector Marketing, 25(2), e1655.

Lykes, M. B., \& Scheib, H. (2016). Visual methodologies and participatory action research: Performing women's community-based health promotion in post-Katrina New Orleans. Global public health, 11(5-6), 742-761.

McElhinny, B. (2017, June 26). Higher ed takes biggest W.Va. budget hit, but how much is too much? Retrieved from http://wvmetronews.com/2017/06/25/231226/

Melvin, E. C. (2020). Tourism, Environmental Stewardship, and Community Engagement on Andros Island, Bahamas (Doctoral dissertation, Duke University).

Minkler, M. (2010). Linking science and policy through community-based participatory research to study and address health disparities. American Journal of Public Health, 100(S1), S81S87.

Morrison, J., Akter, K., Jennings, H. M., Nahar, T., Kuddus, A., Shaha, S. K., ... \& Khan, A. A. (2019). Participatory learning and action to address type 2 diabetes in rural Bangladesh: a qualitative process evaluation. BMC Endocrine Disorders, 19(1), 1-10.

Nazi, K. M., Turvey, C. L., Klein, D. M., \& Hogan, T. P. (2018). A decade of veteran voices: examining patient portal enhancements through the lens of user-centered design. Journal of medical Internet research, 20(7), e10413.

Nonprofit Fundraising Statistics [Updated for 2020]. (2020, April 25). Retrieved October 19, 2020, from https://doublethedonation.com/tips/matching-grant-resources/nonprofitfundraising-statistics/ 
O’Neil, J. (2007). The link between strong public relationships and donor support. Public Relations Review, 33(1), 99-102.

Pressgrove, G. (2017). Development of a Scale to Measure Perceptions of Stewardship Strategies for Nonprofit Organizations. Journalism \& Mass Communication Quarterly, 94(1), 102123. https://doi-org.www.libproxy.wvu.edu/10.1177/1077699016640221

Pressgrove, G., McKeever, B.W. and Collins, E.L. (2015). Investigating Stewardship Strategies on Nonprofit Websites. Public Relations Journal, 9(3). Available online: http://www.prsa.org/Intelligence/PRJournal/Vo19/No3/

Raza, H. (2020). The Role of Reflexivity in Participatory Action Research to Empower Culturally Diverse Communities in Pakistan. Journal of Rural and Community Development, 15(1).

Ritterbusch, A. E. (2016). Exploring social inclusion strategies for public health research and practice: The use of participatory visual methods to counter stigmas surrounding streetbased substance abuse in Colombia. Global Public Health, 11(5-6), 600-617.

Ronzi, S., Pope, D., Orton, L., \& Bruce, N. (2016). Using photovoice methods to explore older people's perceptions of respect and social inclusion in cities: Opportunities, challenges and solutions. SSM-Population health, 2, 732-745.

Rothman, D. (2016). A Tsunami of learners called Generation Z. URL: http://www.Mdle.net/JoumaFA_Tsunami_of_Learners_Called_Generation_Z.pdf.

Schwieger, D., \& Ladwig, C. (2018). Reaching and retaining the next generation: Adapting to the expectations of Gen Z in the classroom. Information Systems Education Journal, $16(3), 45$.

Seemiller, C., \& Grace, M. (2017). Generation Z: Educating and engaging the next generation of students. About Campus, 22(3), 21-26.

Simmonds, S., Roux, C., \& Avest, I. T. (2015). Blurring the boundaries between photovoice and narrative inquiry: A narrative-photovoice methodology for gender-based research. International Journal of Qualitative Methods, 14(3), 33-49.

Singh, A. P., \& Dangmei, J. (2016). Understanding the generation Z: the future workforce. South-Asian Journal of Multidisciplinary Studies, 3(3), 1-5. 
Sitorus, J. H. P., \& Allwine, A. (2020). User Centered Design (UCD) Method to Design Regional Dance Application Based on Multimedia. Jurnal Mantik, 4(2, Agustus), 13691381.

Tindall, N. T. (2007). Fund-raising models at public historically Black colleges and universities. Public Relations Review, 33(2), 201-205.

Van der Riet, M., \& Boettiger, M. (2009). Shifting research dynamics: Addressing power and maximising participation through participatory research techniques in participatory research. South African Journal of Psychology, 39(1), 1-18.

Wang, C. C., Morrel-Samuels, S., Hutchison, P. M., Bell, L., \& Pestronk, R. M. (2004). Flint photovoice: Community building among youths, adults, and policymakers. American journal of public health, 94(6), 911-913.

Wang, C., \& Burris, M. A. (1997). Photovoice: Concept, methodology, and use for participatory needs assessment. Health education \& behavior, 24(3), 369-387.

Wang, C. C. (2006). Youth participation in photovoice as a strategy for community change. Journal of community practice, 14(1-2), 147-161.

Wang, H. (2018, November 15). Generation Z Is The Most Racially And Ethnically Diverse Yet. Retrieved November 16, 2020, from https://www.npr.org/2018/11/15/668106376/generation-z-is-the-most-racially-andethnically-diverse-yet

Wanless, L., Pierce, D. A., Martinez, J. M., Lawrence-Benedict, H. J., \& Kopka, N. (2017). Best Practices in Athletic Donor Relations: The NCAA Football Bowl Subdivision. Journal of Applied Sport Management, 9(3).

Waters, R. D., Bortree, D. S., \& Tindall, N. T. (2013). Can public relations improve the workplace? Measuring the impact of stewardship on the employer-employeerelationship. Employee relations.

Waters, R. D. (2009). Measuring stewardship in public relations: A test exploring impact on the fundraising relationship. Public Relations Review, 35(2), 113-119.

Waters, R. D. (2011). Redefining sewardship: Examining how Fortune 100 organizations use stewardship with virtual stakeholders. Public Relations Review, 37(2), 129-136. https://doi-org.www.libproxy.wvu.edu/10.1016/j.pubrev.2011.02.002 
Wedgeworth, R. (2000). Donor relations as public relations: Toward a philosophy of fundraising.

Weinronk, H., Wexler, L., Trout, L., Rowlett, K., Klakegg, I., Zhen, S., ... \& Moses, J. (2018). New understandings of communities and ourselves: community-based participatory research with Alaska Native and Lower 48 youth. Educational Action Research, 26(3), 439-455.

Whitchurch, J., \& Comer, A.D. (2016). Creating a culture of philanthropy. The Bottom Line: Managing Library Finances, 29, 114-122.

Wilson, N., Dasho, S., Martin, A. C., Wallerstein, N., Wang, C. C., \& Minkler, M. (2007). Engaging Young Adolescents in Social Action Through Photovoice: The Youth

Worley, D. A., \& Little, J. K. (2002). The critical role of stewardship in fundraising: the Coaches vs. Cancer campaign. Public Relations Review, 28(1), 99-112.

Wuthnow, R., \& Hodgkinson, V. A. (1990). The Jossey-Bass nonprofit sector series.Faith and philanthropy in America: Exploring the role of religion in America's voluntary sector. Jossey-Bass.

WVU Foundation: Home. (n.d.). Retrieved from https://www.wvuf.org/

Zenkov, K., \& Harmon, J. (2009). Picturing a writing process: Photovoice and teaching writing to urban youth. Journal of Adolescent \& Adult Literacy, 52(7), 575-584.

2018 Online Giving Statistics, Trends \& Data: The Ultimate List of Giving Stats. (n.d.). Retrieved October 19, 2020, from https://nonprofitssource.com/online-giving-statistics/ 


\section{Appendices}

\section{Appendix A}

\section{EMAIL REQUEST LETTER PHOTOVOICE PARTICIPATION}

\section{INSERT NAME:}

Hi there! I am writing to request your participation in a research project exploring your future commitment to the WVU Reed College of Media. You are invited to participate in this study because you have been identified as someone who has valuable insights on this topic because of your position as a student ambassador.

If you agree to participate in this study, you would participate in a series of virtual collaborations led by Lily McKnight under the supervision of Dr. Geah Pressgrove. The collaborations will last approximately 1-3 hours. Here's a sample timeline!

Early February: one hour-long meeting Late February: three hour-long workshop Early March: one hour-long meeting Late March: three hour-long workshop

These super fun meetings and workshops will be held via Google Jamboard. They work just like a Google Doc! The process should be something you're familiar with.

If you have any questions about this letter or the project, please feel free to call/text me at 304282-1707 or by e-mail at 1mm0026@mix.wvu.edu. If you have questions concerning your rights as a research subject, you should direct them to my instructor, Dr. Geah Pressgrove at geah.pressgrove@mail.wvu.edu.

I hope that you will participate in this project! It will be super fun!

Sincerely,

Lily McKnight

West Virginia University

Reed College of Media 


\title{
Appendix B
}

\section{COVER LETTER FOR PHOTOVOICE VIRTUAL COLLABORATION/EXHIBIT}

\author{
Dear Participant,
}

This letter is a request for you to take part in a research project to explore and visualize your future with the Reed College of Media. This project is being conducted by Lily McKnight MSJ Candidate from the Reed College of Media at WVU under the supervision of Dr. Geah Pressgrove, the Program Chair in the Advertising and Public Relations Department, to fulfil requirements for a Master's Degree in Research. If you decide to participate, you will be asked to attend a total of 4 Zoom meetings ( 2 being meetings and 2 being workshops), and virtually collaborate with your peers via Google Jamboard and take photos responding to the research's prompts. Your participation in this project will take approximately 8 hours throughout the semester. You must be 18 years of age or older to participate. You will receive a Starbucks gift card for your participation via email.

Your involvement in this project will be kept as confidential as legally possible. All data will be reported in the aggregate. Your participation is completely voluntary. You may skip any question that you do not wish to answer and you may discontinue at any time. West Virginia University's Institutional Review Board acknowledgement of this project is on file. Verbal consent for your participation will occur at the beginning of the first Zoom meeting.

If you have any questions about this research project, please feel free to contact me at 304-282-1707 or by e-mail at lmm0026@mix.wvu.edu If you have any questions about your rights as a research participant, please contact the WVU Office of Human Research Protection by phone at 304-293-7073 or by email at $\underline{\text { IRB@mail.wvu.edu. }}$

I hope that you will participate in this research project, as it could help us better understand your future commitment with WVU and the Reed College of Media. Thank you for your time and consideration.

Sincerely,

Lily McKnight 


\section{Appendix C}

\section{PART ONE INSTRUCTIONS MEETING FOLLOW UP EMAIL}

Hello

Thank you for your participation in my professional project. I'm so excited to have your help this semester! Over the course of the next two weeks, your task will be to either take or find 3 photos that answer the following prompt: "What makes you proud to be in the Reed College

family?" If you are on campus this semester and would like to take these photos yourself with your phone or camera, you are welcome to; however, you may also use photos you already have as long as you took them!

After this two week period, we will meet via Zoom in the Part 1 workshop with the other student ambassadors in this project (woohoo!). You will find the Doodle Poll link here (insert link) to select times that work best for you to meet. This workshop will last approximately two to three hours so keep that in mind when selecting times! If you can only come for part of it, or need to leave early, that's fine! Just let me know.

After the poll closes, I'll send you a link for our meeting with the time and Zoom meeting link. It is important that before we meet for the Part 1 workshop, you have your photos saved in a place where you can easily access them to upload to the Jamboard. We will carry out the next steps during our meeting!

Thanks again for your participation in my project! I'm super pumped and look forward to seeing your photos! Please email me if you have any questions.

Sincerely, Lily McKnight 


\section{Appendix D}

\section{MODERATOR GUIDE PART ONE DOCUMENT}

\section{Moderator Guide}

Moderator Guide-Part One Participants (Reed College Ambassadors)

\begin{tabular}{|c|c|c|}
\hline Question Type & Item & Purpose/Variable \\
\hline $\begin{array}{l}\text { Preliminary } \\
\text { *5 mins* }\end{array}$ & $\begin{array}{l}\text { Let's start by going around the room and discuss } \\
\text { some of the places we gathered our photos from. }\end{array}$ & $\begin{array}{l}\text { Re-develop rapport } \\
\text { and comfort among } \\
\text { participants. }\end{array}$ \\
\hline $\begin{array}{l}\text { Introductory } \\
* 5 \text { mins* }\end{array}$ & $\begin{array}{l}\text { What were some of the common places everybody } \\
\text { had? What were the similarities in these places? }\end{array}$ & Icebreaker Question \\
\hline $\begin{array}{l}\text { Transition (In) } \\
* 10 \text { mins* }\end{array}$ & $\begin{array}{l}\text { Let's move into today's topic. } \\
\text { Describe your Reed College family. } \\
\text { How do you want to show this in your exhibit? }\end{array}$ & $\begin{array}{l}\text { Introductory } \\
\text { Question }\end{array}$ \\
\hline \multirow[t]{2}{*}{$\begin{array}{l}\text { Primary 1- } \\
\text { Storytelling } \\
\text { *50 mins* }\end{array}$} & $\begin{array}{l}\text { Let's begin by sharing some of the stories behind our } \\
\text { pictures. }\end{array}$ & $\begin{array}{l}\text { Personal } \\
\text { thoughts/opinions/ } \\
\text { experiences }\end{array}$ \\
\hline & $\begin{array}{l}\text { What about these pictures make you proud to be a } \\
\text { Mountaineer and part of the College of Media } \\
\text { family? }\end{array}$ & Personal Experience \\
\hline \multirow{2}{*}{$\begin{array}{l}\text { Primary 2- } \\
\text { Cluster into themes } \\
\text { *30 mins* }\end{array}$} & $\begin{array}{l}\text { Everybody pick a photo that really speaks to them } \\
\text { (this doesn't have to be your own). }\end{array}$ & Finding Gems \\
\hline & $\begin{array}{l}\text { Take some time and review these chosen photos. } \\
\text { Are there any similarities? Use the Jamboard and try } \\
\text { to organize your gems into themes. } \\
\text { *screenshare HCD worksheet as example* }\end{array}$ & Organize \\
\hline Primary 3- & $\begin{array}{l}\text { Now, let's take up to } 15 \text { minutes and work together } \\
\text { to come up with a caption for our photos. These will }\end{array}$ & Writing \\
\hline
\end{tabular}




\begin{tabular}{|c|c|c|}
\hline $\begin{array}{l}\text { Creative Statements } \\
\text { *15 mins* }\end{array}$ & $\begin{array}{l}\text { act as the labels for the photos under your pictures. } \\
\text { Be creative and have fun with it:) } \\
\text { *screenshare HCD worksheet as example* }\end{array}$ & \\
\hline $\begin{array}{l}\text { Primary 4- } \\
\text { Mapping } \\
\text { *50 mins* }\end{array}$ & $\begin{array}{l}\text { Now let's think of the flow of this exhibit. What story } \\
\text { do we want it to tell about y'all's relationship with } \\
\text { the Media family? } \\
\text { What photo should we start with? Is there one we } \\
\text { know we want to end with? What photos will fill the } \\
\text { gap? } \\
\text { What do you want this to look like? *Explain closure } \\
\text { of MIC and discuss Instagram Story* }\end{array}$ & Mapping out exhibit \\
\hline Conclusion & $\begin{array}{l}\text { What else should we have discussed today but } \\
\text { didn't? } \\
\text { Thank everybody for participation }\end{array}$ & $\begin{array}{l}\text { Probe untapped } \\
\text { content. }\end{array}$ \\
\hline Additional & & \\
\hline
\end{tabular}




\section{Appendix E}

\section{PART TWO PREP EMAIL WITH CHALLENGE}

Hey hey hey!

Thank you again for your participation in my professional project. I am so grateful to have your help and can't wait to share this next round with the College of Media leadership so that they can more effectively cultivate relationships with recent graduates. (Note: Dean Martinelli and Dr. Pressgrove were IN LOVE with our photo exhibit! Y'all crushed it. The MIC is so excited to showcase this exhibit once they open back up.)

So, now that you're photovoice professionals, we will move on to Part 2 of the research and our last meeting! In Part Two, there won't be a prep meeting. Instead, I'll give you your prompts via this email for our workshop! Woohoo!

Attached to this email you will find instructions that outline your challenge. The instructions include a chart that defines the five dimensions of stewardship which experts say are the best way to cultivate relationships. By definition, stewardship is a practice that professionals use to manage an organization's relationship with you as a donor, volunteer, or stakeholder.

You have two weeks to complete the challenge, and then we will meet via Zoom as a group. This workshop will last approximately 2-3 hours. Here's the Doodle Poll link to select times that work best for you.

After the poll closes, I will send you the most voted time and the Zoom link! I will also send you the Jamboard link ahead of time so you can upload your photos at your convenience. There will be sections labeled with each of the five dimensions of stewardship. You should upload your photos to the corresponding Jamboard. We will carry out the next steps during our meeting!

Thanks again for being part of this project and I look forward to seeing your photos! Please email me if you have any questions. :)

Sincerely, Lily McKnight 


\section{Appendix F}

\section{PART 2 LESSON ATTACHED TO PART TWO PREP EMAIL WITH CHALLENGE}

Hello!

Thank you again for your participation in my professional project! I'm still so excited to have your help again this semester! Dr. Pressgrove was IN LOVE with our photo exhibit!! AH! Y'all crushed it. The MIC is so excited to showcase this exhibit once they open back up :)

So Fam, now that you're photovoice professionals, we will move on to Part Two of the research. In Part Two, there won't be a prep meeting--instead, I'll give you your prompts via this email! Woohoo! But, first, I want you to study our fabulous chart/lesson below. This is a chart defining the five dimensions of stewardship. It is described by some researchers as the fifth step to public relations. Stewardship is a practice that professionals use to manage their organization's relationship with you as a donor, volunteer or stakeholder. See below.

\section{STEWARDSHIP CHEAT SHEET}

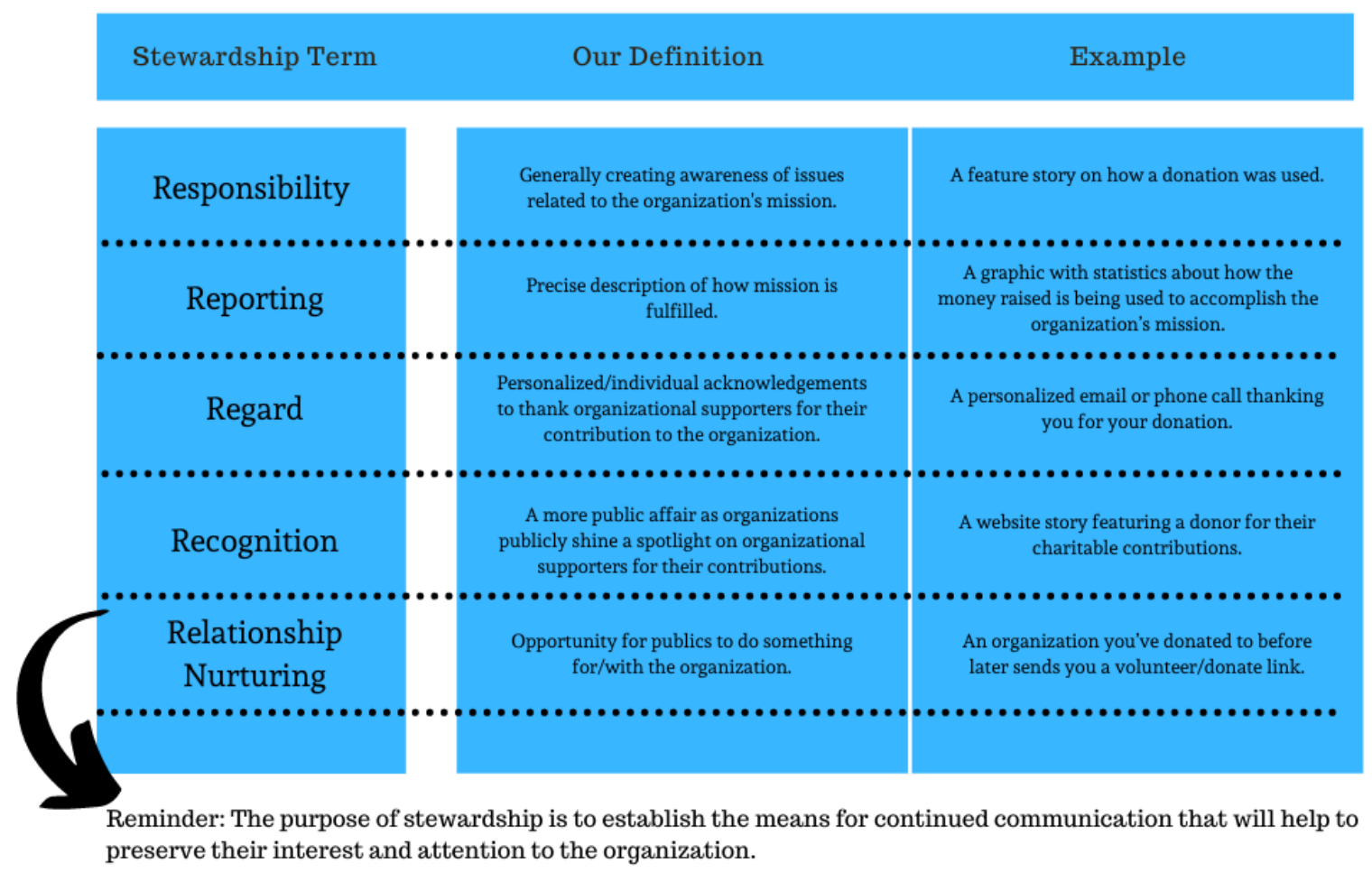

Your task will be: over the course of the next two weeks, take or find (can be a screenshots, something via Google search, etc.) one photo that answers the following prompts:

1. Show an organization demonstrating responsibility;

2. Show an organization demonstrating reporting; 
3. Capture an organization showing regard;

4. Show tan organization displaying recognition and

5. Show an organization nurturing a relationship.

***These photos will not be featured anywhere, they will only be used in this research project.

After this two week period, we will meet via Zoom again with the other student ambassadors in this study. This workshop will last approximately three hours. Here's the Doodle Poll link (insert $\underline{\text { link) }}$ to select times that work best for you to meet. After the poll closes, I will send you the most voted time and the Zoom link! This time, I will also send you the Jamboard link ahead of time so you can upload your photos at your convenience. There will be sections labeled with the five dimensions of stewardship. You should upload your photos to the corresponding Jamboard. We will carry out the next steps during our meeting!

Thanks again for helping me with my project and I look forward to seeing your photos! Please email me if you have any questions.

Sincerely, Lily McKnight 


\section{Appendix G}

\section{MODERATOR GUIDE PART TWO DOCUMENT}

\section{Moderator Guide}

Moderator Guide-Part Two Participants (Reed College Ambassadors)

\begin{tabular}{|c|c|c|}
\hline Question Type & Item & Purpose/Variable \\
\hline $\begin{array}{l}\text { Preliminary } \\
\text { *5 mins* }\end{array}$ & $\begin{array}{l}\text { Let's start by going around the room and discuss } \\
\text { some of the places we gathered our photos from. }\end{array}$ & $\begin{array}{l}\text { Re-develop rapport } \\
\text { and comfort among } \\
\text { participants. }\end{array}$ \\
\hline $\begin{array}{l}\text { Introductory } \\
* 10 \text { mins* }\end{array}$ & $\begin{array}{l}\text { Was the process easier or more challenging than } \\
\text { Part One? } \\
\text { What are some of the things you anticipated you'd } \\
\text { be taking photos of during this Part Two? }\end{array}$ & Icebreaker Question \\
\hline $\begin{array}{l}\text { Transition (In) } \\
* 10 \text { mins* }\end{array}$ & $\begin{array}{l}\text { Let's move into today's topic. } \\
\text { What are some of the reasons you donated to these } \\
\text { organizations you captured? }\end{array}$ & $\begin{array}{l}\text { Introductory } \\
\text { Question }\end{array}$ \\
\hline $\begin{array}{l}\text { Primary 1- } \\
\text { Experiences w/ } \\
\text { prompt }\end{array}$ & $\begin{array}{l}\text { Tell me about your experiences donating to those } \\
\text { charities. }\end{array}$ & Personal Experience \\
\hline \multicolumn{3}{|l|}{ *30 mins* } \\
\hline & $\begin{array}{l}\text { How did you find the opportunity to donate? For } \\
\text { example, was it through a friend, through social } \\
\text { media or an on campus booth? }\end{array}$ & $\begin{array}{l}\text { Source/Knowledge } \\
\text { of donating }\end{array}$ \\
\hline & $\begin{array}{l}\text { What are some things about those organizations } \\
\text { that you valued? }\end{array}$ & Student's values \\
\hline & $\begin{array}{l}\text { Do you intend on donating to this charity again? } \\
\text { Why or why not. }\end{array}$ & Behavioral intent \\
\hline Primary 2- & \multirow{2}{*}{$\begin{array}{l}\text { Think of those photos you took for this prompt... } \\
\text { Now describe to me the best way your college could } \\
\text { properly steward you like these orgs. }\end{array}$} & \multirow[t]{2}{*}{ Stewardship } \\
\hline $\begin{array}{l}\text { [Stewardship thoughts } \\
\text { from photos] }\end{array}$ & & \\
\hline
\end{tabular}




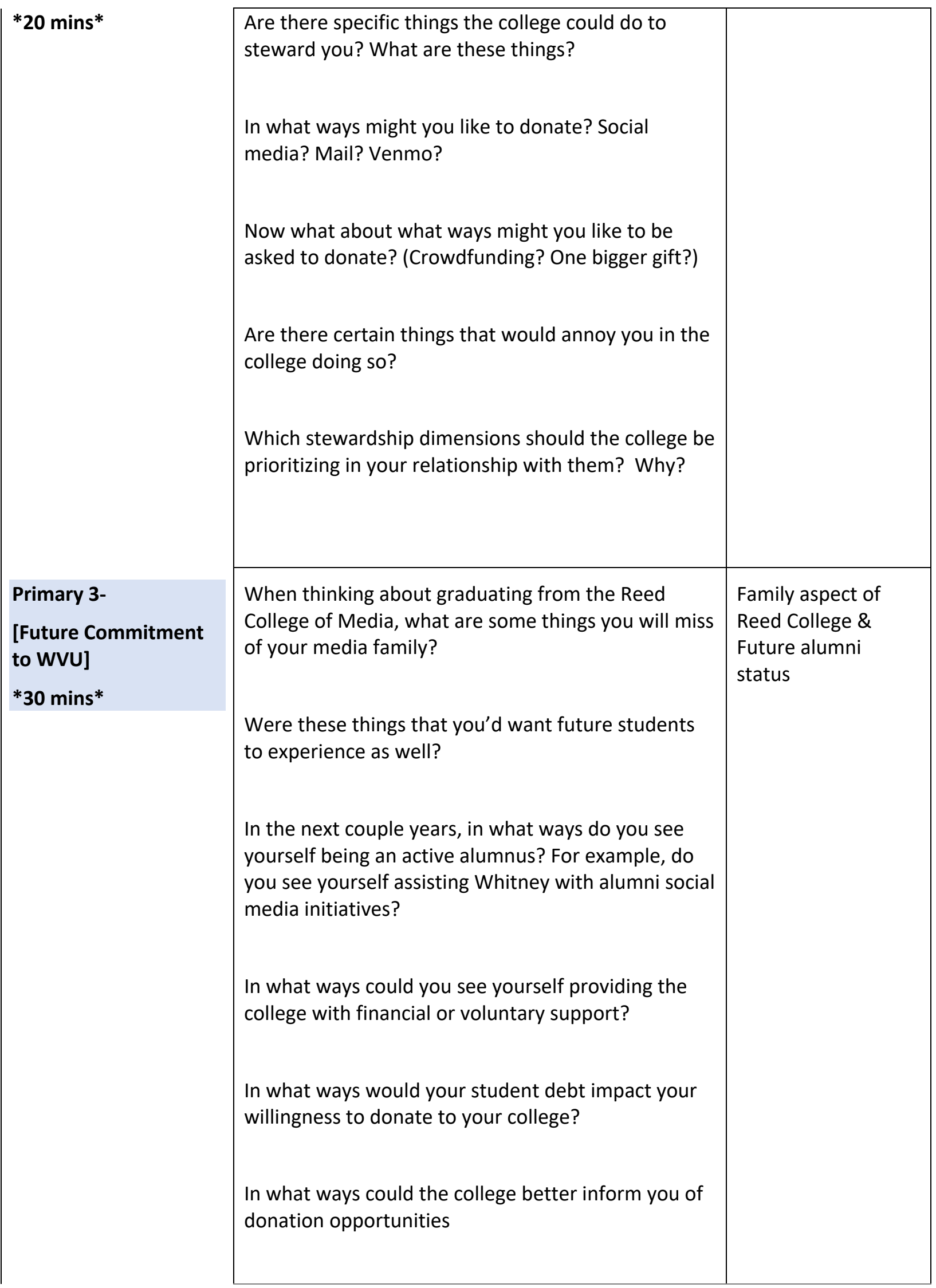




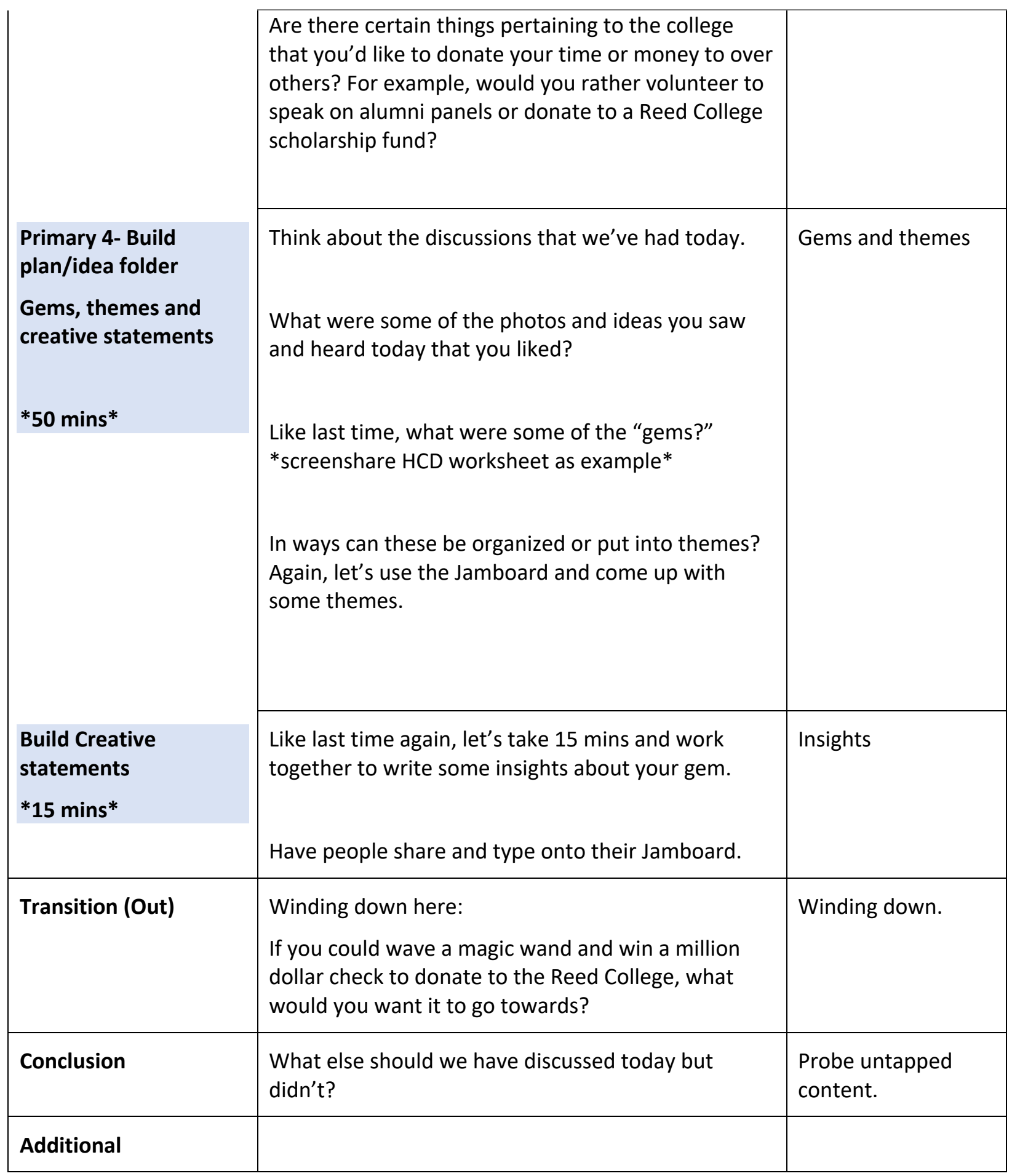




\title{
Appendix H
}

\section{FIRST EMAIL JOSHUA WALTERS (Sent March 22nd, 2021)}

\author{
Hello, Mr. Walters!
}

My name is Lily McKnight and I'm currently a graduate student in the Reed College of Media. I have also been an intern at the WVU Foundation since 2018. For my master's professional project, I have been researching and exploring how higher education development officers can cultivate Year 0 Alumni. This project will include workshops with the Reed College student ambassadors throughout the Spring 2021 semester. These workshops will ultimately lead to the creation of strategies, tactics and recommendations that higher ed development officers could use to better engage this generation.

I would love the opportunity to discuss my project further with you via Zoom. I will reach out to you after the completion of the student ambassador workshops this month to see your availability for a meeting!

Thank you!

Lily McKnight 


\section{Appendix I}

\section{SECOND EMAIL JOSHUA WALTERS (Sent April 6 $\left.{ }^{\text {th }}, 2021\right)$}

\section{Hello, Mr. Walters!}

As we discussed in our March email, I'm reaching out to inform you of the completion of the student ambassador workshops I held this semester. I would love to meet with you this month as I have taken the workshop information and developed a list of strategies, recommendations and tactics that may be useful for higher education development officers.

What is your availability this month for a meeting via Zoom?

Thank you!

Lily McKnight 
Appendix J

IRB FLEX APPROVAL

$3 / 2 / 202$

Kuali Portal Index

Report Incident/Issue

5.2 .1 (Oracle9i)

DashBoard | Proposals | Awards | IRB | COI

Internal Grants | COE | Quicklinks |Jstemmaninedz(d) |

Document Id: $2272781 \quad$ Status: Active - upen to enroulment

KC Protocol ?

Protocol \#: 2101217670

Submission Status: Approved: NHS

Protocol \#: 2101217670
* Principal Investigator: Geah N Pressgrove

Expiration Date: 02/24/2026

Protocol Personnel Permissions Questionnaire Notes \& Attachments Protocol Summary Protocol History Protocol Actions Medusa

- Document was successfully reloaded

Document Overview

( hide)

Document Overviex

\begin{tabular}{r|r|r|r|}
\hline * Description: & IRB/Flex approval for Lily McKnight's Master of Science in Journalism professional project. & \multirow{2}{*}{ Explanation: } & $\oplus$ \\
\hline Organization Document Number: & $\oplus$
\end{tabular}

Required Fields for Saving Document - hide)

\begin{tabular}{lll}
\hline Required Fields for Saving Document ? & ?
\end{tabular}

Protocol Type: NHSR / Flex

Title:

Exploration of How University Development Officers Can Cultivate Year 0 Alums

Principal Investigator: Geah N Pressgrove

Additional Information

\begin{tabular}{|l|l|l|l|}
\hline \multicolumn{4}{|c|}{} \\
\hline Other Identifiers & * Type & * Other Identifier & Approval Date \\
\hline
\end{tabular}

Funding Sources

Keywords

( hide) 
Appendix K

HCD WORKSHEET 1

\section{Worksheet 1: Identifying Themes/Clusters for Findings}

Complete this step after you have captured your learnings, identified the gems and organized data into clusters.

RQ1:

"What makes you proud to be in the Reed College family?"

Theme 1 Name:

Describe/Define in One Sentence:

What are some photos from your sessions that support this definition?

Theme 2 Name:

Describe/Define in One Sentence:

What are some photos from your sessions that support this definition?

Theme 3 Name:

Describe/Define in One Sentence:

What are some photos from your sessions that support this definition? 
Appendix L

HCD WORKSHEET 2

\section{Worksheet 2: Creating Insight Statements for Application/Interpretation}

What does it all mean? Interpret the findings. It is OK to insert your opinions here, but base them on facts from your data.

RQ 1: "What makes you proud to be in the Reed College family?"

Theme:

Insight:

1.

2.

3.

Theme:

Insight:

1.

2.

3.

Theme:

Insight:

1.

2.

3. 


\section{Appendix M}

\section{FIELD NOTES FROM PART 1 WORKSHOP}

Zooming meeting workshop Part 1

Date: March $7^{\text {th }}, 2021$

Time: 1:00pm

- Everybody is comfortable speaking

- Participant M prefers the chat feature instead of unmuting

- Participant $\mathrm{M}$ at work while participating

- Participant A a little late (arrived 13:42)

- Participant C shared photos first (22:50)

- Participant E's laptop was slow with photos

- Participants agree with Participant C's "people, places and opportunities" suggested trademarking that

- Participant M is the youngest participant, just started his journey at Reed in Fall 2020

- Participant S brings up agreeing to participate in this research as another example of people in the Reed College always saying yes to help

- Participant A brings up falling in love with the College of Media's MIC facility as a reason for wanting to come here

- Everybody ok with tool bar and sticky note gem selection

- Participant C brings up nature and people themes (44:06)

- Unsure what to classify Martin doors as

- Class Leader suggests being more abstract with nature theme

- Participant $\mathrm{C}$ suggests switching nature to environment

- Participants agree (46:01)

- Participant M nervous to caption photos

- Participant C loves Twitter because he doesn't enjoy captioning

- Participants don't really seem interested in themes worksheet prefer verbal brainstorming

- Participants want to include country roads

- "Hats off to something" for hat photos, Participant C suggests emojis

- Emojis will leave open interpretation

- Martin picture opens doors to creativity

- Participant A throws out a lot of ideas

- Participant S thinking in marketing standpoint while Participant A thinking from social media standpoint

- Participant E that one to suggest coming back to photos where multiple creative statements were liked or ones without any options

- Like hammock photo because vintage looking

- Ideas comes to include college history in creative statements

- Participant E suggests only using creative statements with emojis, other participants not feeling this

- Participants bring up TikTok trends

- Hard to caption Mirage pic

- Want to make David Smith's drone class an informative caption 
- Participant A wants to include puns

- Door photo becomes the gateway between people and your environment for your Reed College Family

- Wrap begins 1:27:44

- $\quad$ End 1:30:50 


\section{Appendix N}

\section{ZOOM WORKSHOP 1 TRANSCRIPT}

1

00:00:47.190 --> 00:00:48.210

Lily McKnight: hey guys.

2

00:00:48.570 --> 00:00:49.140

Lily McKnight: what's up.

3

00:00:49.890 --> 00:00:51.300

How are you guys.

4

00:00:53.010 --> 00:00:55.350

Participant: have three meetings today and it's Sunday so.

5

00:00:55.620 --> 00:00:55.950

Lily McKnight: I might.

6

00:00:58.050 --> 00:00:59.070

Participant: not be the door.

7

00:00:59.820 --> 00:01:01.770

Lily McKnight: I hill mines, the most fun.

8

00:01:02.070 --> 00:01:03.510

Participant: I think it probably will be.

9

00:01:03.660 --> 00:01:04.620

Lily McKnight: i'm going to strive.

10

00:01:04.650 --> 00:01:06.780

Lily McKnight: For that either the goal.

11

00:01:08.100 --> 00:01:26.910 
Lily McKnight: I think participant is joining us to and then participant joining us later um I don't know about others, but it should go kind of quickly, because I know some people that can't come so hopefully it won't take the whole time because I know that was like kind of alarming.

12

00:01:28.590 --> 00:01:33.660

Lily McKnight: with Dr preska wanted me to say it was going to take three hours, and I was like i'm.

13

00:01:34.890 --> 00:01:36.120

Participant: Not gonna stick around for that.

14

00:01:36.270 --> 00:01:36.660

Lily McKnight: I said.

15

00:01:37.650 --> 00:01:40.140

Lily McKnight: No way I was like new would come to that.

16

00:01:41.220 --> 00:01:43.380

Lily McKnight: Three hours of their time for this.

17

00:01:44.190 --> 00:01:47.280

Lily McKnight: Like just give me the degree and i'm i'm good to go.

18

00:01:48.870 --> 00:01:51.030

Lily McKnight: i'll take slowly will give her another minute.

19

00:01:58.500 --> 00:02:00.390

Lily McKnight: Did you guys have to work sports yesterday.

20

00:02:02.790 --> 00:02:04.260

Participant: Also, that over here.

21

00:02:04.410 --> 00:02:04.650

I. 
22

00:02:05.910 --> 00:02:06.270

Participant: said.

23

00:02:06.330 --> 00:02:12.480

Participant: I was one baseball got canceled I considered signing up for soccer but then I looked in the street and there's like five people there and I was like.

24

00:02:12.480 --> 00:02:13.020

Participant: yeah.

25

00:02:13.680 --> 00:02:14.460

Participant: I like i'm fine.

26

00:02:16.350 --> 00:02:22.410

Participant: yeah I oh my God I my body is ready to shut down.

27

00:02:22.830 --> 00:02:31.860

Participant: Really sports i'm i'm just tired and over it, because we had four home games and seven seven days.

28

00:02:32.520 --> 00:02:32.910

Lily McKnight: Oh, my.

29

00:02:33.210 --> 00:02:40.470

Participant: goodness we had one last Saturday, and then we had one Tuesday Thursday and then yesterday.

30

00:02:41.880 --> 00:02:46.470

Participant: Oh, my God i'm just glad to seasons done I don't have to do basketball anymore.

31

00:02:47.580 --> 00:03:02.640

Lily McKnight: i'm serious like I could not like I did football for two two only two seasons and I was up in the suite wasn't even outside and I was just like I don't know how people were at gameday I feel like I lived. 
32

00:03:03.300 --> 00:03:04.440

Lily McKnight: One is.

33

00:03:04.890 --> 00:03:05.400

Lily McKnight: In like.

34

00:03:05.550 --> 00:03:20.700

Lily McKnight: One game is, you have the before part it's thing you have the during and the after and then I would like walk myself home, like all my friends were like pre game in you know I think game already like crashed for the day and I would literally be like.

35

00:03:22.560 --> 00:03:23.190

Participant: yeah.

36

00:03:23.340 --> 00:03:35.610

Participant: But I lives or or after being on your feet flicks like six or seven hours, and then I came back last year, or I guess two years ago I carried, like the repeats of boxes and to chick fil a.

37

00:03:35.610 --> 00:03:38.310

Participant: Like back to our apartment like the staff.

38

00:03:38.970 --> 00:03:40.500

that's going oh.

39

00:03:43.290 --> 00:03:45.840

Lily McKnight: That was a good part, though the free food.

40

00:03:47.070 --> 00:03:47.850

Lily McKnight: complain.

41

00:03:48.630 --> 00:03:49.800

Participant: It really comes a clutch.

42

00:03:50.280 --> 00:03:54.120 
Lily McKnight: It really does, especially when you just like no you're going home to nothing.

43

00:03:54.810 --> 00:03:55.200

yeah.

44

00:03:56.220 --> 00:03:56.820

Participant: Because it's like.

45

00:03:58.170 --> 00:04:06.210

Participant: Because it's like usually like after a game it's like i'm tired I don't have the energy to cook so I typically just like don't eat or.

46

00:04:06.240 --> 00:04:07.050

Participant: Something yeah.

47

00:04:07.290 --> 00:04:09.030

Participant: Well, my roommate will cook i'm just like.

48

00:04:11.460 --> 00:04:11.820

Participant: Those.

49

00:04:11.850 --> 00:04:17.520

Participant: Those posts football game like working game beers are the best beer like there's like a power ranking of.

50

00:04:18.030 --> 00:04:24.840

Participant: Radical getting back from like a 3pm kickoff and it's like sunset and your tires funneling into like.

51

00:04:25.380 --> 00:04:25.710

Participant: Just like.

52

00:04:26.550 --> 00:04:27.000

That. 
53

00:04:28.020 --> 00:04:28.230

Participant: So.

54

00:04:29.730 --> 00:04:30.810

Participant: it's got to be top three.

55

00:04:30.900 --> 00:04:33.510

Participant: literal test case it's amazing, nothing will compare.

56

00:04:35.130 --> 00:04:37.830

Lily McKnight: Are you guys how what year are you guys.

57

00:04:38.580 --> 00:04:40.080

Lily McKnight: juniors juniors.

58

00:04:41.040 --> 00:04:41.580

yeah.

59

00:04:43.860 --> 00:04:56.670

Lily McKnight: I literally turned 21 I will like a late birthday, so I turned 21 last May, and I was like really like this is gonna be like my time to like shine because all my roommates already 21 and then.

60

00:05:00.300 --> 00:05:00.870

Participant: yeah.

61

00:05:02.190 --> 00:05:02.910

Participant: Go ahead go ahead.

62

00:05:03.180 --> 00:05:07.950

Participant: Oh no I was just gonna say I don't turn 21 until July and corporate doesn't turn 21 November.

63

00:05:08.220 --> 00:05:16.950 
Participant: it's like it's like like done ish who knows by November let's just say if it's safe to have a coordinator 21 st birthday bash.

64

00:05:18.990 --> 00:05:21.150

Participant: i'll be i'll be there will be a good time.

65

00:05:21.270 --> 00:05:23.400

Participant: It will throw it in the yards.

66

00:05:25.260 --> 00:05:26.190

Participant: decide yard.

67

00:05:27.000 --> 00:05:27.900

Lily McKnight: hi Sarah.

68

00:05:29.970 --> 00:05:30.480

Participant: Hello.

69

00:05:31.140 --> 00:05:35.010

Lily McKnight: How was your how was basketball yesterday you take over so good.

70

00:05:35.430 --> 00:05:37.260

Lily McKnight: depressing really.

71

00:05:37.590 --> 00:05:39.000

Participant: yeah I was.

72

00:05:39.750 --> 00:05:41.580

Participant: gonna take over how did I not see this.

73

00:05:42.330 --> 00:05:43.530

Participant: Because I didn't.

74

00:05:43.530 --> 00:05:45.510

Participant: want anyone to see my takeover. 
75

00:05:45.840 --> 00:05:48.600

Participant: Because I totally forgot about it until like.

76

00:05:48.930 --> 00:05:50.130

Participant: Five minutes will tip off.

77

00:05:50.160 --> 00:05:50.790

And I was like.

78

00:05:52.020 --> 00:05:52.680

Lily McKnight: yeah.

79

00:05:52.800 --> 00:05:55.710

Participant: I still gotta do it, so I did it like really quick.

80

00:05:56.010 --> 00:05:56.880

Lily McKnight: He crushed it.

81

00:05:57.180 --> 00:05:58.410

Participant: Okay i'm glad, thank you.

82

00:05:59.520 --> 00:06:05.250

Lily McKnight: I love, do you, like all bundled with like your mask and you guys it Sarah and I was like I love this.

83

00:06:05.280 --> 00:06:09.750

Participant: energy's cold it's cold in the Coliseum like I don't know why.

84

00:06:10.110 --> 00:06:11.460

Participant: rock it's cold.

85

00:06:11.880 --> 00:06:18.600

Participant: Yes, and up where I am not on the floor on the floor time I will I always sweat whatever i'm like striking. 
86

00:06:18.990 --> 00:06:24.630

Participant: or setting up on the on the floor but up up in like where the scene section it's always cold they're.

87

00:06:26.190 --> 00:06:26.550

Participant: Always.

88

00:06:26.580 --> 00:06:29.040

Participant: Does it reach that way hot air rises.

89

00:06:29.160 --> 00:06:30.960

Participant: Sarah so.

90

00:06:32.820 --> 00:06:38.490

Participant: there's like the air conditioner I guess they're like on either side, like by the crow's nest because it's always cold in the crow's nest.

91

00:06:38.970 --> 00:06:41.940

Participant: Last time I was in there, I swear to God it was 80 degrees on the floor.

92

00:06:42.150 --> 00:06:43.530

Participant: It was so hot.

93

00:06:44.700 --> 00:06:45.030

Participant: So.

94

00:06:45.270 --> 00:06:51.210

Participant: Not only was it hi I was trying to ward off Dale to try and get photos of senior day stuff so I was.

95

00:06:51.210 --> 00:06:55.590

Participant: Like walking Dale I saw him, he was like staring at me I was like dude.

96

00:06:57.660 --> 00:06:59.160 
Participant: We started a deal.

97

00:07:02.040 --> 00:07:15.240

Lily McKnight: Alright, so we'll go ahead and i'm checking see if you've got the link for the GM board, and let me know if you didn't um but you guys can just go ahead and.

98

00:07:15.690 --> 00:07:26.100

Lily McKnight: I don't know cuz I don't know if it'd be easier if you all want to make your own slide and put your pictures on that's fine or if you all want to share this one, whatever.

99

00:07:26.670 --> 00:07:27.690

Participant: They on the one.

100

00:07:27.960 --> 00:07:29.070

Lily McKnight: yeah you like that.

101

00:07:29.190 --> 00:07:29.850

Participant: Okay, good.

102

00:07:30.330 --> 00:07:30.570

night.

103

00:07:32.760 --> 00:07:38.760

Lily McKnight: Go ahead and add them all to the this front page per carbons request.

104

00:07:39.870 --> 00:07:47.070

Lily McKnight: And then i'm the Ad image thing is everything on the Left it's the one that looks like it has the like the little mountains on it.

105

00:07:48.210 --> 00:07:48.870

Participant: Oh yeah.

106

00:07:50.160 --> 00:08:00.450

Lily McKnight: And there, I told them i'm not sure if you're on yet, but this this won't go till for Dr press room amy say it was going to take three hours, and I was like oh it's not. 
107

00:08:01.080 --> 00:08:05.820

Participant: I didn't even read that I was like oh yeah I don't I didn't even know that there was a.

108

00:08:06.210 --> 00:08:06.870

Lily McKnight: Possibility I.

109

00:08:07.080 --> 00:08:09.300

Lily McKnight: was like oh my God no one's gonna want to come.

110

00:08:09.300 --> 00:08:14.850

Lily McKnight: Because all day and it's literally like three hours, no, no.

111

00:08:52.380 --> 00:08:53.670

Participant: How many photos do you want.

112

00:08:55.080 --> 00:08:57.420

Lily McKnight: um did you all take three.

113

00:08:58.590 --> 00:09:07.950

Lily McKnight: You can put like, if you want to put all the ones, he took that's fine if you want to pick a couple that's fine to whatever you want um, if you like, all of them i'd love to see them.

114

00:09:10.080 --> 00:09:11.010

Participant: A list of like.

115

00:09:11.640 --> 00:09:12.180

Participant: Oh sorry.

116

00:09:12.660 --> 00:09:17.100

Participant: I have a list of like five mediocre fetters so I don't know what you want it.

117

00:09:17.550 --> 00:09:21.150

Lily McKnight: Oh yeah no, you can add them all, so in a couple. 
118

00:09:25.020 --> 00:09:32.550

Lily McKnight: For, but you can pick ones that aren't yours, so if you want to go ahead and put all of them that works too.

119

00:09:34.440 --> 00:09:38.430

Participant: I was gonna ask is it okay if we upload pictures that we took a while ago and.

120

00:09:39.150 --> 00:09:48.840

Lily McKnight: that's totally fine like as long as you are the one that took them you just can't use anything like that you saw like our instagram or something like that.

121

00:09:48.990 --> 00:09:53.850

Lily McKnight: Okay, hang up and we wouldn't want someone to walk in there and be like hey I took that.

122

00:09:55.680 --> 00:09:56.100

Participant: fair.

123

00:10:01.140 --> 00:10:02.520

Participant: To make this look at this.

124

00:10:06.780 --> 00:10:11.760

Lily McKnight: These are so good i'm so jealous think you guys are so good, with just like the lighting and stuff like.

125

00:10:11.760 --> 00:10:15.330

Lily McKnight: i'm not talented in this realm like at all.

126

00:10:15.660 --> 00:10:19.080

Participant: The real compliment is you got to say, while your camera takes really nice pictures.

127

00:10:21.180 --> 00:10:21.930

Participant: yeah right. 
128

00:10:22.590 --> 00:10:23.220

Participant: Speaking of.

129

00:10:23.550 --> 00:10:24.390

Lily McKnight: camera right.

130

00:10:25.620 --> 00:10:32.040

Participant: Speaking of that there's one of the student manage for managers for basketball his name is Bud and.

131

00:10:33.150 --> 00:10:47.430

Participant: For like an end of the year, like appreciation posts for like all the staff or whatever says, having you take a photo of like a bunch of them, and so I got a couple of them and I sent him to him he's like hey man that cameras nice i'm like yeah man sure is.

132

00:10:48.690 --> 00:10:49.500

Participant: You either.

133

00:10:51.180 --> 00:10:53.850

Lily McKnight: nothing to do with my talent or ability it's just.

134

00:11:16.080 --> 00:11:19.350

Lily McKnight: Oh, my gosh I love the cookie PIC that's great.

135

00:11:23.790 --> 00:11:25.380

Participant: courtesy of our Queen Whitney.

136

00:11:26.130 --> 00:11:28.350

Lily McKnight: wow I really do live for Whitney.

137

00:11:34.050 --> 00:11:35.280

Participant: Is that in below.

138

00:11:36.120 --> 00:11:37.950

Participant: that's in the low hotel lobby. 
139

00:11:39.060 --> 00:11:41.970

Participant: Exactly exactly I love this picture.

140

00:11:45.510 --> 00:11:47.790

Participant: Whenever we went that one time.

141

00:11:49.530 --> 00:11:50.010

Participant: um.

142

00:11:50.430 --> 00:12:00.660

Participant: I was going to include a I have one of my brands or any photos I was gonna put a bunch and then I realized that I can't find them anywhere, I went to the Google drive and everyone else's photos are there, except mine and they're all.

143

00:12:01.260 --> 00:12:01.740

Participant: That crap.

144

00:12:02.370 --> 00:12:03.030

Participant: And they're not like.

145

00:12:05.580 --> 00:12:07.500

Participant: yeah diploma mine.

146

00:12:08.880 --> 00:12:16.680

Participant: I have this these past couple weeks have been like insanely busy for me, so I just pulled a bunch of not been a few of my old photos.

147

00:12:19.980 --> 00:12:23.850

Lily McKnight: I knew that you guys would probably be like oh like we just have like.

148

00:12:24.180 --> 00:12:25.680

Lily McKnight: That like we just.

149

00:12:28.980 --> 00:12:31.080 
Participant: Basically yeah.

150

00:12:32.910 --> 00:12:35.820

Participant: I also have one of Sarah on here as well.

151

00:12:36.240 --> 00:12:37.620

Participant: yeah Sir.

152

00:12:38.490 --> 00:12:41.730

Participant: From a i'll just let you see yourself okay.

153

00:12:43.980 --> 00:12:49.110

Participant: that's a thing we all, like to take pictures that we all take pictures of each other, but like sometimes we forget to send them to each.

154

00:12:49.110 --> 00:12:49.380

Participant: Other.

155

00:12:49.530 --> 00:12:50.550

Participant: And you just have them.

156

00:12:50.940 --> 00:12:51.210

yeah.

157

00:12:53.550 --> 00:12:55.440

Lily McKnight: a pleasant surprise later right.

158

00:12:59.130 --> 00:12:59.280

here.

159

00:13:00.360 --> 00:13:03.990

Participant: And I really like it, I think that's corbin or SAS i'm not sure.

160

00:13:07.680 --> 00:13:09.420

Participant: i'd be one with the cookie I think that's mark. 
161

00:13:11.640 --> 00:13:13.350

Participant: Okay, wait woodburn.

162

00:13:14.880 --> 00:13:16.290

Participant: Oh no is that.

163

00:13:16.650 --> 00:13:18.240

Participant: Martin all dummy there I.

164

00:13:20.280 --> 00:13:22.020

don't know your campus buildings.

165

00:13:24.120 --> 00:13:24.870

Lily McKnight: Honest mistake.

166

00:13:25.770 --> 00:13:28.890

Participant: yeah please keep that they're just huge.

167

00:13:29.520 --> 00:13:30.030

justice.

168

00:13:31.110 --> 00:13:31.950

Participant: beggar.

169

00:13:32.400 --> 00:13:33.810

Participant: My laptop absolute.

170

00:13:33.810 --> 00:13:35.280

Participant: banger oh wait hold on.

171

00:13:36.060 --> 00:13:38.490

Participant: hold on one SEC, I might have some some good stuff that drove it. 
00:13:42.330 --> 00:13:43.860

Participant: hey sorry i'm late.

173

00:13:44.100 --> 00:13:44.220

Participant: I.

174

00:13:45.090 --> 00:13:46.380

Participant: don't have anywhere to put my photos.

175

00:13:47.370 --> 00:13:48.300

Participant: I know you might have to make.

176

00:13:48.330 --> 00:13:48.960

Participant: Our slide.

177

00:13:50.640 --> 00:13:51.030

Participant: slide.

178

00:13:52.230 --> 00:13:55.920

Lily McKnight: corbin it has the responsibility has to lie with you, you know.

179

00:13:56.910 --> 00:13:57.990

Participant: This is your decision.

180

00:13:58.560 --> 00:14:00.570

Participant: yeah corbin without Fuck the.

181

00:14:02.910 --> 00:14:03.900

phone on one side.

182

00:14:05.250 --> 00:14:07.890

Participant: i'm assuming it's clear frame i'm guessing.

183

00:14:09.180 --> 00:14:09.450

Participant: Oh. 
184

00:14:09.750 --> 00:14:11.550

Participant: How do I do.

185

00:14:13.740 --> 00:14:15.300

Lily McKnight: I just added.

186

00:14:15.330 --> 00:14:17.430

Lily McKnight: The link to the GM board.

187

00:14:17.790 --> 00:14:20.790

Participant: Everybody pull up to the newly created second slide.

188

00:14:22.920 --> 00:14:24.090

Participant: New slide just dropped.

189

00:14:26.010 --> 00:14:26.610

Participant: Have.

190

00:14:27.600 --> 00:14:27.660

A.

191

00:14:28.860 --> 00:14:30.330

Participant: photo of corbin that $I$ just.

192

00:14:30.360 --> 00:14:31.050

Participant: Thought Oh, this is.

193

00:14:31.290 --> 00:14:32.640

Participant: So chaotic.

194

00:14:34.530 --> 00:14:35.100

Participant: How do we look. 
00:14:35.370 --> 00:14:39.600

Participant: At pictures to a different a different all the nature, one should you.

196

00:14:39.600 --> 00:14:39.780

Participant: Read.

197

00:14:40.110 --> 00:14:40.980

Participant: The first slide.

198

00:14:41.490 --> 00:14:42.300

Participant: Then we can move.

199

00:14:43.080 --> 00:14:44.130

Participant: We can move on.

200

00:14:44.790 --> 00:14:49.470

Lily McKnight: I think you should be able to copy and paste but maybe that's not a thing.

201

00:14:49.800 --> 00:14:51.120

Participant: I kind of hate that, though.

202

00:14:51.360 --> 00:14:53.040

Lily McKnight: yeah i'm super sorry i'm.

203

00:14:54.660 --> 00:15:00.120

Lily McKnight: Well i'm sorry yeah it's messy this happened when I did my practice one, but I was kind of like.

204

00:15:01.980 --> 00:15:17.100

Lily McKnight: um, but we want to leave them wherever and then we can organize them all together if you guys want to do that now i'm whatever whatever is like more pleasing for you guys because you're the photographers.

205

00:15:21.870 --> 00:15:23.610

Participant: names on one slide non. 
206

00:15:23.610 --> 00:15:23.940

means.

207

00:15:25.680 --> 00:15:26.670

Participant: Yes, that's perfect.

208

00:15:28.770 --> 00:15:36.180

Participant: let's just say like lily like this is like so like important and professional for her and we're just making it into something so chaotic.

209

00:15:36.420 --> 00:15:39.360

Lily McKnight: Oh, my God I just appreciate you guys.

210

00:15:40.500 --> 00:15:45.510

Lily McKnight: This was like I don't know if any of you are considering your MSG but.

211

00:15:47.490 --> 00:15:48.510

Participant: I barely considering.

212

00:15:51.570 --> 00:15:51.900

Participant: Maybe.

213

00:15:53.640 --> 00:15:55.830

Lily McKnight: Maybe a little something else I don't know, but you didn't.

214

00:15:58.110 --> 00:16:05.640

Participant: I don't know I like I Grad school isn't like something I would like i'm set on but like if I get a GA position like.

215

00:16:05.790 --> 00:16:06.840

Lily McKnight: yeah yeah.

216

00:16:07.620 --> 00:16:15.870

Lily McKnight: You could be being when he's GA has been the best thing that ever happened to me like if I was not whitney's GA no way, I would still be doing. 
217

00:16:31.350 --> 00:16:32.130

Lily McKnight: message me.

218

00:16:32.490 --> 00:16:35.460

Lily McKnight: And she was like Oh, I thought the workshop was it seven.

219

00:16:38.070 --> 00:16:38.490

Participant: Oh.

220

00:16:41.040 --> 00:16:47.070

Participant: I know I just got to work and, like I dealt with my customers I sat down, it was like one on one I was like no.

221

00:16:47.430 --> 00:16:48.090

crappy.

222

00:16:49.650 --> 00:16:50.790

Participant: Market has been cancelled.

223

00:16:56.400 --> 00:17:00.510

Lily McKnight: And does anyone Adam did you add your PICs.

224

00:17:02.610 --> 00:17:03.900

Participant: I know i'm getting them right now.

225

00:17:04.050 --> 00:17:04.800

Lily McKnight: Okay perfect.

226

00:17:06.270 --> 00:17:07.320

Participant: She says i'm sorry.

227

00:17:07.470 --> 00:17:16.500

Lily McKnight: Let us know it's fine no worries I was telling them um they made me say it was going to take three hours it's definitely not so. 
00:17:17.580 --> 00:17:18.570

Lily McKnight: This is chill.

229

00:17:38.430 --> 00:17:42.390

Lily McKnight: I probably have to cut out the part where I said don't get your Ms J but.

230

00:17:45.330 --> 00:17:45.540

Participant: Could.

231

00:17:47.370 --> 00:17:47.760

Participant: Do.

232

00:17:50.550 --> 00:17:53.100

Lily McKnight: Like Nice, where I was promoting the Program.

233

00:18:02.910 --> 00:18:20.220

Lily McKnight: I won't say like who because you know I don't have it in me to like be saucy but somebody who was supposed to come today sent me an email this morning that um they couldn't come because they hurt i'm having a date.

234

00:18:23.460 --> 00:18:28.500

Lily McKnight: And they're like it went well, though, and I was like Oh, I mean a good to hear.

235

00:18:29.760 --> 00:18:31.110

Lily McKnight: I was a happy for you.

236

00:18:32.820 --> 00:18:34.980

Participant: I love the listener honest.

237

00:18:35.460 --> 00:18:42.420

Lily McKnight: that's an issue they were like Oh, you know, like sorry just being transparent, I was like no i'm here for like. 
00:18:44.190 --> 00:18:45.960

Participant: A date at 1pm on a Sunday.

239

00:18:48.240 --> 00:18:49.230

Participant: As a more wholesome.

240

00:18:49.530 --> 00:18:50.160

In the middle.

241

00:18:55.980 --> 00:18:58.260

Participant: lily I have a question are we allowed to like.

242

00:18:59.610 --> 00:19:07.920

Participant: submit more pictures after this day because my idea for like one of my photos, though, like event hasn't happened until next week.

243

00:19:08.370 --> 00:19:21.990

Lily McKnight: yeah absolutely so there's gonna be another one of these, if you want to use it then or, if you want to put it in the photo exhibit for this part we can totally add that in later um.

244

00:19:26.550 --> 00:19:36.120

Lily McKnight: um and then we can throw it in later, you and I can just get on and put it in OK cool totally up to you guys it's all lies with you so.

245

00:20:01.830 --> 00:20:03.330

Lily McKnight: I love that airdrop sound.

246

00:20:03.690 --> 00:20:07.410

Participant: I love the airdrop sound it's very pleasing.

247

00:20:07.470 --> 00:20:11.160

Lily McKnight: it's like satisfying because it's like yes like it work like it went through.

248

00:20:26.760 --> 00:20:32.130

Lily McKnight: Oh corbin or seth can you guys still do an instagram tomorrow. 
00:20:34.200 --> 00:20:34.560

Participant: Yes.

250

00:20:35.430 --> 00:20:36.870

Lily McKnight: Yes, i'm sure cool.

251

00:20:39.630 --> 00:20:44.940

Lily McKnight: It can be super short and sweet it doesn't have to be any thing out of this world.

252

00:20:46.530 --> 00:20:51.420

Lily McKnight: Wishing everything you do it's just crazy out of this world perfect but.

253

00:20:52.170 --> 00:20:52.920

Participant: We don't miss.

254

00:20:53.820 --> 00:20:55.200

Lily McKnight: You really don't you really.

255

00:20:55.470 --> 00:21:07.560

Lily McKnight: want you to have and then also freakin Sarah your guys's take talks blow me and whitney's like I love water like I could never.

256

00:21:10.290 --> 00:21:14.970

Lily McKnight: So many people us a message with sarah's and they are like a home.

257

00:21:15.390 --> 00:21:23.730

Lily McKnight: What did they say they were like we love the caption it was like no printer just facts or something like before that.

258

00:21:26.130 --> 00:21:28.170

Participant: Most of my life is spent on tech pop.

259

00:21:29.280 -->00:21:30.270 
Participant: fx new printer.

260

00:21:31.650 --> 00:21:32.790

Participant: I have an idea was.

261

00:21:32.880 --> 00:21:36.900

Participant: On it'll be like something like for the recall media like hey i'm.

262

00:21:38.580 --> 00:21:44.280

Participant: there's like some behind the scenes tips of like what it's like to be in the recording media blah blah and then i'm just gonna Jimmy will.

263

00:21:47.880 --> 00:21:49.770

Participant: You just got Jimmy would.

264

00:21:50.700 --> 00:21:52.410

Participant: You just got Jimmy will.

265

00:21:52.950 --> 00:21:55.800

Lily McKnight: show respect your flourishing just I don't know what that is.

266

00:21:57.360 --> 00:21:58.590

Participant: Is for one division.

267

00:22:00.000 --> 00:22:02.400

Lily McKnight: Oh OK, I have heard of that.

268

00:22:03.900 --> 00:22:05.310

Participant: As you should very good.

269

00:22:14.640 --> 00:22:16.020

Lily McKnight: Are you done adding Adam.

270

00:22:16.620 --> 00:22:17.550

Participant: Yes, ma'am. 
00:22:17.820 --> 00:22:18.600

Lily McKnight: All right.

272

00:22:19.710 --> 00:22:24.180

Lily McKnight: All right, so just get started most this will just be talking it's be super chill.

273

00:22:24.660 --> 00:22:41.910

Lily McKnight: um so first we'll go around and you don't have to do every single picture you can just kind of do what you feel and what's your vibe and way um you can just kind of stay, you know, like where are some of the places that you got your pictures from and where you took them.

274

00:22:45.060 --> 00:22:49.380

Lily McKnight: Whoever wants to go first corbin your first in my little box, if you want to start.

275

00:22:50.880 --> 00:22:53.280

Participant: I bet um so.

276

00:22:54.300 --> 00:23:02.670

Participant: I had other photos in mind that were previously taken at the first one in the top left corner, which is from our brand journey trips, the point pleasant.

277

00:23:03.960 --> 00:23:06.570

Participant: Last year now, which feels like way longer than that.

278

00:23:07.800 --> 00:23:13.080

Participant: But I guess my my theme for like talking about the call, just like the people, the places and the opportunities.

279

00:23:14.250 --> 00:23:25.020

Participant: So I, I have some photos somewhere that probably represent a better but i'm still looking for my hard drive that I had everything on last year crashed so.

280

$00: 23: 25.650$--> 00:23:30.990 
Participant: anyways what in the top left that's a from when we are all done in point pleasant for brand journey.

281

00:23:31.530 --> 00:23:36.540

Participant: That was the point was in high school versus mahalo basketball game that we were shooting so it was like the first time that.

282

00:23:36.870 --> 00:23:42.090

Participant: sentence, there were there too, so they know what i'm talking about it was like the first time that we were down there in point pleasant and brand journey.

283

00:23:42.510 --> 00:23:48.600

Participant: very sad that it did not get renewed as a possible like capstone project because they they cut off funding for the thing but.

284

00:23:49.560 --> 00:23:53.010

Participant: yeah that's when the basketball game, I thought that was just a really cool opportunity, especially for like.

285

00:23:53.460 --> 00:24:01.350

Participant: Class stuff because, like being in a lecture or just like a normal classes is fun, but being able to like travel and do really cool stuff for class.

286

00:24:01.740 --> 00:24:09.060

Participant: As like an integral part of it is really great to that was definitely a cool opportunity, I think that photo kind of represents that well that was in the locker room before that game.

287

00:24:09.570 --> 00:24:21.840

Participant: And then the one one over which I can't I don't know if you guys can like see what I selected, but the the hat photo that was from a trip that seth and I had some friends took down to spruce knob that was in like the spruce knob recreation area.

288

00:24:22.920 --> 00:24:27.150

Participant: And I just a w had down there and that kind of represents the places.

289

00:24:28.440 --> 00:24:37.410 
Participant: Part of it just because what you're doing is very pretty and $I$ have some other a bunch of other photos of West Virginia state but that's one that kind of includes the logo and kind of the w branding so.

290

00:24:37.770 --> 00:24:45.960

Participant: And then over here on the right hand corner, this is one $I$ took it was a like an open house, maybe at the end of like freshman year so.

291

00:24:46.500 --> 00:24:54.600

Participant: way before code and I don't know I just kind of liked how the framing is and it's nothing too special but inside Martin Hall, where we spend a lot of our time so.

292

00:24:54.630 --> 00:25:00.360

Lily McKnight: I love the lights on that one like just the way it all lined up it's a really good PIC yeah thanks.

293

00:25:00.660 --> 00:25:04.980

Participant: So nothing crazy in terms of the photos here, but I think they'll have a little bit of a meaning, no, no.

294

00:25:05.040 --> 00:25:10.290

Lily McKnight: Definitely, I really like that is anyone else, want to share where they took there's.

295

00:25:11.970 --> 00:25:17.970

Participant: i'm so shocked upload button my laptop my internet's been crazy slow, but when I finish uploading I will go.

296

00:25:18.930 --> 00:25:19.590

Okay.

297

00:25:21.180 --> 00:25:21.960

Participant: i'll go.

298

00:25:24.090 --> 00:25:36.750

Participant: OK, so my this one of what burn right here, I like actually took on accident, I was just like sitting on a on the bench outside of Martin and i'm. 
299

00:25:37.230 --> 00:25:53.160

Participant: Like took it with my phone but it turned out really good like nice quality, so I was like Oh, this is um I don't know I feel like that's like representational of what we do, sometimes in the $J$ school is like accidental like creativity, all the time.

300

00:25:54.930 --> 00:25:59.040

Participant: And, and that I was sitting on a bench outside of Martin felt felt right.

301

00:26:00.750 --> 00:26:09.810

Participant: there's that one, and then I uploaded this one and one on the second slide that were like behind the scenes from a mirage shoot that I like.

302

00:26:10.620 --> 00:26:16.200

Participant: It was like my article idea my curation of the outfits and that was like one of my favorite.

303

00:26:16.650 --> 00:26:27.270

Participant: pieces that we've done and I really like these behind the scenes, because I like this one is like very posed in editorial and then the one on the second slide there like you see the fun like they're laughing and.

304

00:26:29.040 --> 00:26:34.830

Participant: Kathleen these are my two friends alley and Kelly that are both twins and both like very models.

305

00:26:36.000 --> 00:26:47.730

Participant: Like a great model so um yeah I thought that one was cool capturing and that was like my i'm doing another shoot for mirage this week that I want more behind the scenes photos out because $I$.

306

00:26:47.730 --> 00:26:48.060

Lily McKnight: Think.

307

00:26:48.420 --> 00:26:51.630

Participant: That they could be cool one might be accessing modeling. 
308

00:26:54.180 --> 00:26:55.140

Lily McKnight: modeling tape you.

309

00:26:55.680 --> 00:27:04.470

Participant: Know God I I always hate getting picture staging because I am like terrible opposing and saying what like what i'm taking photos of people posing as always, my.

310

00:27:05.520 --> 00:27:07.920

Participant: weak point but maybe.

311

00:27:08.220 --> 00:27:11.130

Participant: If you're posing as bad it's my fault not yours, because.

312

00:27:13.440 --> 00:27:21.570

Lily McKnight: I don't take the fall right yeah I really love this I don't I like how you had the mirage element in there, I like that yeah.

313

00:27:22.530 --> 00:27:34.290

Lily McKnight: colo so um you know with a lot of these, I think we can see, like the small connections like mirage or students or drugs or honestly like you said, Martin.

314

00:27:34.830 --> 00:27:43.800

Lily McKnight: It sounds like you are sitting outside on march in accidentally took the picture corbin had the photo of the inside of Martin.

315

00:27:44.460 --> 00:28:03.720

Lily McKnight: So I think we can see that, like a lot of us are going to have kind of those similar experiences and whatnot so what looking at all of these like what do you think are some of the like commonalities and whatnot that, like you, all had in mind with the pictures that you took for this.

316

00:28:07.500 --> 00:28:12.180

Participant: I think corbin nailed it with his people places opportunities.

317

00:28:12.510 --> 00:28:18.600 
Lily McKnight: yeah That was really That was really good curve at all, I might have to my have to use that for something.

318

00:28:19.470 --> 00:28:20.670

Participant: trademark restricted.

319

00:28:22.110 --> 00:28:23.160

Participant: Access fee to that.

320

00:28:25.140 --> 00:28:36.930

Lily McKnight: um so with that i'm will go in and we'll talk a little bit about today's main topic, but how would you all describe.

321

00:28:38.190 --> 00:28:55.260

Lily McKnight: Your read college family, and this can be you know your friends your opportunities or your places i'm just kind of will i'll take a turn with this one and in how How would you describe that that family that you've created here.

322

00:28:58.920 --> 00:28:59.550

Participant: Let me go first.

323

00:29:00.270 --> 00:29:00.780

sure.

324

00:29:02.370 --> 00:29:06.420

Participant: there's a group of people that I really care about, and then I hope really care about me.

325

00:29:08.820 --> 00:29:10.470

Participant: I don't care about you at all.

326

00:29:12.060 --> 00:29:13.710

Participant: They really like it.

327

00:29:14.190 --> 00:29:16.140

Participant: don't just stop Doug Warren. 
328

00:29:19.140 --> 00:29:19.650

Participant: yeah yeah.

329

00:29:22.890 --> 00:29:27.960

Participant: I don't know i'll think of more other stuff to say that's that's what I got for now.

330

00:29:28.080 --> 00:29:28.890

Give me a couple minutes.

331

00:29:31.380 --> 00:29:37.350

Lily McKnight: Absolutely, I mean I think for somebody like me I didn't really start in the reed college.

332

00:29:38.280 --> 00:29:46.710

Lily McKnight: I want to be like a cow girl when I first came to college and I was in like animal science, you know, and I was going to these classes.

333

00:29:47.190 --> 00:29:54.630

Lily McKnight: And I didn't know anyone like no one wanted to be friends in class, like everyone was so like.

334

00:29:55.170 --> 00:30:04.440

Lily McKnight: You know, like driven is a great thing to be, but it was almost like a point where I felt like I had no friends, which is kind of like a sad.

335

00:30:05.070 --> 00:30:15.720

Lily McKnight: vibe I mean it is i'm being you know I loved I loved what I was learning, but I was like can I really like sustain this for the next four years, when I feel like people.

336

00:30:16.080 --> 00:30:28.110

Lily McKnight: In here view me as like a direct competition for like grades or something and I feel like if I wanted to like hang out with them outside of class, they would like hate me. 
00:30:29.640 --> 00:30:45.720

Lily McKnight: But I don't know and then you know you go to the because you were so creative and you know creativity only does better, the more people you have and the more ideas you have, so I think that is definitely something that I noticed, and I think that has a lot to do.

338

00:30:47.340 --> 00:30:59.820

Lily McKnight: With our family aspect, and I really do think like when you compare us to kind of other programs like I really do think that, just so how you all are on here right now on you're all like bfs like that's so fun to me oh.

339

00:31:01.320 --> 00:31:05.430

Lily McKnight: But that's how maybe I would start describing mine, I definitely say.

340

00:31:06.480 --> 00:31:19.950

Lily McKnight: i'm creative open to being friends, you know I think that's one of the very first things like you walk in a class and they're so small, like you, almost like have to you have to sit at a table with someone like you have to talk to them right it's like weird.

341

00:31:22.530 --> 00:31:27.810

Lily McKnight: But set your next on my on my blog I don't know if it's the same for like everyone I don't know if everyone.

342

00:31:27.840 --> 00:31:29.490

Participant: Sorry, I don't think it is.

343

00:31:30.840 --> 00:31:32.460

Lily McKnight: For your next I think we're gonna go.

344

00:31:32.970 --> 00:31:35.370

Participant: Can you can you repeat the question I forgot it already.

345

00:31:35.970 --> 00:31:40.020

Lily McKnight: yeah sorry sorry, you can hear me college family.

346

00:31:40.920 --> 00:31:53.700 
Participant: um honestly I don't really know I mean obviously like corbin said, I mean it's people that I really care about, and then I hopefully that hopefully also care about me a lot and.

347

00:31:54.420 --> 00:32:05.940

Participant: Like people that I share a lot in common with that, like I wasn't really not necessarily that I wasn't expecting but like that it's really nice to have so many people that I have a lot of things in common with.

348

00:32:06.420 --> 00:32:07.890

Lily McKnight: uh huh that's really me.

349

00:32:09.450 --> 00:32:11.490

Lily McKnight: Mark deanna go you next time I black.

350

00:32:12.210 --> 00:32:15.150

Participant: For sure I guess i'm like the young bloke here.

351

00:32:17.010 --> 00:32:28.170

Participant: So I started in the fall, but I would say, like everyone in the college always says like yes, without hesitation like it doesn't matter what it is doesn't matter who you are.

352

00:32:28.590 --> 00:32:39.480

Participant: Like if you want something or like you asked like a favor of someone or like you need information it doesn't matter who you talk to like you're always going to get a yes, and there are there's always gonna be someone to help you out.

353

00:32:42.360 --> 00:32:42.660

yeah.

354

00:32:43.860 --> 00:32:44.370

Lily McKnight: Sarah.

355

00:32:46.500 --> 00:32:52.290

Participant: it's funny that that mark brought that up because literally you literally just messaged me on slack like. 
356

00:32:53.880 --> 00:33:00.660

Participant: This like for project can be really cool like to be a part of it, I was like yeah sure, just like somebody else.

357

00:33:05.460 --> 00:33:16.650

Participant: Right like ever since like my freshman year I always saw that like it's so hard not to have friends in the reed college and media like you have to either like really be an asshole.

358

00:33:17.370 --> 00:33:26.100

Participant: And nobody likes you or you just like have to be like so like set on like one thing that you'd like don't want to even like talk to other people.

359

00:33:28.050 --> 00:33:37.260

Participant: But I really like like family is like a like a huge important thing to me especially growing up so like being able to have that $w$ is so.

360

00:33:37.710 --> 00:33:49.740

Participant: Like heartwarming to me like someone show like I feel like they are my family instead of my actual family um because I can talk to them about things I can find my family about a.

361

00:33:50.340 --> 00:34:01.110

Participant: By it's just really cool to have like those people who are obviously very not related to you at all, but beyond like talk to them like they're your brother or your sister that kind of thing and then.

362

00:34:01.560 --> 00:34:09.330

Participant: To be able to like actually cyber bully them and then to like not care and then cyber bullying you back that's also really fun $I$.

363

00:34:09.540 --> 00:34:10.470

Lily McKnight: Everything right.

364

00:34:11.370 --> 00:34:23.670 
Participant: yeah that was like the biggest thing, like the small class aspects like you have to you have to like talk to other people like you can't go for years, like not meeting anyone or being friends with anybody so that's really cool.

365

00:34:28.290 --> 00:34:30.480

Lily McKnight: Adam you next on my Bible, if you want to go.

366

00:34:31.440 --> 00:34:36.000

Participant: All right, alright so i'm similar to like what everyone's been saying, I feel like.

367

00:34:36.810 --> 00:34:49.350

Participant: i'm before I came to $w$ view like when I was in high school, I was like i'm not going to w like I I need to get out of this stay like I can't do this, but then I toward and like literally touring Martin and touring.

368

00:34:50.130 --> 00:35:04.950

Participant: The media innovation Center I was like oh wait yeah I want to come here, I don't know it felt like Google like it felt like such a modern that collaborative space, and I feel like this space is only representational of the people like.

369

00:35:06.720 --> 00:35:12.030

Participant: everyone's minds like just work a million miles a minute and I feel like a lot of like the best connections i've made have been.

370

00:35:12.420 --> 00:35:30.990

Participant: Like my student orgs like mirage and film club it's just like anytime we're working on something it's like 100 people are like adding on to the idea and it's like bouncing off of each other and like just feels very professional and like excited to like get shit done love and.

371

00:35:32.640 --> 00:35:40.290

Participant: yeah I think everyone is just very creative and driven and I remember also like being a freshman I was like I don't know if this is like.

372

00:35:40.680 --> 00:35:45.240

Participant: Obviously i'm doing the two majors I was like I think i'm like more of the actor like i'm not really liking this. 
373

00:35:45.690 --> 00:35:50.970

Participant: Because i'm this i'm like learning how to do like newspaper writing like this is not what I want to do, but then like.

374

00:35:51.120 --> 00:36:03.210

Participant: getting into the upper level classes and like joining the org and meeting new people I was like oh like this, like journalism can be so many different things like this is like this, so creative and so flexible and stuff like that.

\section{5}

00:36:03.570 --> 00:36:06.930

Lily McKnight: $\mathrm{mm}$ hmm absolutely I think he said that really well and I think.

376

00:36:07.770 --> 00:36:08.910

Lily McKnight: something about.

377

00:36:09.330 --> 00:36:23.310

Lily McKnight: This project and photo voice, you know um what you've all said to me right now, you know if this or something a little more, you know intimate a little more vulnerable something that you can take a picture of.

\section{8}

00:36:23.730 --> 00:36:36.360

Lily McKnight: To show instead of like having to you know put your heart out there and think of all these things that like we've said today, like we're all saying kind of like the exact same things and it's really cool.

379

00:36:36.960 --> 00:36:43.500

Lily McKnight: To see you all take these thoughts and then like how you kind of are relating those to these pictures.

380

00:36:44.700 --> 00:36:52.500

Lily McKnight: And I think that's something that's going to be really helpful, you know all the things that you said today and what makes you feel like you're a part of a family when you're here.

381

00:36:52.980 --> 00:36:58.590

Lily McKnight: is something that you know definitely Whitney could use for other kids that want to come here like you said, Adam. 
382

00:36:58.890 --> 00:37:11.460

Lily McKnight: You know, you were in high school and you're like oh I don't want to go to wvu that's where everyone goes, you know, like, I want to get out there and meet new people, but you can totally do that, while also coming here, so I think that was a really interesting.

383

00:37:12.480 -->00:37:24.690

Lily McKnight: point that you brought up so Thank you everyone for sharing that, so now we will go ahead and go back into our jam board, and I want you all to think.

384

00:37:25.470 --> 00:37:34.830

Lily McKnight: You know all the things that you said already, and we've gone around and shared I want you to go in and I want you to pick you can pick two.

385

00:37:35.640 --> 00:37:47.970

Lily McKnight: gems so in human Center design a gem, is something that stands out to you or connects with you on it can be in any way, so I want you to go, and I want you to pick two pictures.

386

00:37:48.690 --> 00:37:54.450

Lily McKnight: You can kind of move them around into like a little corner let's your say something i'm a little hectic sorry.

387

00:37:55.230 --> 00:38:05.340

Lily McKnight: But what's really important here is they don't have to be your own photos so you still get credit for the photo but for the purpose of this exercise in this workshop.

388

00:38:05.940 --> 00:38:17.670

Lily McKnight: If you want to pick your own that's perfect if another person's photo really speaks to you, like you can pick that one too so i'll give you guys a couple minutes, and you can go through and pick two pictures each.

389

00:38:21.600 --> 00:38:24.450

Participant: Can we just like put a post it note on the pictures that we.

390

00:38:24.540 --> 00:38:26.430 
Lily McKnight: Oh yeah that's perfect cool.

391

00:38:27.240 --> 00:38:29.730

Lily McKnight: That might be easier than like moving them around sorry.

392

00:38:31.380 --> 00:38:42.990

Lily McKnight: I have this super cool thing it was called mural and it's really huge and it makes everything really small so is actually good board and I sign up for it, and then they charge my credit card like $\$ 24$ and I was like.

393

00:38:44.190 --> 00:38:45.480

Lily McKnight: All or.

394

00:38:45.690 --> 00:38:47.730

Participant: not sustainable, or maybe we're not.

395

00:38:47.730 --> 00:38:48.270

Participant: gonna do.

396

00:38:49.590 --> 00:38:52.350

Lily McKnight: I was like Dr P, should you pay for it, I don't know.

397

00:38:56.580 --> 00:38:59.310

Participant: We see each other sticky notes are now can we just hear it.

398

00:38:59.340 --> 00:39:01.500

Participant: yeah you should be able to.

399

00:39:24.450 --> 00:39:29.370

Participant: I was just going to put my initials but then I remembered that my initials $R$ SS.

400

00:39:30.240 --> 00:39:31.410

Participant: it's probably not a good idea. 
00:39:48.450 --> 00:39:49.530

Participant: The photos are gone.

402

00:39:51.960 --> 00:39:53.040

Participant: Inside is just an am.

403

00:39:54.960 --> 00:39:57.480

Participant: Happy what is happening.

404

00:39:58.020 --> 00:40:00.420

Participant: I was just like trying to receive okay.

405

00:40:01.260 --> 00:40:05.010

Lily McKnight: $\mathrm{Oh}$, my gosh like a brief second and I was like what the heck was that.

406

00:40:20.850 --> 00:40:21.360

Jimmy.

407

00:40:23.310 --> 00:40:23.760

Lily McKnight: Jimmy.

408

00:40:26.940 --> 00:40:29.190

Participant: I know I spelled my name wrong That was the point.

409

00:40:39.150 --> 00:40:41.040

Participant: We, we can only pick two.

410

00:40:43.200 --> 00:40:44.760

Lily McKnight: More you totally can.

411

00:40:45.870 --> 00:40:46.800

Participant: i'm picking three.

412

00:40:54.480 --> 00:41:00.270 
Lily McKnight: See you guys are so like fun and like eager I was like I feel like people are gonna be like oh my God like we have to pick to.

413

00:41:20.430 --> 00:41:22.530

Lily McKnight: Can you guys hear my dryer going off right now.

414

00:41:24.090 --> 00:41:27.660

Lily McKnight: No, I got a release things a little song.

415

00:41:28.740 --> 00:41:30.060

Participant: I love whenever they do.

416

00:41:30.450 --> 00:41:32.790

Lily McKnight: A really sounds like a little like bell set.

417

00:42:02.070 --> 00:42:05.250

Lily McKnight: And then, when you guys are done just let me know.

418

00:42:18.150 --> 00:42:25.740

Lily McKnight: Alright cool i'm kind of loving that some of you like pick the same ones, because, like they're really good pictures um.

419

00:42:26.490 --> 00:42:34.950

Lily McKnight: OK, so now we'll take some time we'll all go through will look at the jam board and see what pictures we took or we picked.

420

00:42:35.940 --> 00:42:44.100

Lily McKnight: and any similarities in the pictures and then like Sarah you brought this up earlier we'll go through and we'll try to put them.

421

00:42:44.820 --> 00:42:53.550

Lily McKnight: into themes so for this i'm going to flash you guys this worksheet for a second and we don't have to do it like this, just some questions.

422

00:42:54.150 --> 00:43:08.220 
Lily McKnight: That, I think, helped to like organize our thoughts for this part so i'm in human Center design will call these like themes or clusters well, if I can figure out how to share screen one second.

423

00:43:13.380 --> 00:43:14.220

Lily McKnight: Can you see that.

424

00:43:15.390 --> 00:43:22.620

Lily McKnight: cool cool so this first part you'll see like you know, we have our question what makes you proud to be in the college family.

425

00:43:23.130 --> 00:43:29.520

Lily McKnight: We can go through and pick a theme, and then you know what are some photos from that session.

426

00:43:30.030 --> 00:43:41.520

Lily McKnight: That would go ahead and support this theme so there's no set number of themes, there could be one theme, there could be like three so kind of whatever you guys think i'm.

427

00:43:42.210 --> 00:44:01.980

Lily McKnight: We can go into the jam board and then I don't know if it would be easiest i'm like I can move the pictures around you guys can move the pictures around whatever kind of works for you all, but as anyone seen any sort of theme, with the pictures that you guys chose.

428

00:44:02.610 --> 00:44:04.680

Participant: They want nature based.

429

00:44:05.100 --> 00:44:06.030

Lily McKnight: Nature based.

430

00:44:06.090 --> 00:44:08.040

Participant: Okay, so I nature and people.

431

00:44:08.670 --> 00:44:13.170

Lily McKnight: need people to do you want them or keep them together. 
432

00:44:13.800 --> 00:44:14.520

Participant: Separate him.

433

00:44:14.850 --> 00:44:15.210

yeah.

434

00:44:16.440 --> 00:44:22.830

Participant: At least I say you separate them into nature photos which can have people in and then like people specific photos.

435

00:44:23.340 --> 00:44:24.930

Participant: Okay ah.

436

00:44:32.010 --> 00:44:34.200

Lily McKnight: Did you say something sorry I froze for a second.

437

00:44:37.620 --> 00:44:48.030

Lily McKnight: Okay, so nature and people I like it so let's go I made another one so let's do will do page.

438

00:44:49.230 --> 00:44:51.300

Lily McKnight: Three will be people.

439

00:44:52.470 --> 00:45:02.910

Lily McKnight: And then for can be nature and whoever has their sticky note can go move those pictures on to these slides.

440

00:45:06.090 --> 00:45:09.660

Lily McKnight: And although I might have said this backwards, but i'll go add.

441

00:45:11.460 --> 00:45:12.690

Participant: Moving the gems.

442

00:45:12.960 --> 00:45:15.510 
Lily McKnight: Yes, yes, your gems.

443

00:45:18.990 --> 00:45:19.740

Lily McKnight: gems.

444

00:45:29.100 --> 00:45:35.400

Participant: What would we classify this one of Martin Hall, that is not really major or people.

445

00:45:36.690 --> 00:45:41.130

Lily McKnight: We can make another theme, or we can get real abstracts.

446

00:45:42.030 --> 00:45:44.520

Lily McKnight: Environment environment.

447

00:45:44.640 --> 00:45:45.540

environments.

448

00:45:48.570 --> 00:45:51.990

Participant: Like unless I can like move it was like.

449

00:45:55.410 --> 00:45:58.230

Lily McKnight: Okay, so we want to make another one that says environment.

450

00:45:59.430 --> 00:46:01.170

Participant: I think we could change nature to environment.

451

00:46:01.200 --> 00:46:01.860

Participant: yeah we could just.

452

00:46:01.890 --> 00:46:02.430

yeah.

453

00:46:03.900 --> 00:46:04.590

Lily McKnight: I like that. 
00:46:21.450 --> 00:46:23.460

Participant: me in the corner that one picture.

455

00:46:28.380 --> 00:46:31.650

Participant: That picture you like you friggin ruin that shot i'm sorry.

456

00:46:32.610 -->00:46:34.110

Participant: yeah I don't have the.

457

00:46:35.400 --> 00:46:38.040

Participant: cover for like photoshopping.

458

00:46:42.360 --> 00:46:43.590

Participant: motivation to do.

459

00:46:45.600 --> 00:46:46.290

Lily McKnight: That picture.

460

00:46:49.980 --> 00:46:50.880

Lily McKnight: I love that.

461

00:46:52.020 --> 00:46:57.210

Participant: Like like an Alter Ego like whenever I don't give a shit about my appearance that.

462

00:47:00.810 --> 00:47:01.650

Participant: We all have it.

463

00:47:02.280 --> 00:47:02.820

yeah.

464

00:47:05.610 --> 00:47:08.520

Lily McKnight: Okay, are there any other ones that need moved over. 
465

00:47:13.800 --> 00:47:14.700

looks like.

466

00:47:16.590 --> 00:47:17.190

me today.

467

00:47:19.290 --> 00:47:24.030

Lily McKnight: cool we got this one with the okay cool I was looking for the one with the hat because I like that one.

468

00:47:28.770 --> 00:47:42.210

Lily McKnight: Alright cool so next in human centered design once people would go through and pick there are gems i'm now go through, and we can all work together on this.

469

00:47:43.650 --> 00:47:49.500

Lily McKnight: And we're gonna kind of make captions for these pictures on, and these will kind of act as little like.

470

00:47:50.010 --> 00:47:58.620

Lily McKnight: Labels almost like kind of like a caption like if you were going to post on instagram or in our case, like they're going to be an exhibit.

471

00:47:59.430 --> 00:48:04.230

Lily McKnight: Which we'll talk about in a little bit um so kind of just like a little creative statement.

472

00:48:04.830 --> 00:48:13.260

Lily McKnight: For each of the pictures that you know, this can relate to the theme, it cannot relate to being like it's totally whatever you guys want um.

473

00:48:13.920 --> 00:48:28.770

Lily McKnight: If it's easier, we can go one by one picture and someone can brainstorm or, if you want, we could all pick a picture and whatever you guys think will be easiest and most creative for you all.

474

00:48:35.010 --> 00:48:40.050 
Participant: Individual picture I don't want the responsibility of caption photo without other people.

475

00:48:40.290 --> 00:48:44.160

Lily McKnight: Okay cool so let's go over here to environment.

476

00:48:45.450 --> 00:48:50.220

Lily McKnight: We have this beautiful picture of our lovely Sarah i'm.

477

00:48:51.630 --> 00:48:54.120

Lily McKnight: over here and there was this shot by seth.

478

00:48:57.390 --> 00:48:57.930

Participant: Which one.

479

00:48:58.680 --> 00:48:59.160

Lily McKnight: This one.

480

00:48:59.760 --> 00:49:00.330

me.

481

00:49:05.250 --> 00:49:06.900

Participant: Like sarah's hiding Oh, my goodness.

482

00:49:14.340 -->00:49:17.700

Participant: know, I was talking about the one in the people where i'm, just like in the corner.

483

00:49:19.140 --> 00:49:20.910

Participant: With David David Smith encounter.

484

00:49:21.600 --> 00:49:23.790

Lily McKnight: You little head right there it's great.

485

00:49:24.810 --> 00:49:25.560 
Lily McKnight: Okay cool.

486

00:49:30.000 --> 00:49:30.840

Lily McKnight: Not Sarah.

487

00:49:32.280 --> 00:49:34.950

Lily McKnight: And who did I just make them bigger with us somebody else sorry.

488

00:49:35.190 --> 00:49:38.040

Participant: No i'm bigger because my laptop is so small.

489

00:49:39.720 --> 00:49:45.390

Lily McKnight: So you can go through does anyone have any kind of idea caption for this.

490

00:49:48.030 --> 00:49:48.690

huh.

491

00:49:52.080 --> 00:49:55.050

Participant: The mountains are calling, and I must answer.

492

00:49:59.310 --> 00:50:08.640

Participant: I love, I was gonna take all of us one singular brain cell to come up with it usually takes me an hour to find a caption that I will post with my patients.

493

00:50:08.820 --> 00:50:10.500

Lily McKnight: Literally same, though.

494

00:50:10.740 --> 00:50:19.410

Participant: You know I that's why I work, mainly on on Twitter and not on like the main instagram for $\mathbf{w}$ because $I$ can $T$ shirt with captions.

495

00:50:22.140 --> 00:50:28.710

Participant: or when we say caption with this to like the caption to an instagram post or is this like a descriptive captain. 
00:50:29.310 --> 00:50:30.480

So.

497

00:50:31.830 --> 00:50:41.610

Lily McKnight: um I don't know when the media creation Center it's gonna be like up and rolling again I don't know if anyone in here has any knowledge on that.

498

00:50:42.090 --> 00:50:55.860

Lily McKnight: um, but if you want to, we can make, I think, for now it's going to go on instagram and then whenever it opens up, we can go hang them up in the media innovation Center so these can be the same.

499

00:50:56.430 --> 00:51:04.050

Lily McKnight: caption and descriptor we can do different whatever you guys are feeling if you feel like they should be different.

500

00:51:05.250 --> 00:51:06.630

Lily McKnight: Totally up to you all.

501

00:51:11.370 --> 00:51:13.710

Participant: Are we hanging up like all of our pictures.

502

00:51:14.340 --> 00:51:16.860

Lily McKnight: I just I little gems okay.

503

00:51:17.190 --> 00:51:20.220

Participant: Out of the one is good there the country roads lyric I like that.

504

00:51:20.400 --> 00:51:22.140

Lily McKnight: Oh, I do like that Adam.

505

00:51:24.000 --> 00:51:25.890

Lily McKnight: So is that is that our winner.

506

00:51:26.280 --> 00:51:29.250

Participant: yeah we're going for like the short and sweet ones yeah I think that's. 
00:51:30.450 --> 00:51:30.750

Lily McKnight: Great.

508

00:51:31.740 --> 00:51:33.270

Lily McKnight: Added in you get.

509

00:51:42.450 --> 00:51:43.560

okey dokey.

510

00:51:46.260 --> 00:51:46.650

whoa.

511

00:51:48.390 --> 00:51:50.610

Participant: whoa alright cool.

512

00:51:50.940 --> 00:51:51.630

love that.

513

00:51:52.830 --> 00:51:58.410

Lily McKnight: Alright, so next time we have a little hat picture here with a little mountain near on it, I like that one.

\section{4}

00:51:59.640 --> 00:52:00.120

Lily McKnight: um.

515

00:52:01.530 --> 00:52:13.410

Lily McKnight: So it's under our environment theme and then i'll show you guys this too, I had this but I didn't really know that actually was that helpful ball show it to you for a second just to say I did it i'm.

516

00:52:14.820 --> 00:52:15.090

Participant: Okay.

517

00:52:15.120 --> 00:52:16.500 
Lily McKnight: i'm horrible sorry.

518

00:52:17.610 --> 00:52:19.500

Lily McKnight: But here's the little um.

519

00:52:20.850 --> 00:52:39.120

Lily McKnight: here's like a little this is how someone would do like if you're doing it to work sheets, you know have your theme, and then you could pick three insights and use that to form a caption if you want I think that's a lot, but what if that helps you guys organize it in your brain.

520

00:52:40.770 --> 00:52:43.680

Participant: that's what I was thinking more.

521

00:52:43.920 --> 00:52:45.000

Participant: Exact one.

522

00:52:47.070 --> 00:52:48.060

Participant: surgeon.

523

00:52:51.660 --> 00:52:52.560

Participant: Good one.

524

00:52:53.520 --> 00:52:54.690

Lily McKnight: You guys like that one.

525

00:52:57.450 --> 00:52:59.340

Participant: It makes my blood boil.

526

00:53:04.680 --> 00:53:09.960

Participant: um Hats off to maybe something else Hats off to.

527

00:53:10.740 --> 00:53:11.550

Participant: One wonderful. 
00:53:14.850 --> 00:53:15.420

Participant: that's not bad.

529

00:53:17.160 --> 00:53:20.610

Participant: it's usually like Hats off for like capping off.

530

00:53:22.200 --> 00:53:22.530

Participant: No.

531

00:53:22.860 --> 00:53:23.490

Participant: just put it.

532

00:53:26.340 --> 00:53:27.180

just put a cap on.

533

00:53:28.680 --> 00:53:30.450

Participant: One singular hat emoji.

534

00:53:30.870 --> 00:53:31.440

Lily McKnight: One day.

535

00:53:32.700 --> 00:53:33.210

Participant: Yes.

536

00:53:33.540 --> 00:53:33.870

Participant: And then.

537

00:53:35.250 --> 00:53:35.610

Participant: that's it.

538

00:53:35.640 --> 00:53:38.490

Participant: that's all yes leaves it open to interpretation.

539

00:53:41.250 --> 00:53:42.510

Participant: we're officially fine art. 
00:53:46.800 --> 00:53:49.500

Lily McKnight: Okay, so I can put that in if I suddenly like.

541

00:53:50.490 --> 00:53:51.570

i'm not gonna lie.

542

00:53:53.610 --> 00:53:54.510

Participant: To you put emoji.

543

00:53:54.540 --> 00:53:58.620

Participant: like it, but like not not the emoji we're just gonna say hat emoji.

544

00:53:59.430 --> 00:54:00.360

Participant: Oh, my God yes.

545

00:54:01.080 --> 00:54:02.220

Participant: Mountain emerging.

546

00:54:02.460 --> 00:54:04.500

Participant: that's the captures yes.

547

00:54:06.210 --> 00:54:06.510

Okay.

548

00:54:07.950 --> 00:54:08.280

Yes.

549

00:54:14.310 --> 00:54:19.320

Lily McKnight: All right now we have our key little i'm Martin hall doors pick.

550

00:54:21.630 --> 00:54:23.220

Participant: I feel like this one should be like. 
00:54:24.600 --> 00:54:30.690

Participant: The doors are open for you the doors are open for creativity, or something.

552

00:54:32.820 --> 00:54:33.360

Participant: doors are.

553

00:54:33.390 --> 00:54:33.840

Participant: open.

\section{4}

00:54:33.930 --> 00:54:37.950

Participant: Your create with every read college of media.

\section{5}

00:54:38.490 --> 00:54:41.640

Participant: What about like a like start here go anywhere.

556

00:54:42.480 --> 00:54:43.920

wow.

557

00:54:48.990 - > 00:54:49.800

Lily McKnight: That was deep.

558

00:54:50.370 --> 00:54:50.550

Participant: So.

559

00:54:50.880 --> 00:54:52.140

it's kind of confusing.

560

00:54:53.190 --> 00:54:54.030

Participant: Not gonna lie.

561

00:54:56.820 --> 00:54:57.150

Participant: A door.

562

00:54:57.810 --> 00:54:58.290

Lily McKnight: open and. 
563

00:54:59.730 --> 00:55:00.300

Participant: unlocked.

564

00:55:00.720 --> 00:55:01.950

Participant: All of them just be.

565

00:55:02.100 --> 00:55:02.730

emoji.

566

00:55:06.060 --> 00:55:08.820

Participant: doctrine fresco was like now what the hell is this come on.

567

00:55:10.410 --> 00:55:10.650

Lily McKnight: Like.

568

00:55:10.710 --> 00:55:12.210

Lily McKnight: let's know kept me.

569

00:55:17.160 --> 00:55:17.670

Okay.

570

00:55:19.650 --> 00:55:24.960

Participant: What about like through these doors have walked like the best of friends or something like that.

571

00:55:26.520 --> 00:55:30.600

Participant: it's not about the pictures we've taken it's about the friends, we made along the way.

572

00:55:36.810 --> 00:55:46.620

Participant: Of like instagram and my posting this out a certain time is that wrong like i'm like the doors closing on another school year like.

573

00:55:48.180 --> 00:55:48.330 
Participant: Have a.

574

00:55:48.360 --> 00:55:49.860

Participant: Great summer amount hands.

575

00:55:50.430 --> 00:55:51.750

Lily McKnight: Have a great sorry guys.

576

00:55:53.310 --> 00:55:57.450

Participant: I love, all of us like thinking of it in like a marketing standpoint.

577

00:55:57.930 --> 00:55:59.610

Participant: Not in an artist example it.

578

00:55:59.880 --> 00:56:00.780

Participant: Were brainwashed.

579

00:56:01.470 --> 00:56:03.750

Lily McKnight: I don't think it's gonna reach enough I don't know.

580

00:56:05.310 --> 00:56:06.720

Participant: what's our target audience.

581

00:56:08.070 --> 00:56:10.260

Participant: People who enjoy doors specifically.

582

00:56:12.510 --> 00:56:15.600

Participant: Extended door have been photographing.

583

00:56:17.700 --> 00:56:19.920

Lily McKnight: Okay, that is why i'm take.

584

00:56:19.980 --> 00:56:28.440

Lily McKnight: Talk is i'm like I act like the hashtag I pick on tech talk is like making or breaking me because i'm like we had no likes on. 
585

00:56:31.200 --> 00:56:31.650

Lily McKnight: Bad.

586

00:56:33.360 --> 00:56:33.540

Lily McKnight: Oh.

587

00:56:35.760 -->00:56:36.060

Participant: Oh, what.

588

00:56:37.830 --> 00:56:39.150

Participant: We adore it why.

589

00:56:40.380 --> 00:56:40.950

Participant: grid.

590

00:56:44.490 --> 00:56:50.010

Participant: I was thinking like there's like hand sanitizer in the picture we should also incorporate the hand sanitizer anything.

591

00:56:51.720 --> 00:56:52.800

Participant: i'll shoot day my hands.

592

00:56:56.520 --> 00:57:00.600

Lily McKnight: Your read college family wants you to wash your friggin hands yeah.

593

00:57:01.050 --> 00:57:02.520

Participant: You dirty bastard.

594

00:57:03.960 --> 00:57:07.110

Participant: wash your hands before you touch the door there that's it.

595

00:57:07.350 --> 00:57:09.180

Lily McKnight: that's it all we need to share. 
596

00:57:14.880 --> 00:57:17.940

Lily McKnight: We can come back to this one, we can go to a different way and we'll come back.

597

00:57:20.790 --> 00:57:22.290

Participant: let's stick a pin on and circle back around.

598

00:57:25.530 --> 00:57:28.140

Lily McKnight: hey Thank you sounds from now on, we can only use.

599

00:57:28.140 --> 00:57:30.240

Participant: Terrible like business corporate.

600

00:57:31.290 --> 00:57:31.860

Participant: sayings.

601

00:57:33.240 --> 00:57:36.990

Participant: So it's a circle back around to this, I don't know if I have the bandwidth to really.

602

00:57:38.190 --> 00:57:39.960

Participant: finish this project, and he is sort of.

603

00:57:43.320 --> 00:57:44.190

Lily McKnight: My hammock.

604

00:57:44.550 --> 00:57:45.240

Participant: that's corbin.

605

00:57:46.830 --> 00:57:47.490

Lily McKnight: Is it really.

606

00:57:48.210 --> 00:57:49.110

Participant: yeah yeah. 
607

00:57:49.500 --> 00:57:50.370

Participant: That was taken.

608

00:57:51.630 --> 00:57:58.200

Participant: On one of my film cameras, when we were camping and he's terribly out of focus, but I think that just adds to it, you know.

609

00:57:58.740 --> 00:57:59.250

Lily McKnight: It only.

610

00:58:00.420 --> 00:58:00.780

Participant: yeah.

611

00:58:01.950 --> 00:58:07.020

Participant: And I love that the light League is like right down the middle I I really enjoyed the.

612

00:58:07.890 --> 00:58:09.330

Participant: spooky these kind of.

613

00:58:14.040 --> 00:58:18.330

Participant: This was taken like 9am in the freezing cold mountain.

614

00:58:20.730 --> 00:58:21.630

Participant: phenomenal time.

615

00:58:22.950 --> 00:58:26.580

Lily McKnight: corbin I feel like if it's you you, you have to caption it I don't know.

616

00:58:29.130 --> 00:58:30.060

Participant: A.

617

00:58:38.010 --> 00:58:40.500

Participant: wait to be everyone for the door, or we. 
618

00:58:41.130 --> 00:58:41.910

Participant: Come back around to.

619

00:58:42.090 --> 00:58:43.740

Participant: We put a pin in a corbin.

620

00:58:49.980 --> 00:58:53.130

Participant: need some help for this one nothing's really coming to mind right now.

621

00:58:54.240 --> 00:58:55.680

Participant: Go with Sam awesome.

622

00:58:55.980 --> 00:58:59.190

Participant: It looks like really, really, really vintage.

623

00:59:01.620 --> 00:59:04.590

Participant: Similar we act like it's really, really been did you and I was not.

624

00:59:05.850 --> 00:59:06.600

Participant: This is, this is actually.

625

00:59:06.810 --> 00:59:07.260

A picture.

626

00:59:08.820 --> 00:59:10.590

Participant: In the class of 1945.

627

00:59:11.970 --> 00:59:13.830

Lily McKnight: Our first reed college graduate.

628

00:59:14.310 --> 00:59:15.420

Participant: yeah exactly.

629

00:59:16.380 --> 00:59:17.340 
Participant: yeah the College.

630

00:59:17.400 --> 00:59:18.150

shimmery.

631

00:59:19.380 --> 00:59:21.960

Participant: No one would know how would they know.

632

00:59:22.560 --> 00:59:23.580

Lily McKnight: They want they know.

633

00:59:24.090 --> 00:59:24.210

How.

634

00:59:26.430 --> 00:59:33.480

Participant: that's a good idea for tick tock we could use this picture in like talking about your project lily and be like, how would they know.

635

00:59:35.490 --> 00:59:39.270

Participant: My Nike sneakers in front that's The one thing that the there's enough of it.

636

00:59:39.870 --> 00:59:40.500

Lily McKnight: I didn't even.

637

00:59:41.730 --> 00:59:42.240

Participant: I couldn't even.

638

00:59:42.420 --> 00:59:44.910

Participant: Really, you can't even really tell what they.

639

00:59:45.390 --> 00:59:45.660

look like.

640

00:59:46.950 --> 00:59:49.530

Participant: look like it's like you're like a military dude. 
641

00:59:49.770 --> 00:59:51.240

Lily McKnight: I gotta say the same thing.

642

00:59:55.110 --> 00:59:55.440

Lily McKnight: How.

643

00:59:58.020 --> 00:59:58.620

Lily McKnight: We need to.

644

01:00:00.750 --> 01:00:03.030

Participant: have one singular emoji and.

645

01:00:05.970 --> 01:00:07.920

Participant: There was two mo geez there's a mountain in a CAP.

646

01:00:10.110 --> 01:00:10.440

Participant: True.

647

01:00:11.250 --> 01:00:11.580

Participant: it's true.

648

01:00:16.830 --> 01:00:23.370

Lily McKnight: We can move on to this on the model, one we can give that long ago it's definitely hard to like come up with like.

649

01:00:24.900 --> 01:00:37.710

Lily McKnight: Creative statements, I think, because it almost is like a caption you know it's like what when someone would be coming in looking at these pictures like what the little being like underneath is going to say you know.

650

01:00:39.060 --> 01:00:39.660

Lily McKnight: um.

651

01:00:40.860 --> 01:00:45.240 
Lily McKnight: it's definitely hard I literally struggle with the caption for like an entire day.

652

01:00:46.830 --> 01:00:48.180

Participant: yeah same honestly.

653

01:00:53.700 --> 01:00:57.450

Participant: Creating photos creating memory.

654

01:01:01.410 --> 01:01:02.250

Participant: Something.

655

01:01:02.430 --> 01:01:04.260

Participant: About like all smiles or something like.

656

01:01:04.260 --> 01:01:06.060

Participant: that yes, yes, yes, yes.

657

01:01:06.180 --> 01:01:08.280

Participant: yeah always a good time sort of thing.

658

01:01:09.150 --> 01:01:09.540

yeah.

659

01:01:13.200 --> 01:01:13.950

Participant: mile.

660

01:01:14.640 --> 01:01:16.200

Participant: smiles only club.

661

01:01:24.120 --> 01:01:33.990

Lily McKnight: And if some of them like if we went to say like you know less captioning like we could go more the route like a like a true like creative statement you know, like.

662

01:01:35.430 --> 01:01:37.140 
Lily McKnight: These pictures are taken.

663

01:01:39.270 --> 01:01:46.590

Lily McKnight: During a mirage photo shoot for $X \mathrm{y} \& z$ like if we wanted to go there, we absolutely can like totally no rules on this.

664

01:01:48.750 --> 01:01:49.890

Lily McKnight: For funds, you know.

665

01:02:02.040 --> 01:02:02.700

Participant: This is hard.

666

01:02:04.020 --> 01:02:04.890

Lily McKnight: It definitely is $I$.

667

01:02:07.800 --> 01:02:09.540

Participant: want mile movie camera motor.

668

01:02:11.640 --> 01:02:13.650

Participant: I say we just do everything in emojis.

669

01:02:14.880 --> 01:02:16.710

Lily McKnight: You want to tell me can.

670

01:02:17.790 --> 01:02:19.260

Participant: I say this, I think it'd be funny.

671

01:02:19.950 --> 01:02:21.480

Participant: yeah be cool.

672

01:02:21.840 --> 01:02:23.160

Participant: It will be, it will be pretty funny.

673

01:02:23.220 --> 01:02:24.240

Participant: it'd be very hip. 
674

01:02:24.900 --> 01:02:25.650

As the kids.

675

01:02:27.210 --> 01:02:27.600

Participant: it'd be.

676

01:02:28.830 --> 01:02:30.360

Participant: it'd be busting us to can say.

677

01:02:32.760 --> 01:02:34.050

Is that Boston I know.

678

01:02:35.130 --> 01:02:36.630

Lily McKnight: He saw that today out.

679

01:02:38.520 --> 01:02:38.850

Participant: there.

680

01:02:39.300 --> 01:02:40.680

Participant: busting genome.

681

01:02:42.210 --> 01:02:45.330

Participant: dive woman pisses me off on tech talk so much the key.

682

01:02:46.260 --> 01:02:47.190

Lily McKnight: aikido girl.

683

01:02:48.150 --> 01:02:49.230

Lily McKnight: bell pepper like it's an.

684

01:02:49.650 --> 01:02:55.530

Participant: apple and then a block of cream cheese in and everything but the bagels evening and she's like this is how. 
685

01:02:56.700 --> 01:03:02.160

Participant: That is no, I am not a nutritionist by any means, but like you can eat bread.

686

01:03:06.480 --> 01:03:07.740

Participant: For thousands of years.

687

01:03:10.110 --> 01:03:13.200

Participant: she's gonna die if you eat one chroma bread.

688

01:03:14.340 --> 01:03:17.310

Participant: $\mathrm{Oh}$, you got some pasta there it is $\mathbf{5 0}$ pounds.

689

01:03:21.480 --> 01:03:21.870

Participant: dead.

690

01:03:23.430 --> 01:03:29.460

Lily McKnight: And she literally puts like a whole thing like salami on there and i'm like how are we justify like.

691

01:03:29.550 --> 01:03:29.970

Participant: I know.

692

01:03:30.240 --> 01:03:35.190

Lily McKnight: Eight slices of salami and a block of cream cheese, but you can't have a piece of bread.

693

01:03:35.850 --> 01:03:36.900

Participant: The waffles.

694

01:03:36.960 --> 01:03:41.970

Participant: walking you cannot have one slice of bread, you can have an entire stick of salami.

695

01:03:42.210 --> 01:03:42.480

Lily McKnight: she's. 
696

01:03:42.660 --> 01:03:50.130

Participant: Like a block of cheese in a waffle maker and she's like my Quito waffles they're done inside girl you just you just remove the block of American cheese.

697

01:03:50.220 --> 01:03:50.820

Lily McKnight: yeah.

698

01:03:51.000 --> 01:03:52.410

Participant: You know pizza and then she.

699

01:03:52.410 --> 01:03:59.040

Participant: puts cheese in that thing until it becomes so gross and hard then adds more cheese and she's like that's pizza.

700

01:03:59.910 --> 01:04:01.140

Participant: it's late you read the green.

701

01:04:02.340 --> 01:04:03.120

Lily McKnight: side.

702

01:04:03.360 --> 01:04:04.140

Participant: I know.

703

01:04:04.500 --> 01:04:06.030

Participant: it's like three foods.

704

01:04:06.180 --> 01:04:08.400

Participant: And just in different like way.

705

01:04:08.700 --> 01:04:10.410

Participant: Like dried meat.

706

01:04:11.190 --> 01:04:12.540

Participant: Cheese block. 
01:04:14.490 --> 01:04:16.530

Participant: Vegetable that's it it's three foods.

708

01:04:19.620 --> 01:04:27.180

Lily McKnight: Also, if you eat too much I didn't know this, if you eat too much of everything but the bagel seasoning like you would test positive for.

709

01:04:29.550 --> 01:04:31.050

Participant: yeah cuz of the poppy seeds in.

710

01:04:31.710 --> 01:04:33.270

Lily McKnight: The poppy seeds or whatever.

711

01:04:33.840 --> 01:04:34.260

Participant: yeah.

712

01:04:34.290 --> 01:04:39.090

Lily McKnight: she's like a nurse or so so like, how can you eat that much.

713

01:04:39.420 --> 01:04:41.160

Participant: He might be on heroin, though, if you like.

714

01:04:41.160 --> 01:04:41.400

Look.

715

01:04:44.220 --> 01:04:44.730

Participant: I see my.

716

01:04:46.260 --> 01:04:46.920

Participant: cover.

717

01:04:47.100 --> 01:04:47.760

Participant: My you. 
718

01:04:48.810 --> 01:04:50.460

Participant: Know it's the seasoning guys don't.

719

01:04:51.330 --> 01:04:52.080

Participant: worry about it.

720

01:04:52.200 --> 01:04:54.150

Participant: don't mind the bruises on my arms.

721

01:04:57.930 --> 01:05:03.780

Lily McKnight: Okay, so do we want to do all emojis or do we want to keep thinking on words.

722

01:05:08.100 --> 01:05:09.210

Participant: Making mags.

723

01:05:10.620 --> 01:05:12.840

Participant: and shaping smiles.

724

01:05:14.580 --> 01:05:17.820

Participant: Word happens, we have a mo geez as a backup.

725

01:05:18.720 --> 01:05:19.770

Lily McKnight: I like that I like.

726

01:05:22.170 --> 01:05:22.470

Lily McKnight: It.

727

01:05:22.560 --> 01:05:23.310

Participant: that's not the captain.

728

01:05:25.620 --> 01:05:26.040

Participant: Captain cabin. 
01:05:27.510 --> 01:05:29.910

Lily McKnight: Adam I like that I like that caption.

730

01:05:31.530 --> 01:05:31.980

Participant: To.

731

01:05:32.340 --> 01:05:32.490

I.

732

01:05:34.110 --> 01:05:36.810

Lily McKnight: mean it's up to you guys, but I do like it.

733

01:05:37.170 --> 01:05:40.500

Participant: To think smiles reminds me of like an orthodontist office.

734

01:05:40.950 --> 01:05:42.090

Participant: Oh, my God.

735

01:05:43.020 --> 01:05:45.540

Participant: i'm trying to be a little bit alliterative I can't think of another word.

736

01:05:47.550 --> 01:05:49.320

Participant: But I hit the source COM.

737

01:05:49.350 --> 01:05:51.540

Participant: I literally just did, and the other word is like.

738

01:05:51.540 --> 01:05:53.550

Participant: spawn which sounds gross.

739

01:05:53.760 --> 01:05:54.480

spawn.

740

01:05:56.490 --> 01:05:57.840

Participant: spawning smiles. 
741

01:05:59.670 --> 01:06:01.230

Participant: You can say sharing smiles.

742

01:06:01.530 --> 01:06:02.460

inspiring.

743

01:06:04.740 --> 01:06:05.550

Participant: inspiring.

744

01:06:09.120 --> 01:06:10.890

Lily McKnight: inspiring that's good.

745

01:06:13.530 --> 01:06:14.790

Participant: yeah looking fine.

746

01:06:15.540 --> 01:06:18.360

Lily McKnight: Making magazine and inspiring smiles.

747

01:06:19.980 --> 01:06:22.530

Lily McKnight: that's fun that's killer.

748

01:06:23.670 --> 01:06:24.330

Lily McKnight: I love it.

749

01:06:26.640 --> 01:06:28.650

Lily McKnight: throw it in Adam, you can have the honors.

750

01:06:29.100 --> 01:06:30.000

Sure thing.

751

01:06:31.200 --> 01:06:32.940

Participant: We say sharing or inspiring. 
01:06:36.030 --> 01:06:36.570

Lily McKnight: Whichever way.

753

01:06:41.250 --> 01:06:44.280

Lily McKnight: I kind of feel like it's like a little magazine ad or something like.

754

01:06:46.740 --> 01:06:48.000

Lily McKnight: Like a little tagline.

755

01:06:49.860 --> 01:06:54.990

Participant: And I feel like we're these are like the really cringe your book like sub headlines.

756

01:06:57.270 --> 01:06:57.750

are doing.

757

01:07:03.120 --> 01:07:07.200

Participant: Although we're like having a moral dilemma during that they just do that with never moore's.

758

01:07:11.010 --> 01:07:12.900

Lily McKnight: Okay, do we want to move to this drone one.

759

01:07:17.190 --> 01:07:18.210

Participant: recoups.

760

01:07:21.810 --> 01:07:26.190

Participant: should be like so like inspiring and then someone should just be like emojis and then.

761

01:07:26.520 --> 01:07:28.080

Participant: fly and with the ball is.

762

01:07:30.210 --> 01:07:34.560

Participant: This man Joe Kleiner Jones over Syria nothing bad will happen. 
763

01:07:37.530 --> 01:07:39.540

Participant: check out this sexy chicken, the left.

764

01:07:39.540 --> 01:07:40.140

corner.

765

01:07:44.760 --> 01:07:46.410

Participant: Can you do better shot me out of that.

766

01:07:46.980 --> 01:07:47.640

Participant: I will.

767

01:07:52.440 --> 01:07:55.980

Participant: No actually i'm gonna leave it like that we're gonna put that up like that.

768

01:08:00.480 --> 01:08:04.620

Participant: The caption like fly high because that's always been someone.

769

01:08:12.180 --> 01:08:13.980

Participant: Just like the school energy that's it.

770

01:08:15.300 --> 01:08:15.630

Lily McKnight: This.

771

01:08:19.170 --> 01:08:19.710

Participant: guy's been.

772

01:08:21.360 --> 01:08:23.370

Participant: driving the limit at the reed college.

773

01:08:29.610 --> 01:08:29.820

Lily McKnight: guys.

774

01:08:30.390 --> 01:08:30.930 
Participant: Although like.

775

01:08:32.520 --> 01:08:41.340

Participant: Like I feel like we all know that that's like a drone remote in connors hands, I feel like some people be like what's that you know.

776

01:08:41.430 --> 01:08:43.380

Lily McKnight: that's a good point that's a good point.

777

01:08:44.400 --> 01:08:55.800

Lily McKnight: So maybe this is one where we you know are maybe like describing more what's happening like maybe this one requires like a real sentence.

778

01:08:55.830 --> 01:09:07.410

Participant: could be like Professor David Smith and i'm not I don't know I got a Professor David Smith and like person like create visual storytelling journalism from both on the ground and in the air.

779

01:09:08.280 --> 01:09:12.960

Participant: that's good national professional we're newspaper company now.

780

01:09:14.310 --> 01:09:16.950

Lily McKnight: yeah you want to add that in you guys like that one.

781

01:09:18.330 --> 01:09:18.750

Participant: I like them.

782

01:09:19.290 --> 01:09:21.810

Lily McKnight: cool I think that'll be good to Sarah cuz.

783

01:09:23.280 --> 01:09:25.710

Participant: Like you said i'm gone or Taylor.

784

01:09:28.800 --> 01:09:30.120

Participant: Connor two o's. 
785

01:09:34.590 --> 01:09:36.150

Participant: lily are you ready, I can do it.

786

01:09:36.630 --> 01:09:38.070

Lily McKnight: Oh yeah you can do it, you got it.

787

01:09:43.080 --> 01:09:44.610

Participant: See carbons little bubbles.

788

01:09:48.570 --> 01:09:52.500

Participant: Oh, I just thought of a capture for the one of corporate in the hammock and can it be just hanging out.

789

01:09:54.690 --> 01:09:55.050

Participant: yeah.

790

01:09:55.500 --> 01:09:58.530

Participant: I love it live laugh love i'm a genius recognizer.

791

01:10:00.060 --> 01:10:01.290

Participant: alive uh huh.

792

01:10:06.450 --> 01:10:07.530

Participant: it's so good.

793

01:10:09.990 --> 01:10:10.200

Participant: But.

794

01:10:10.890 --> 01:10:12.570

Participant: I think that should be the one for the door.

795

01:10:13.920 --> 01:10:16.590

Participant: doesn't correlate at all live. 
01:10:18.630 --> 01:10:19.530

text smaller.

797

01:10:21.240 --> 01:10:22.110

Participant: Make it smaller.

798

01:10:23.460 --> 01:10:24.600

Lily McKnight: Thank you yeah.

799

01:10:26.130 --> 01:10:26.520

there.

800

01:10:34.170 --> 01:10:34.530

Participant: it's.

801

01:10:46.830 --> 01:10:50.070

Participant: I love the thing drawling them.

802

01:10:51.210 --> 01:10:53.460

Participant: We actually keep can we actually keep them.

803

01:10:54.330 --> 01:10:56.490

Participant: alive, I think it does do.

804

01:10:57.180 --> 01:10:57.900

Lily McKnight: A lot of.

805

01:10:58.920 --> 01:11:00.810

Lily McKnight: Maybe we could, without the.

806

01:11:00.870 --> 01:11:02.100

Double Horn.

807

01:11:05.460 --> 01:11:06.540

Lily McKnight: preska would be like. 
808

01:11:09.150 --> 01:11:10.590

Lily McKnight: i'm going to send them an email.

809

01:11:16.800 --> 01:11:17.400

Participant: To Adam.

810

01:11:18.300 --> 01:11:19.440

Lily McKnight: Adam Thank you.

811

01:11:20.220 --> 01:11:23.400

Participant: I feel like now caption makes the other ones.

812

01:11:25.980 --> 01:11:27.060

Participant: Fire fire.

813

01:11:28.050 --> 01:11:35.550

Participant: We got to meet her brother David Smith it's tuned Connor Taylor three visual storytelling journalism for go on the ground and in the air.

814

01:11:37.320 --> 01:11:43.260

Lily McKnight: yeah I mean we can't make them all, like that, or if you guys like the mixture I think it's fine I think it's, however.

815

01:11:44.190 --> 01:11:46.110

Participant: I think diversity.

816

01:11:46.260 --> 01:11:46.860

Participant: yeah.

817

01:11:47.490 --> 01:11:50.340

Participant: The diversity merging.

818

01:11:52.830 --> 01:11:58.560

Participant: corny corny to liners, and then like literal like captions. 
819

01:11:58.650 --> 01:12:01.410

Lily McKnight: And a nice mixture of agee's love it.

820

01:12:02.790 --> 01:12:05.550

Lily McKnight: Okay, now we have our lovely Sarah over here.

821

01:12:18.480 -->01:12:20.160

Participant: brand journey thanks.

822

01:12:23.370 --> 01:12:25.050

Participant: yeah rip brand journey.

823

01:12:44.220 --> 01:12:45.060

Lily McKnight: any others.

824

01:12:48.870 --> 01:12:52.020

Participant: um I I just googled type puns.

825

01:12:53.430 --> 01:13:00.390

Participant: I think the caption should be I just watched to silkworms have a race it ended in a tie.

826

01:13:03.810 --> 01:13:04.890

Lily McKnight: Oh, my gosh.

827

01:13:06.960 --> 01:13:08.130

Lily McKnight: I kind of love it.

828

01:13:08.610 --> 01:13:11.220

Participant: And they should also makes sarah's photo just.

829

01:13:11.310 --> 01:13:12.270

Participant: Just hanging out. 
830

01:13:15.780 --> 01:13:17.490

Participant: Just hanging out, part two, electric.

831

01:13:18.900 --> 01:13:21.150

Participant: To part 250 years later.

832

01:13:22.560 --> 01:13:26.250

Participant: All smiles here at the point pleasant brand launch.

833

01:13:27.210 --> 01:13:31.470

Participant: I sure hope but definitely virus doesn't come by and destroy the whole plan.

834

01:13:33.480 --> 01:13:34.680

Participant: that'd be terrible.

835

01:13:44.280 --> 01:13:50.130

Lily McKnight: Any winners on that one now you like Sarah I feel like your opinion matters, the most because you're.

836

01:13:53.670 --> 01:13:56.850

Participant: Just terrible captions I literally like you have to wait a day.

837

01:13:57.180 --> 01:13:58.410

Participant: Before picture.

838

01:14:00.390 --> 01:14:00.840

Participant: Like.

839

01:14:01.500 --> 01:14:04.140

Participant: Like outfit on point or something like that.

840

01:14:06.420 --> 01:14:08.130

Participant: Because of the point wasn't sure oh my. 
01:14:08.130 --> 01:14:09.300

Participant: God wow.

842

01:14:09.420 --> 01:14:10.680

Participant: that's God now that's good.

843

01:14:11.100 --> 01:14:13.110

Participant: yeah I like that I like that.

844

01:14:13.920 --> 01:14:15.300

Lily McKnight: yeah you want to add it in.

845

01:14:16.710 --> 01:14:17.070

Participant: sure.

846

01:14:19.020 --> 01:14:20.580

Participant: Yes, we're.

847

01:14:22.020 --> 01:14:23.010

Participant: That should just be it.

848

01:14:23.550 --> 01:14:25.830

Participant: call me ranch dressing.

849

01:14:34.830 --> 01:14:36.870

Lily McKnight: Okay sorry only one left is the doors.

850

01:14:40.170 --> 01:14:40.830

Participant: back to the door.

851

01:14:40.860 --> 01:14:47.370

Participant: Do we want to do, like a like a cheesy one for that or do you want to do a real one, because I think I could maybe have an idea for a real one.

852

01:14:47.670 --> 01:14:49.260 
Participant: I think this one should have.

853

01:14:49.320 --> 01:14:52.410

Participant: The most serious caption yeah.

854

01:14:52.830 --> 01:14:53.280

Participant: yeah.

855

01:14:53.760 --> 01:14:55.710

Participant: It is like a very dramatic photo.

856

01:14:55.950 --> 01:14:56.850

yeah.

857

01:14:57.930 --> 01:15:01.350

Participant: Like a the Martin whole doors are.

858

01:15:02.280 --> 01:15:03.000

Participant: Like the history.

859

01:15:03.120 --> 01:15:04.230

Participant: or something.

860

01:15:04.620 --> 01:15:14.250

Participant: there's like yeah the mark the Martin hold doors are both a portal to downtown morgantown and an entrance point to the rest of the world, or something like that.

861

01:15:16.710 --> 01:15:20.760

Participant: At what point saying that sentence, did you realize you had no clue where that sentence was.

862

01:15:20.760 --> 01:15:21.090

gone. 
01:15:25.200 --> 01:15:27.390

Participant: I do, like the word portal, though.

864

01:15:27.420 --> 01:15:28.230

Participant: That like makes it.

865

01:15:28.710 --> 01:15:29.370

Participant: super.

866

01:15:29.730 --> 01:15:31.620

Lily McKnight: super serious mm hmm.

867

01:15:31.860 --> 01:15:40.470

Participant: Good good should be like like what mark said earlier about like how many people have walked through these doors it's.

868

01:15:41.520 --> 01:15:43.860

Participant: A mountain years of walk through the door.

869

01:15:44.820 --> 01:15:47.310

Participant: To creativity and greatness.

870

01:15:53.400 --> 01:15:54.240

Participant: Through this door.

871

01:15:55.260 --> 01:15:56.730

Participant: These mahogany.

872

01:15:58.020 --> 01:16:02.160

Participant: mahogany whatever polished.

873

01:16:03.450 --> 01:16:06.690

Participant: 1800 doors.

874

01:16:12.810 --> 01:16:20.580 
Lily McKnight: I don't know what year like Martin started I don't know if it's like or was built like i'm pretty sure it's one of the first buildings.

875

01:16:21.660 --> 01:16:24.030

Lily McKnight: sold his own characters yeah.

876

01:16:24.360 --> 01:16:26.550

Participant: We could we could talk about that.

877

01:16:27.030 --> 01:16:35.070

Lily McKnight: We could tie that in you know, like these stories have been here since the beginning or something along those lines.

878

01:16:37.170 --> 01:16:38.430

Lily McKnight: 1870 wow.

879

01:16:43.470 --> 01:16:44.280

Participant: 70 .

880

01:16:45.690 --> 01:16:49.920

Participant: Thousands of mountain years have walked through these doors.

881

01:16:50.220 -->01:16:52.260

Participant: I think generations have a good word.

882

01:16:52.860 --> 01:16:54.060

Participant: yeah yeah.

883

01:16:54.840 --> 01:16:56.790

Lily McKnight: We can also use corbin portal.

884

01:16:57.570 --> 01:17:00.240

Lily McKnight: Yes, since 1870.

885

01:17:01.170 --> 01:17:03.000 
Lily McKnight: generating mountaineers.

886

01:17:03.810 --> 01:17:07.290

Participant: have used mahogany mahogany wooden doors.

887

01:17:08.250 --> 01:17:08.580

Since.

888

01:17:09.900 --> 01:17:15.540

Participant: These uh these doors and Martin hall i've served as a portal for I don't know where i'm going with this.

889

01:17:15.810 --> 01:17:17.520

Participant: Generations of creativity.

890

01:17:18.000 --> 01:17:20.490

Participant: yeah gender generation creativity is good.

891

01:17:21.060 --> 01:17:21.420

Lily McKnight: I love.

892

01:17:21.450 --> 01:17:22.920

Lily McKnight: Yes, i'm here.

893

01:17:26.160 --> 01:17:29.580

Lily McKnight: All right, let's say it again i'll throw it in.

894

01:17:29.790 --> 01:17:33.660

Participant: Like since since 1870 these doors have served as.

895

01:17:35.250 --> 01:17:36.840

Participant: The portal to.

896

01:17:37.860 --> 01:17:38.010

Participant: Get. 
897

01:17:38.430 --> 01:17:38.790

Participant: away.

898

01:17:39.000 --> 01:17:43.380

Participant: or get away yeah gateway to excellence for generations of creators, what do we said, like.

899

01:17:43.380 --> 01:17:45.270

Lily McKnight: craters whoa it.

900

01:17:45.300 --> 01:17:45.990

Participant: takes to create.

901

01:17:46.410 --> 01:17:46.800

Participant: work.

902

01:17:46.890 --> 01:17:49.770

Participant: For creatives creatives or creators, I think, would work.

903

01:17:50.100 --> 01:17:54.780

Participant: I think creators, maybe, but it's like this it's like the same it's like a different like fully.

904

01:17:54.840 --> 01:17:56.010

Participant: Read the same idea.

905

01:17:56.970 --> 01:18:01.440

Participant: Would it be better to say like how many years is that to 50.

906

01:18:02.490 --> 01:18:07.650

Participant: However, many years, that is, instead of like it'd be more condensed.

907

01:18:08.850 --> 01:18:12.300

Participant: it's like 250 years of. 
908

01:18:13.890 --> 01:18:16.410

Participant: 951.

909

01:18:16.680 --> 01:18:20.460

Participant: Maybe like for over 151 years instead of since.

910

01:18:20.490 -->01:18:26.460

Participant: 1877 it's like saying 1870 makes it seem like a lot farther away.

911

01:18:26.610 --> 01:18:28.380

Participant: yeah yeah.

912

01:18:30.720 --> 01:18:32.730

Lily McKnight: yeah so keep 1870.

913

01:18:33.150 --> 01:18:33.870

yeah.

914

01:18:35.100 --> 01:18:37.320

Participant: Probably aren't the same doors that were there in a.

915

01:18:40.530 --> 01:18:40.920

Lily McKnight: hotel.

916

01:18:41.400 --> 01:18:42.060

systems.

917

01:18:44.160 --> 01:18:46.530

Participant: architect is of the second empire electric.

918

01:18:46.560 --> 01:18:49.200

Participant: style to principal floors wasn't added for inner. 
01:18:49.350 --> 01:18:50.340

Participant: city kids me based.

920

01:18:52.230 --> 01:18:52.770

Participant: off of those.

921

01:18:54.090 --> 01:18:54.660

Participant: know.

922

01:18:57.960 --> 01:19:10.950

Lily McKnight: Okay card when I don't know if you are the one that said, the final version of this or if it's somebody else, but I have since 1870 these stores have served as the gateway to generations of creators.

923

01:19:11.340 --> 01:19:11.850

Participant: Oh.

924

01:19:12.000 --> 01:19:13.230

Participant: They went to.

925

01:19:13.470 --> 01:19:17.940

Participant: Should we just say gateway to like excellence for gateway to success or like gateway.

926

01:19:18.060 --> 01:19:20.970

Participant: To the world Jones I think excellent sounds good.

927

01:19:21.120 --> 01:19:23.370

Participant: gateway to excellent theory or any of.

928

01:19:23.430 --> 01:19:24.780

Participant: The Martin all people.

929

01:19:26.610 --> 01:19:29.130

Lily McKnight: So, since 1870 these doors have served. 
930

01:19:31.500 --> 01:19:33.570

Lily McKnight: As a gateway excellence.

931

01:19:34.680 --> 01:19:42.000

Participant: I kind of liked having like creatives or like creators, because it's like you, then you kind of know where those doors are.

932

01:19:42.150 -->01:19:46.830

Participant: yeah that's the that's the end of it, for, as like the gateway to excellence for generations of creators.

933

01:19:46.950 --> 01:19:47.640

Participant: Okay gotcha.

934

01:19:48.720 --> 01:19:49.020

Participant: Sorry.

935

01:20:07.980 --> 01:20:11.880

Lily McKnight: All the all the creative statements we like them.

936

01:20:12.840 --> 01:20:15.150

Participant: Are we really leaving the hat is just two images.

937

01:20:15.630 --> 01:20:16.230

Yes.

938

01:20:19.740 --> 01:20:20.130

Lily McKnight: Please.

939

01:20:21.750 --> 01:20:40.320

Lily McKnight: Alright, so i'm now we'll think of the flow of our exhibit in what story, we wanted to tell about everyone's relationship with their media family, so what picture, do you think we should start with.

940

01:20:41.610 --> 01:20:46.200 
Participant: I think we should start with that one of the person on the cliff at ravindra.

941

01:20:47.550 --> 01:20:48.090

Participant: The fog.

942

01:20:48.810 --> 01:20:49.680

Lily McKnight: like that.

943

01:20:49.710 --> 01:20:50.310

Participant: yeah that one's.

944

01:20:51.390 --> 01:20:51.810

Participant: With them.

945

01:20:52.320 --> 01:20:58.980

Participant: I think it would be we start with that one and, like the other outside ones, and then have the door.

946

01:21:01.980 --> 01:21:02.640

Lily McKnight: I like that.

947

01:21:05.370 --> 01:21:06.840

Participant: whoa whoa whoa.

948

01:21:07.200 --> 01:21:09.810

Participant: Definitely took that picture ravindra.

949

01:21:12.210 --> 01:21:12.630

Participant: I did.

950

01:21:12.810 --> 01:21:20.460

Lily McKnight: that's mine okay okay it wasn't sure cool so i'm going to add another slide over here i'm.

951

01:21:22.980 --> 01:21:30.630 
Lily McKnight: Sorry, and I label, it is our flow slide so ultimately like I would go print these out.

952

01:21:31.860 --> 01:21:43.740

Lily McKnight: And hang them in the media innovation Center whenever they open um but then also this will be the order that they're going to be on instagram to for bring a reference.

953

01:21:44.880 --> 01:21:47.460

Lily McKnight: So we want to start with.

954

01:21:48.630 --> 01:21:48.840

Lily McKnight: The.

955

01:21:49.860 --> 01:21:51.420

Lily McKnight: Little cliff picture.

956

01:21:54.960 --> 01:22:05.790

Lily McKnight: And then, if somebody to like if you guys want to go in and like change the shape or change the size, whatever if we want to do that we can to I can print them all the same size.

957

01:22:07.020 --> 01:22:13.740

Lily McKnight: Whatever everyone's feeling I don't want to like change anyone's picture too much because that makes me really nervous.

958

01:22:23.670 --> 01:22:24.450

Lily McKnight: So we have.

959

01:22:25.950 --> 01:22:27.360

Lily McKnight: ravens rock picture.

960

01:22:32.250 --> 01:22:34.290

Lily McKnight: Next, one we can go.

961

$01: 22: 36.330-->01: 22: 37.710$ 
Participant: i'm thinking hammock.

962

01:22:39.150 --> 01:22:41.520

Participant: Easy that's what I was thinking.

963

01:22:42.300 --> 01:22:43.530

Participant: yeah yeah.

964

01:22:43.950 --> 01:22:46.380

Participant: We can do we can do the high, and then the.

965

01:22:46.560 --> 01:22:46.920

door.

966

01:22:48.150 --> 01:22:48.630

Lily McKnight: yeah.

967

01:23:08.070 --> 01:23:08.580

Lily McKnight: And he said.

968

01:23:09.930 --> 01:23:10.320

Participant: yeah.

969

01:23:11.400 --> 01:23:12.330

Participant: I did not mean to grab.

970

01:23:14.430 --> 01:23:15.540

Lily McKnight: You totally can.

971

01:23:30.480 --> 01:23:32.700

Lily McKnight: Okay, and then the war.

972

01:23:36.000 --> 01:23:38.700

Lily McKnight: guys i'm really liking, the door caption i'll say it. 
973

01:23:41.100 --> 01:23:43.350

Lily McKnight: yeah I agree kind of makes me emotional.

974

01:23:44.340 --> 01:23:46.290

Participant: way to excellence.

975

01:23:47.370 --> 01:23:49.650

Participant: I think people will weep makes you that.

976

01:23:54.450 --> 01:23:56.580

Participant: Little like Stan the boxes issue.

977

01:23:59.400 --> 01:24:01.650

Lily McKnight: Okay, so what we have.

978

01:24:04.080 --> 01:24:06.390

Lily McKnight: We just did our door in our flow.

979

01:24:07.470 --> 01:24:08.730

Lily McKnight: Okay, I.

980

01:24:12.630 --> 01:24:19.080

Participant: think we can do the one a David and Connor flying since it's still has somewhat of an HR element in the bag, with the trees in the sky.

981

01:24:20.340 --> 01:24:21.000

Participant: For the door.

982

01:24:23.010 --> 01:24:23.640

Participant: To door.

983

01:24:26.070 --> 01:24:29.550

Lily McKnight: So I think you can have the door separate environment or people. 
01:24:33.870 --> 01:24:38.310

Lily McKnight: and incorporate something else you know, whatever you're feeling.

985

01:24:39.090 --> 01:24:40.290

Participant: Now I like it.

986

01:24:40.410 --> 01:24:42.930

Participant: yeah I think like separating it's a good idea.

987

01:24:43.440 --> 01:24:44.400

Participant: yeah yeah I agree.

988

01:24:44.820 --> 01:24:51.120

Participant: yeah yeah we could make that one of them in nature, last night, where it's like a.

989

01:24:52.260 --> 01:24:52.830

Participant: Going back.

990

01:24:53.190 --> 01:24:54.870

Participant: full circle moment.

991

01:24:55.980 --> 01:24:57.030

Participant: that's the cycle.

992

01:25:03.780 --> 01:25:04.440

Participant: Like that Adam.

993

01:25:06.510 --> 01:25:10.890

Participant: So do we want to do the one to Sarah or the model.

994

01:25:13.590 --> 01:25:15.870

Participant: I I feel like it works either way.

995

01:25:16.500 --> 01:25:18.480 
Participant: I feel like going dark to light.

996

01:25:18.930 --> 01:25:20.880

Participant: Then back outside would be cool.

997

01:25:21.210 --> 01:25:22.170

To start with a new.

998

01:25:23.430 --> 01:25:23.970

Lily McKnight: model.

999

01:25:25.200 --> 01:25:29.280

Participant: Because the inside of the the picture of the door is kind of darker.

1000

01:25:30.780 --> 01:25:31.320

Participant: So.

1001

01:25:32.250 --> 01:25:33.690

Lily McKnight: Okay, so models.

1002

01:25:40.020 --> 01:25:42.360

Lily McKnight: And then miss Sarah and her tie.

1003

01:25:52.680 --> 01:25:54.810

Lily McKnight: I love that we capitalized point.

1004

01:25:57.090 --> 01:25:57.750

Lily McKnight: love that.

1005

01:25:58.410 --> 01:25:59.070

boy.

1006

01:26:01.050 --> 01:26:06.690

Lily McKnight: Okay, so he just did models, then Sarah and then we have the drone pick. 
1007

01:26:07.710 --> 01:26:08.010

Your.

1008

01:26:10.950 --> 01:26:12.510

Participant: I think that flow is really nice.

1009

01:26:13.200 --> 01:26:13.560

Participant: I liked.

1010

01:26:14.640 --> 01:26:15.630

Participant: It before a lot.

1011

01:26:20.610 --> 01:26:30.480

Lily McKnight: You know I like to we have a combination of like cute little captions we have is, we have to serious once we have an emoji one like i'm here for it.

1012

01:26:33.300 --> 01:26:37.410

Participant: And that's like all it's all different styles of journalism anyway, like.

1013

01:26:38.850 --> 01:26:42.360

Lily McKnight: yeah it says everything that we said earlier, you know.

1014

01:26:43.980 --> 01:26:44.460

Lily McKnight: super Ki.

1015

01:26:45.180 --> 01:26:46.110

moon.

1016

01:26:47.130 --> 01:27:06.690

Lily McKnight: Okay, so this will be the flow that like he said on these will be on instagram I don't know when i'm yet um and then whenever I can get them in the media innovation Center there'll be there i'll send you guys an email and Adam if you want to throw in another one you totally can.

1017

01:27:07.710 --> 01:27:21.420 
Lily McKnight: We can work it out, no biggie can we also go through, and could you put a sticky note on the ones that you in our in our flow and the ones that you guys took pictures of so we can include authors.

1018

01:27:22.470 --> 01:27:24.480

Lily McKnight: Authors photographers sorry.

1019

01:27:25.350 --> 01:27:29.250

Participant: Okay sorry i'm dumb are we doing this again with another set of pictures.

1020

01:27:31.530 --> 01:27:35.730

Lily McKnight: Wealthy in exhibit though it'll be for something else gotcha.

1021

01:27:36.180 --> 01:27:39.330

Participant: yeah i'll probably just say the picture that I was going to take for that.

1022

01:27:39.840 --> 01:27:40.980

Lily McKnight: yeah that's perfect.

1023

01:27:41.190 --> 01:27:44.430

Participant: it's gonna be similar to this one anyway, like behind the scenes.

1024

01:27:44.460 --> 01:27:54.540

Lily McKnight: You know, God, so this next part will be just kind of like how this one way it was like a little 1015 minute or i'll explain the next prom.

1025

01:27:55.200 --> 01:28:14.220

Lily McKnight: The next one won't be it's like the not as fun one i'm sorry, but it is just be it'll be quicker though it'll just be me ask you questions it's basically a focus group the next one is its role it's real simple but still pictures and still lots of fun.

1026

01:28:35.070 --> 01:28:44.580

Lily McKnight: Why you guys are Dean, is there anything else that you guys want to add to this, I really appreciate you guys helping me i'm.

1027

01:28:45.540 --> 01:28:58.770 
Lily McKnight: A lot with this and your guys's pictures were very phenomenal and I really do think that you know and people come and visit and stevie's like they'll think we're super fun and cool because we are.

1028

01:29:00.180 --> 01:29:06.090

Lily McKnight: But if you guys have anything else to add to this or want to see something else.

1029

01:29:07.110 --> 01:29:08.190

Lily McKnight: Now it's your time.

1030

01:29:09.480 --> 01:29:11.190

Lily McKnight: You have anything else to add.

1031

01:29:12.930 --> 01:29:13.710

There anything.

1032

01:29:17.730 --> 01:29:22.560

Participant: You need us to send you the photos like in a different way, besides just this jam board, so you can print them.

1033

01:29:23.460 --> 01:29:29.370

Lily McKnight: Though yes good good call there if you do want to send them to me um.

1034

01:29:34.830 --> 01:29:35.730

Thanks for coming.

1035

01:29:36.750 --> 01:29:37.380

Thanks for coming.

1036

01:29:39.390 --> 01:29:39.960

Lily McKnight: um.

1037

01:29:41.160 --> 01:29:52.260 
Lily McKnight: yeah if you guys want to go ahead and send me like I don't know what the best way because I don't like I don't want to like mess up anyone's picture quality or anything I don't know what would be the best way you.

1038

01:29:52.260 --> 01:29:52.740

Participant: Know should.

1039

01:29:52.890 --> 01:29:53.940

Participant: You know, should be fine.

1040

01:29:54.330 --> 01:29:56.520

Participant: email or worried to do a Google drive.

1041

01:29:57.810 --> 01:29:59.010

Lily McKnight: Let you want to do that it's.

1042

01:29:59.010 --> 01:29:59.790

Participant: probably going to be easier.

1043

01:30:01.080 --> 01:30:14.700

Lily McKnight: OK cool so i'll send you guys out one, and then you guys can send in the ones that you pick um for the actual exhibit and then they all have authors.

1044

01:30:15.570 --> 01:30:30.810

Lily McKnight: Okay cool awesome well, thank you guys like so much, I really appreciate it, I hope it didn't take up too much time um but I super appreciate your help i'm if it wasn't too horrible I hope you'll do it again with me.

1045

01:30:32.100 --> 01:30:39.330

Lily McKnight: But I think it's super fun i'll definitely send you guys an email whenever I find out that it's going to go out on social and go up.

1046

01:30:40.470 --> 01:30:46.710

Lily McKnight: In the media innovation Center so i'll keep you guys posted cool awesome well, thank you guys. 
01:30:49.350 --> 01:30:49.680

Participant: bye.

1048

01:30:50.370 --> 01:30:50.640

bye. 


\section{Appendix O}

\section{FIELD NOTES FROM PART 2 WORKSHOP}

- Five participants

- All on time

- Two graduate students, one freshmen, two juniors

- $\quad$ Pics mostly pulled from internet

- Some from Day of Play

- $\quad$ Yes to Facebook fundraiser

- Prefer donating to organizations with the same values as them, especially those politically involved

- Don't round up change because that's a tax deduction for business ***TikTok

- Reed College needs to find good balance

- "They like know that we're at the end of our schooling so they don't need to put in any effort in showing responsibility or regard"

- Lack of relationship nurturing in MSJ program applicable to future donating

- Themes: teamwork, eye contact and change

- Want to include duplicate photos under themes since they fall in multiple categories

- Want to do cheesy captions

- Split decision between most important dimension

- $\quad$ Easy creative statements

- Seem to have a lot of fun but def tired of participating LOL

- Done at 1:37:39 


\section{Appendix P}

\section{ZOOM WORKSHOP 2 TRANSCRIPT}

1

00:01:33.420 --> 00:01:34.020

Participant: How are you.

2

00:01:34.560 --> 00:01:38.370

Lily McKnight: Good ready ready to like get wrapping up on this.

3

00:01:38.370 --> 00:01:41.340

Lily McKnight: stuff threefold the literal same way.

4

00:01:41.640 --> 00:01:48.720

Participant: yeah I actually just spoke with my thesis chair today and i'll have my draft done of my entire thesis by next Friday, which is.

5

00:01:48.900 --> 00:01:50.280

Participant: crazy very.

6

00:01:50.580 --> 00:01:51.180

Oh, my God that.

7

00:01:52.290 --> 00:01:52.740

Participant: thing.

8

00:01:53.760 --> 00:02:01.110

Participant: So the goal is to defend either the 28th or 29th or 30th so like cutting it very, very close, but.

9

00:02:01.110 --> 00:02:03.240

Lily McKnight: i'm doing the same thing i'm really scheduled for the.

10

00:02:04.470 --> 00:02:04.920

Lily McKnight: Like. 
11

00:02:05.970 --> 00:02:08.220

Participant: happening there's a helicopter taking.

12

00:02:09.960 --> 00:02:15.570

Lily McKnight: I still not you see your dark hair and lily like I literally like have to do a double take, but I love it.

13

00:02:17.160 --> 00:02:18.420

Lily McKnight: super fabulous.

14

00:02:19.590 --> 00:02:25.170

Participant: i'm defending the seven and now graduating until August, but i'm still walking in there, so.

15

00:02:25.770 --> 00:02:27.930

Lily McKnight: Oh, my God I love the energy.

16

00:02:28.950 --> 00:02:29.880

Participant: A helicopter.

17

00:02:32.040 --> 00:02:36.870

Lily McKnight: I haven't gotten wasn't worth it, though, let me tell you 400 some dollars nope.

18

00:02:41.040 --> 00:02:44.880

Lily McKnight: It my mom is like you can cover that and I was like I can't.

19

00:02:45.630 --> 00:02:50.070

Participant: I tell my parents if they wanted me to walk and they needed to like.

20

00:02:50.760 --> 00:02:54.390

Lily McKnight: I like i'm probably got like sell my like kidney or something.

21

00:02:55.530 --> 00:03:03.090 
Participant: I just went for the cheap one like just a cap and gown like that's it and even do like one of those bundle packages, and it was only $\$ 100$ so.

22

00:03:03.480 --> 00:03:04.350

Lily McKnight: whoa.

23

00:03:04.410 --> 00:03:05.610

Lily McKnight: Did you get the masters.

24

00:03:06.330 --> 00:03:08.970

Lily McKnight: yep where did you find that.

25

00:03:09.210 --> 00:03:23.100

Participant: So on the website, when you go to like look at the CAP and gown so they, the first thing that they're at you, is the bundles and that's what is like $300 \$ 400$, but if you go to like just the CAP and gown and you select like the Masters it's only $\$ 100$.

26

00:03:27.090 --> 00:03:32.760

Lily McKnight: Almost that makes me wanna pass out, I did not do that, I really paid like the hangar it was like you have to pay for the hangar.

27

00:03:34.200 --> 00:03:38.430

Lily McKnight: So REP little big out they go for me.

28

00:03:38.820 --> 00:03:39.930

Participant: Okay, it happens.

29

00:03:40.230 --> 00:03:48.930

Lily McKnight: Okay um so i'll go ahead and send you guys, this is a link work if I put it in the chat like that doesn't actually work.

30

00:03:50.280 --> 00:03:53.370

Lily McKnight: I don't know OK so i'll drop the jam board.

31

00:03:54.450 --> 00:03:55.290

Participant: link. 
00:03:55.830 --> 00:03:59.940

Lily McKnight: And you guys can upload your pictures, like last time.

33

00:04:03.990 --> 00:04:05.370

Lily McKnight: I see if this works.

34

00:04:08.520 --> 00:04:12.990

Lily McKnight: Oh, it totally works, Dr fresco was like it doesn't work when you drop a link in the chat.

35

00:04:16.620 --> 00:04:19.320

Lily McKnight: And let me know if it doesn't work.

36

00:04:24.180 --> 00:04:35.610

Lily McKnight: So you can see, you can flip through and I went ahead and put a little sticky i'm with each of the five dimensions and you guys can just put.

37

00:04:37.080 --> 00:04:43.020

Lily McKnight: upload a corresponding PIC and, if you want to put your name like really did super FAB.

38

00:04:49.260 --> 00:04:51.210

Lily McKnight: Mark have you been playing any tennis.

39

00:04:53.760 --> 00:04:58.620

Participant: Honestly i've been so busy with like everything else that hasn't even been on my radar.

40

00:04:58.860 --> 00:05:03.960

Lily McKnight: rarely see him, I have not been to club tennis not one time since like September.

41

00:05:04.860 --> 00:05:06.480

Participant: Even again all the texts that. 
42

00:05:07.620 --> 00:05:10.650

Lily McKnight: Oh, my gosh yeah, why do they talk every day all day.

43

00:05:11.130 --> 00:05:24.210

Participant: Eric kills me, though, because he's like okay we're all gonna we're all going to meet we're all going to play this day there's like a half hour before we're supposed to play he's like can't make it sorry every time.

44

00:05:24.420 --> 00:05:27.510

Lily McKnight: Every single time I got Sarah I didn't play tennis.

45

00:05:30.090 --> 00:05:39.060

Lily McKnight: Literally I used to be NUTS at tennis and then I graduated and I was like i'm never ever ever playing again and I really didn't for like three years.

46

00:05:41.130 --> 00:05:51.600

Lily McKnight: It just like it was so like it was so toxic our tennis was, and I was like as soon as I don't have to do that anymore sees my parents aren't making me go, I am not going.

47

00:05:52.290 --> 00:06:02.160

Participant: I love playing tennis I tried to play whenever I can but the weather hasn't been nice until up and up until this point so i've been going out a lot more play.

48

00:06:02.460 --> 00:06:03.930

Lily McKnight: Do you go to club at all.

49

00:06:04.560 --> 00:06:05.970

Participant: And now I just play.

50

00:06:07.050 --> 00:06:09.750

Participant: At the courts by the REC.

51

00:06:10.080 --> 00:06:10.500

Lily McKnight: Oh yeah. 
00:06:10.980 --> 00:06:14.670

Participant: Just like just with a few friends like i'm not doing it like seriously or anything.

53

00:06:15.120 --> 00:06:15.840

Participant: I just find a.

54

00:06:15.930 --> 00:06:16.830

Lily McKnight: way to do it.

55

00:06:18.360 --> 00:06:22.740

Lily McKnight: Daily childlike organize you and i'm just like I can't I just can't do this like I.

56

00:06:23.160 --> 00:06:27.150

Lily McKnight: lead the efforts, but I can't I can't do it, I can't get with it.

57

00:06:31.530 --> 00:06:34.980

Lily McKnight: Was it hard to find pictures for this stuff you can be honest.

58

00:06:37.320 --> 00:06:40.770

Lily McKnight: yeah I feel like I didn't even know what any of this was.

59

00:06:41.070 --> 00:06:42.870

Participant: A lot of the stuff is just like screenshots from.

60

00:06:42.900 --> 00:06:44.160

Participant: yeah some Twitter.

61

00:06:44.550 --> 00:06:49.590

Participant: uh huh I stalk and typed in all the last words and then put in.

62

00:06:49.650 --> 00:06:50.610

Lily McKnight: I love that.

63 
00:06:54.900 --> 00:06:57.330

Participant: Like still trying to figure out how to do this i'm sorry.

64

00:06:57.690 --> 00:06:59.490

Lily McKnight: No you're taking your time.

65

00:07:01.620 --> 00:07:05.520

Participant: kaylee's like putting actual meaningful photos and.

66

00:07:09.360 --> 00:07:14.070

Participant: I just want the Bill Gates route and just literally went on their foundation website and then was like.

67

00:07:15.150 --> 00:07:18.360

Participant: This works with fits directly with the examples that she was given so.

68

00:07:18.750 --> 00:07:19.740

Lily McKnight: that's perfect.

69

00:07:33.150 --> 00:07:37.980

Participant: I promise i'm not wearing sunglasses inside it's like actually break and i'm in the car so.

70

00:07:38.370 --> 00:07:41.100

Lily McKnight: Are you driving the Tennessee.

71

00:07:41.580 --> 00:07:53.640

Participant: No i'm sitting in the parking lot because i'd run errands and then $I$ had a work meeting at five and a word meeting at 607 so i'm chillin in the car.

72

00:07:53.910 --> 00:07:55.080

Lily McKnight: shout out to you.

73

00:07:56.370 --> 00:07:57.150

Lily McKnight: For showing up. 
74

00:07:58.530 --> 00:07:59.610

Participant: never get a job.

75

00:08:01.380 --> 00:08:03.870

Participant: Eating this is recording isn't it sorry Dr price grew.

76

00:08:04.230 --> 00:08:06.150

Lily McKnight: Oh, my gosh last time I literally.

77

00:08:06.180 --> 00:08:09.270

Lily McKnight: said Fuck and it's in the transcript and I was like.

78

00:08:10.860 --> 00:08:11.460

Participant: It again.

79

00:08:12.240 --> 00:08:16.860

Lily McKnight: As I did, but she was like I won't look through those and I was like okay.

80

00:08:18.300 --> 00:08:26.430

Participant: it's all right, Dr price grove if you're watching this I should probably not she said that in a couple of our like group meetings and our class this year so it's all good.

81

00:08:28.230 --> 00:08:30.270

Participant: She can't say anything about it she's not alone.

82

00:08:30.810 --> 00:08:36.720

Lily McKnight: No, no, she this is research Okay, this is this is real research.

83

00:08:38.670 --> 00:08:39.090

Participant: sure.

84

00:08:45.390 --> 00:08:46.020

Participant: is lying.

85 
00:08:47.970 --> 00:08:52.890

Lily McKnight: Okay, tell me find a really good pictures oh my God I love the Bill Gates theme, I really do.

86

00:09:19.980 --> 00:09:25.590

Lily McKnight: Is in kaylee to this is not take the full time last time it only took half the time so.

87

00:09:26.610 --> 00:09:26.940

Lily McKnight: You want.

88

00:09:27.270 --> 00:09:29.490

Participant: to hire this person is.

89

00:09:29.580 --> 00:09:39.960

Lily McKnight: Dr press group told me, I had to tell everyone is going to last three hours, and I was like oh my God no one's gonna come no one's going to come on three hours of someone's time no.

90

00:09:40.320 --> 00:09:41.850

Participant: Listen, I have to eat dinner.

91

00:09:42.660 --> 00:09:44.640

Lily McKnight: So that's, the most important.

92

00:09:44.640 --> 00:09:47.580

Participant: about to go through the drive through with me if this last three hours.

93

00:09:49.440 --> 00:09:51.390

Lily McKnight: what's your drive through go to.

94

00:09:51.900 --> 00:09:54.510

Participant: Honestly i'm getting arby's because I want to Jamaica.

95

00:09:55.770 --> 00:09:56.400

Participant: More normal. 
96

00:09:57.900 --> 00:10:00.030

Lily McKnight: The gym Okay, so good.

97

00:10:03.270 --> 00:10:07.230

Participant: But i'm also like trying out this vegetarian thing and it's like no working at all.

98

00:10:07.650 --> 00:10:11.190

Participant: Really, because chicken nuggets are so good.

99

00:10:11.370 --> 00:10:13.110

Lily McKnight: I love chicken nuggets.

100

00:10:15.780 --> 00:10:26.070

Participant: US past attarian for two years and then I just started eating chicken again I can't eat any other meat, because it makes me sick, but I started the protein intake.

101

00:10:26.760 --> 00:10:37.050

Participant: that's like my thing to like I eat so much shaking but I don't eat any other meat and there's not like a chicken attarian, I guess, I could be like, whatever the poultry one is but.

102

00:10:37.200 --> 00:10:40.710

Participant: chicken like trying to eat duck or anything.

103

00:10:44.550 --> 00:10:53.040

Lily McKnight: I don't think I could go without like like bacon I hate really I love it.

104

00:10:54.060 --> 00:10:55.140

Participant: I love it.

105

00:10:57.270 --> 00:11:04.830

Lily McKnight: You know I don't know I like proud of people that I can do that because I have no like self control and it comes to at all. 
00:11:05.670 --> 00:11:10.350

Participant: I have no self control when it comes to cheese like I could never be vegan because.

107

00:11:12.240 --> 00:11:17.760

Participant: I just couldn't ever like I don't drink milk bull like cheese yeah never.

108

00:11:21.150 --> 00:11:27.570

Lily McKnight: Is everybody good are doing need another minute i'm looking another minute.

109

00:11:42.000 --> 00:11:59.850

Lily McKnight: Okay, so everyone is wrapping up um whoever wants to start if we just want to go around I literally have let's start by going around the room, but we're not all in the same room so that's fine i'm in talk about like where you guys went and found your photos.

110

00:12:05.160 --> 00:12:06.180

Lily McKnight: gonna go first lily.

111

00:12:07.680 --> 00:12:12.270

Participant: Sure Okay, you want me to do each of them, or you just want to do responsibility.

112

00:12:13.350 --> 00:12:16.470

Lily McKnight: You can do all of yours, at one time.

113

00:12:17.250 --> 00:12:29.190

Participant: Okay, so for responsibility, that was the only one, I didn't find on I stalk um I feel like Nike does a really good job of showing like social responsibility.

114

00:12:29.610 --> 00:12:30.720

Participant: When it comes to like.

115

00:12:31.020 --> 00:12:32.280

Participant: The caper Nick stuff. 
116

00:12:33.720 --> 00:12:39.540

Participant: The stop agent he, like I think they do a really good job of like voicing their opinions.

117

00:12:39.840 --> 00:12:41.970

Participant: So that's what I put first responsibility.

118

00:12:42.990 --> 00:12:43.800

Participant: And then.

119

00:12:45.870 --> 00:12:52.950

Participant: For reporting I just did like a generic picture of someone giving their boss or colleague, like a report.

120

00:12:55.140 --> 00:12:58.020

Participant: But I feel like a company as a whole, like.

121

00:12:59.100 --> 00:13:05.520

Participant: It starts from the bottom so like a company would have to report to each other, sorry if there's car noises.

122

00:13:06.840 --> 00:13:16.770

Participant: And then for regard I did a picture of people in masks and their fist pumping instead of handshaking so they're showing regard for the pandemic.

123

00:13:16.800 --> 00:13:18.570

Lily McKnight: happens, but you can make sure.

124

00:13:19.530 --> 00:13:20.640

Participant: shout out to Isaac.

125

00:13:22.500 --> 00:13:23.880

Participant: And then for.

126

00:13:23.880 --> 00:13:32.190 
Participant: Recognition I did employees clapping I was going to do a trophy so, mark you got that one but.

127

00:13:34.020 --> 00:13:41.430

Participant: I did the they're clapping for each other and then for a relationship nurturing I did like a group hug type thing.

128

00:13:42.300 --> 00:13:51.360

Participant: And I was like thinking about what this could be because I actually don't know which company it's from but like it could be like relationship nurturing between.

129

00:13:51.690 --> 00:14:04.230

Participant: Colleagues, and between employees from the same company or the company could be like coaching and adult soccer league or something and nurturing relationships with the Community so.

130

00:14:04.620 --> 00:14:12.810

Lily McKnight: I love that those those are really good time, thanks for sharing your welcome with someone else like to share.

131

00:14:18.720 --> 00:14:20.670

Lily McKnight: Carmen I feel like you're dying to talk.

132

00:14:21.360 --> 00:14:21.870

Participant: Oh yeah.

133

00:14:23.760 --> 00:14:35.070

Participant: Sure okay so uh I kind of centered all my stuff around one brand which I thought is a corporation that shows a decent amount of responsibility and that's Patagonia.

134

00:14:35.640 --> 00:14:42.480

Participant: The favorite of brad and chad's everywhere, but I think they actually do a good job at like you know being responsible so.

135

00:14:43.740 --> 00:14:44.370

Participant: The first one. 
136

00:14:45.390 --> 00:14:53.430

Participant: If you zoom in there, you see it's $1 \%$ for the planet is the flag and $1 \%$ for the planet is like a nonprofit organization that.

137

00:14:54.240 --> 00:15:04.800

Participant: tries to get big companies to pledge to like donate $1 \%$ of their annual profits to like climate change, solutions and charities and stuff like that.

138

00:15:05.220 --> 00:15:11.640

Participant: um they also include a lot of social justice stuff in there, too, because they kind of understand that you can't just be like don't let her and will save the planet like you got to.

139

00:15:12.030 --> 00:15:14.130

Participant: Have like tough conversations and stuff like that so.

140

00:15:14.850 --> 00:15:20.880

Participant: that's I guess I got that off patagonia's website so I assume that's something that works for them, or one of their brand ambassadors or something.

\section{1}

00:15:21.210 --> 00:15:27.090

Participant: wearing their clothing and also kind of wrapping the $1 \%$ for the planet brand which is pretty cool and then for the second one.

142

00:15:27.930 --> 00:15:33.240

Participant: And this is from Patagonia his website is, you can see the screenshot with their logo and everything.

143

00:15:33.840 --> 00:15:42.360

Participant: And it pretty much just so as the individual grants that they give their money to so through that link, you can go and check out all of the different nonprofits and.

144

00:15:42.720 --> 00:15:50.220

Participant: Organizations that they work with around the US and around the country, and so, if you want to go, you know follow them on social media or send them a couple dollars, whatever. 
145

00:15:50.760 --> 00:15:59.100

Participant: They kind of link all their information out so they have a central hub where any of the organizations, they work with can kind of list themselves and hopefully get more eyes and more money and stuff.

\section{6}

00:16:00.660 --> 00:16:09.660

Participant: And then for regard this is directly from the 1\% for the planet site and this kind of just shows their partner companies that they work with.

\section{7}

00:16:09.960 --> 00:16:14.010

Participant: Because they try to get the corporations to pledge $1 \%$ their profits, so this is kind of.

\section{8}

00:16:14.730 --> 00:16:24.390

Participant: The page that highlights the projects that they're working on and their partners that they're working on them with and then these long form stories when you click on them, you could read about what like what the impact has been and how you can support it.

\section{9}

00:16:26.550 -->00:16:37.080

Participant: And then, for the recognition Patagonia tweeted, I guess, so it was a little over a week ago, or maybe when we can go right now about how they were partnering with anti.

\section{0}

00:16:37.740 --> 00:16:47.910

Participant: pipeline protest and stuff like that so kind of fits in with their self and climate change mission and then, finally, the last one also kind of fits in the same.

151

00:16:48.660 -->00:16:55.230

Participant: thing with Patagonia they have a like i'm not sure if what it would be called like a subset of the brand called Patagonia action works, where.

152

00:16:55.530 --> 00:17:03.240

Participant: that's kind of their like nonprofit arm that works with other organizations and people and organizers and stuff to to kind of bring more attention and more money to them so.

153

00:17:04.260 --> 00:17:05.730 
Lily McKnight: I really like your.

154

00:17:06.750 --> 00:17:13.350

Lily McKnight: regard picture that was really that's cool that they have that i'm on their website.

155

00:17:14.760 --> 00:17:26.310

Participant: Yet if you go to the Patagonia main page it's like the second or third tab at the top menu is activism so it's not even like hey buy our stuff that's almost like a hidden compared to the activism stuff, which is good.

156

00:17:26.760 --> 00:17:29.040

Lily McKnight: is good, thank you for sharing.

157

00:17:30.150 --> 00:17:32.370

Lily McKnight: um so those of you that did.

158

00:17:32.400 --> 00:17:43.530

Lily McKnight: Part one and then compare it to part two, did you think this was easier like finding pictures, or do you think it was easier going out and taking the pictures.

159

00:17:45.960 --> 00:17:47.460

Lily McKnight: Or does anyone have an opinion.

160

00:17:48.690 --> 00:17:52.020

Participant: I think it was easier to go out and like actually take the pictures.

161

00:17:52.290 --> 00:17:52.800

Participant: uh huh.

162

00:17:53.130 --> 00:17:53.790

Lily McKnight: cuz into like.

163

00:17:54.240 --> 00:17:55.350

Participant: um yeah. 
164

$00: 17: 55.920-->00: 17: 56.310$

uh huh.

165

00:17:57.480 --> 00:17:58.320

Lily McKnight: Okay well.

166

00:17:58.710 --> 00:18:00.060

Lily McKnight: Thank you um.

167

00:18:00.090 --> 00:18:13.740

Lily McKnight: So what are some of the things when you guys read the email, what did you think you would be going and finding pictures of like did you felt like you understood it from the email or did you feel like you kind of had to go like explore a little bit.

168

00:18:17.670 --> 00:18:23.850

Participant: I think I understood it, I just had no idea where to look for stuff like I understand what I had I understood what I had to do I.

169

00:18:23.850 --> 00:18:25.380

Participant: Just wasn't sure exactly how to.

170

00:18:25.380 --> 00:18:25.800

Lily McKnight: Do it.

171

00:18:26.910 --> 00:18:30.810

Participant: Because I knew I wasn't going to be taking photos because I didn't know what I would take photos of myself.

172

00:18:31.320 --> 00:18:35.670

Participant: And I wasn't sure like where to look for screenshots and stuff like that.

173

00:18:35.970 --> 00:18:36.330

Lily McKnight: uh huh.

174

00:18:38.160 --> 00:18:43.650 
Participant: If you search those things like the five prompts you gave us like nothing comes up like.

175

00:18:43.830 --> 00:18:46.920

Participant: When you search like organization showing regard.

176

00:18:47.490 --> 00:18:50.130

Lily McKnight: Like my nothing comes up yeah.

177

00:18:51.300 --> 00:18:55.590

Lily McKnight: And then I made it hard oh my God i'm so.

178

00:18:55.650 --> 00:18:57.390

Lily McKnight: thinking and kind of.

179

00:18:57.600 --> 00:19:08.910

Lily McKnight: Going in searching what these other places have done for your pictures um have you guys ever like donated to charity or had any experience donating to charity.

180

00:19:11.340 --> 00:19:13.290

Lily McKnight: or any organizations like that.

181

00:19:15.300 --> 00:19:19.410

Lily McKnight: It can be volunteering to it doesn't have to be monetary.

182

00:19:20.850 --> 00:19:32.880

Participant: I know, so my family like each Christmas PICs like a something that we care about to like give money to and like half of our Christmas present like basically goes to that.

183

00:19:33.420 --> 00:19:40.590

Participant: organization so like that's not really me willingly giving money that's my parents being like here's half your Christmas present.

184

00:19:41.100 --> 00:19:43.050

Lily McKnight: That you see so $Q$. 
185

00:19:43.620 --> 00:19:50.010

Participant: But I mean it makes you feel better like knowing that because it's always like organizations that you really care about so.

186

00:19:51.690 --> 00:19:53.310

Lily McKnight: So when you guys.

187

00:19:53.490 --> 00:19:57.780

Lily McKnight: are like searching on like gutsy social media or something like, how do you see.

188

00:19:58.320 --> 00:20:01.170

Lily McKnight: These opportunities to.

189

00:20:02.490 --> 00:20:14.010

Lily McKnight: donate and most can be like a said, like money or time like I don't know like sometimes I think when I asked myself this question like I really think of those like booths that people like set up.

190

00:20:14.670 --> 00:20:27.150

Lily McKnight: kind of like the tables like kind of in front of Martin in that little area I know to like Facebook has like fundraisers I don't know what you guys have seen before, and in terms of that.

191

00:20:31.680 --> 00:20:33.150

Participant: what's the what's the question.

192

00:20:33.930 --> 00:20:36.810

Lily McKnight: How have you seen sorry I kind of got talking with that one.

193

00:20:37.830 --> 00:20:42.390

Lily McKnight: um have you guys seen opportunities to donate before.

194

00:20:46.140 --> 00:20:57.600 
Participant: I feel like I used to see those posts on Facebook, where it's like, for my birthday this year i'm doing this, but then like I haven't seen any of them forever, so I don't know what.

195

00:20:58.170 --> 00:20:59.520

Lily McKnight: The fundraisers.

196

00:20:59.610 --> 00:21:00.090

Participant: yeah.

197

00:21:00.360 --> 00:21:00.870

uh huh.

198

00:21:03.540 --> 00:21:12.960

Lily McKnight: I think another thing that I see a lot to are those, like those Bingo boards, where you like, then mo for.

199

00:21:14.190 --> 00:21:18.420

Lily McKnight: A thing you know, like put your name like over a Bingo board and they'll play Bingo.

200

00:21:20.100 --> 00:21:33.720

Lily McKnight: But let's say you guys have donated time or money to an organization before So what are some things in an organization and you can even use the ones that you pulled like corbin you pulled Patagonia.

201

00:21:34.050 --> 00:21:41.310

Lily McKnight: What are some things about an organization that you would value enough to donate your time or money.

202

$00: 21: 45.630-->00: 21: 50.970$

Lily McKnight: Is there something that stands out to you with certain organizations that you value.

203

00:21:52.800 --> 00:22:00.540

Participant: Obviously i'd have to believe in their work and, like the organization itself i'm not going to give money or time to something that i'm not like fully on board with. 
00:22:01.320 --> 00:22:16.230

Participant: would also like to see that would I do to actually make like a direct impact and so i'm not just giving money to some organization that's just going to like spin it around and use it for anything that's not like directly what I wanted to go to you know anything.

205

00:22:17.130 -->00:22:24.780

Lily McKnight: Other than Patagonia like do you have another organization that you know you would value enough to donate your time.

206

00:22:25.170 --> 00:22:35.130

Participant: Going not a company, because they have enough money and they could just give them more, even if, like like yeah that's great Patagonia is like donating stuff but there's something in a profit off like people i'm sure in sweatshop Labor somewhere.

207

00:22:35.130 --> 00:22:46.350

Participant: Because they make it so it's kind of all like posturing I donated a lot to last year to political candidates, I agree with and also raised a seeing eye puppy in high school.

208

00:22:48.090 --> 00:22:55.680

Participant: that's technically I guess volunteering I wouldn't I don't think i'd give to a like a company, though.

209

00:22:56.040 --> 00:23:04.290

Participant: And it's funny because I got it as like an ad PR student i'm like oh yeah that's really great and then I think about i'm like I don't freaking care like they have enough money they can do it themselves, they don't need my stuff.

210

00:23:04.650 --> 00:23:05.340

Right.

211

00:23:06.690 --> 00:23:08.880

Lily McKnight: So, have you I know sorry I let you go.

212

00:23:09.480 --> 00:23:10.500

Lily McKnight: Right sure yeah. 
213

00:23:10.680 --> 00:23:24.570

Participant: I think like i'm so much more inclined to donate to like a business or company that's like politically involved, but only if it aligns with like my beliefs, like, I think a lot, some people disagree with that because they're like.

\section{4}

00:23:24.600 --> 00:23:27.540

Participant: A company shouldn't be like political, but I think i'm so much more.

215

00:23:27.540 --> 00:23:28.380

Participant: inclined to like.

216

00:23:28.680 --> 00:23:39.960

Participant: donate to like Patagonia or like something that obviously like has stuff that I care about rather than someone who is just like quiet and doesn't really take a stance on it.

217

00:23:41.430 --> 00:23:45.900

Lily McKnight: mm hmm So what do you think about like a place like chick fil a.

218

00:23:47.820 --> 00:23:52.830

Lily McKnight: Like you know, and I mean a place that kind of takes these stances that maybe.

219

00:23:53.910 --> 00:24:00.390

Lily McKnight: You wouldn't necessarily agree with like, how do you think you like balance that in your head.

220

00:24:02.430 --> 00:24:17.610

Participant: I really like chick fil a's nugget, but I also have extremely socialist parents who like refused to shop at walmart or hobby lobby because they're like owned by the same type of owners that chick fil a has so I think it just like.

221

00:24:19.050 --> 00:24:20.340

Participant: I don't know I.

222

00:24:21.390 --> 00:24:22.950

eat at chick fil a sometimes. 
223

00:24:24.690 --> 00:24:25.080

Participant: they're.

224

00:24:25.350 --> 00:24:28.290

Participant: Like disagree with their political stances so.

225

00:24:28.650 -->00:24:30.960

Participant: It kind of goes against what I was just saying, but.

226

00:24:31.410 --> 00:24:44.880

Lily McKnight: No, I completely agree and I think that you know, we see that, with a lot of organizations to like, especially when they take a stance that maybe we don't necessarily agree with, but we are like I love hobby lobby, I really do.

227

00:24:45.120 --> 00:24:56.100

Lily McKnight: But like there are a lot for me, at the same time um So do you think that's something you know we definitely consider when we're looking to spend our money somewhere looking to spend our time there.

228

00:24:57.360 --> 00:25:12.090

Lily McKnight: But to kind of shift gears a little bit um have you guys ever had an experience, where wvu tried to Stewart you in any way or ask you for time or money, other than your tuition.

229

00:25:14.250 --> 00:25:27.360

Participant: donate to this year's Dover you day of giving everybody give us money, I had to do a bunch of social stuff for that so again it's like the advertising person who, who also works for the school is like yeah it's good and then I think about it i'm like.

230

00:25:29.010 --> 00:25:29.610

Participant: I don't even.

231

00:25:30.720 --> 00:25:32.040

Lily McKnight: So what do you. 
$00: 25: 32.190-->00: 25: 46.260$

Lily McKnight: describe to me, the best way that you think let's bring it down a scale so let's Someone described, maybe the best way that the reed college could Stewart you personally.

233

00:25:49.290 --> 00:25:52.800

Participant: I think if it was something like for something specific.

234

00:25:53.670 -->00:26:06.660

Participant: Like wanting to like fund a trip, or like build some new building or get some new gear like something like that $I$ think if they ran a campaign to like put your money to something specific.

235

00:26:07.110 --> 00:26:11.580

Participant: It would be easier to donate rather than just like 30 to the College just cuz.

236

00:26:11.940 --> 00:26:12.420

Lily McKnight: uh huh.

237

00:26:13.050 --> 00:26:14.700

Lily McKnight: No, I totally see what you mean there.

238

00:26:15.180 --> 00:26:26.460

Lily McKnight: So you're thinking you want it kind of can we have your time or money for $X \mathrm{y} \& z$ specific yeah anybody else.

239

00:26:29.160 --> 00:26:36.810

Participant: I agree, I think I would be so much more inclined, like, I know that ma che last year, or this year, whenever they did it they like.

240

00:26:37.170 --> 00:26:47.520

Participant: fundraise specifically for that and, like since that was something I was passionate about an undergrad like I was like willing to donate because it was for them specifically.

241

00:26:48.210 --> 00:26:50.010

Participant: So I definitely think putting. 
00:26:50.370 --> 00:26:55.170

Participant: Like a label on it and saying like this is going for this or this will buy this.

243

00:26:55.620 --> 00:26:57.420

Participant: makes me more inclined to want to donate.

244

00:26:58.020 --> 00:26:58.920

Absolutely.

245

00:27:00.390 --> 00:27:01.650

Lily McKnight: Now corbin you have kind of a.

246

00:27:01.650 --> 00:27:07.350

Lily McKnight: Different experience like he said, because you ran for wvu for that didn't you.

247

00:27:08.880 --> 00:27:10.530

Participant: I helped I was on the team.

248

00:27:10.710 --> 00:27:12.930

Participant: I definitely did it all by myself, but I was there.

249

00:27:13.500 --> 00:27:15.840

Participant: yeah yeah I was there.

250

00:27:16.680 --> 00:27:24.060

Participant: I did I did a lot of you, if for like four hours of the day, if you tweeted at us or use the hashtag I was the one responding to people so.

251

00:27:24.570 --> 00:27:25.860

Lily McKnight: yeah fame right.

252

00:27:26.760 --> 00:27:37.320 
Participant: The have really, really great ahead Oh, I was nice it was um it was like boomers that were actually being Nice, for once, and it was really there was like karen's tweeting pictures of their dogs instead.

253

00:27:37.680 --> 00:27:48.120

Participant: Of like complaining about like the university saying the quality is good or something so it was actually a nice break that when people were Nice on social media said they complain about the most insane sure they're very racist as well.

254

00:27:48.540 --> 00:27:48.900

Lily McKnight: Oh, my.

255

00:27:49.290 --> 00:27:49.680

gosh.

256

00:27:51.510 --> 00:28:05.820

Lily McKnight: i'm so, in what ways might you guys like to donate like, for example, like social media campaigns like by mail like Ben mo what what ways, would you guys like to donate.

257

00:28:07.050 --> 00:28:08.910

Lily McKnight: would be the most convenient for you.

258

00:28:10.590 --> 00:28:18.930

Participant: I think the most convenient I think all of us would say, this would be like through benbow cuz that's just like so easy it's just it takes two seconds.

259

00:28:19.350 --> 00:28:27.750

Participant: I mean I donate a lot of stuff like through like the Facebook fundraisers and things like that and I donate a lot of money it's like the different animal shelters that's.

260

00:28:28.080 --> 00:28:31.050

Participant: that's my thing I mean Anybody who knows me knows that I got dogs and.

261

00:28:32.550 --> 00:28:42.030

Participant: shelters all the time and i'm saving all the animals, and I want to have my own rescue one day, so you know that's where my money goes yeah so. 
00:28:43.950 --> 00:28:44.550

Lily McKnight: yeah now.

263

00:28:46.440 --> 00:28:53.250

Participant: If you do that are like credit cards, the last of that I donated to is all via like act blue, which is like the Democrat fundraising site.

264

00:28:53.520 --> 00:29:01.950

Participant: And you just like put in your credit card or debit card and just like charge that's that so that's that's The last thing I remember, like the last way I donated uh huh.

265

00:29:02.820 --> 00:29:05.130

Lily McKnight: Have you any of you ever donated with like.

266

00:29:06.000 --> 00:29:08.280

Lily McKnight: Like actual cash anywhere.

267

00:29:10.950 --> 00:29:14.250

Participant: Just like little donation boxes i'd say.

268

00:29:15.570 --> 00:29:22.110

Participant: it's more like a oh i'm here and it's here sort of thing not like a plan.

269

00:29:23.790 --> 00:29:26.370

Lily McKnight: it's like in the moment decision yeah.

270

00:29:26.850 --> 00:29:27.330

Lily McKnight: $\mathbf{m m}$ hmm.

271

00:29:28.260 --> 00:29:36.480

Lily McKnight: And do you guys ever do the like round up for the American cancer society or something like that.

272

00:29:39.450 --> 00:29:43.170 
Lily McKnight: Like if you went to like CVs and they're like can we round up your.

273

00:29:43.620 --> 00:29:49.140

Participant: I read that it's all tax write offs for the businesses because they can say that they were like part of a terrible yeah.

274

00:29:50.130 --> 00:29:51.600

Participant: Maybe it was on tix dog or something.

275

00:29:51.660 --> 00:29:58.380

Participant: But apparently that's just like a taxing for them so that they can get a tax break by saying that they do like a certain amount of charitable work.

276

00:29:59.220 --> 00:30:01.590

Lily McKnight: So you don't you don't donate to those.

277

00:30:01.710 --> 00:30:08.610

Participant: know if I were if I were going to donate to the like American cancer society wherever I would just give them money directly i'm not going to go through CVs like.

278

00:30:10.740 --> 00:30:11.610

Lily McKnight: Oh, my gosh I.

279

00:30:12.450 --> 00:30:16.320

Lily McKnight: can't believe that that's a scam I feel like it makes total sense, though.

280

00:30:17.340 --> 00:30:19.590

Participant: i'm gonna look that up and see if I could find articles and the link.

281

00:30:19.920 --> 00:30:21.360

Lily McKnight: Oh, my God, please do.

282

00:30:24.090 --> 00:30:28.770

Lily McKnight: So we just talked about you know ways we might want to do it. 
00:30:30.150 --> 00:30:32.160

Lily McKnight: Now, what about ways.

284

00:30:33.420 --> 00:30:36.420

Lily McKnight: Might you like, to be asked to donate.

285

00:30:38.220 --> 00:30:49.680

Lily McKnight: That makes sense, so there's this thing called crowdfunding and crowdfunding would be like you know the recall is going to ask a whole bunch of people for like a really small donation.

286

00:30:50.250 --> 00:30:59.610

Lily McKnight: Or you can have somebody commit to like a super big donation, but you wouldn't ask them as many times, does that make sense.

287

00:31:01.020 --> 00:31:08.820

Lily McKnight: So I don't know if you guys have ever I don't know that i've personally ever been asked for a big donation because i'm worth no money.

288

00:31:10.050 --> 00:31:16.680

Lily McKnight: But even with time to so what what ways might you like, to be asked to donate.

289

00:31:19.740 --> 00:31:24.810

Participant: You know it's like kind of makes me mad whenever they're like really passive aggressive about it.

290

00:31:25.650 --> 00:31:40.710

Participant: like this, this corporation like needs you to donate now bubble bubble blah like making it like really like urgent that you Danny when it's like not urgent at all really like makes me not want to do.

291

00:31:42.450 --> 00:31:45.720

Lily McKnight: When they make it seem like life or death in the moment right like someone.

292

00:31:45.750 --> 00:31:50.130 
Lily McKnight: Were counting on your \$3 donation.

293

00:31:53.100 --> 00:31:53.640

Lily McKnight: Oh, did you.

294

00:31:56.040 --> 00:31:57.030

Lily McKnight: Should we watch it.

295

00:31:58.410 --> 00:32:00.000

Lily McKnight: Let me see if I can share it.

296

00:32:01.320 --> 00:32:03.210

Participant: Well, power cited tick boxes.

297

00:32:03.870 --> 00:32:08.130

Lily McKnight: But this is this is real, this is work right now guys, this is this.

298

00:32:08.130 --> 00:32:09.090

Lily McKnight: Is research.

299

00:32:13.200 --> 00:32:15.180

Lily McKnight: Am I sharing my screen I don't even know.

300

00:32:16.260 --> 00:32:16.800

Lily McKnight: know.

301

00:32:17.820 --> 00:32:19.200

Lily McKnight: corbin you know play to take talk.

302

00:32:21.240 --> 00:32:22.530

Participant: will share my screen.

303

00:32:23.430 --> 00:32:27.780

Lily McKnight: I don't know, can you do that guys i'm really technologically challenged. 
304

00:32:28.050 --> 00:32:33.090

Participant: I think I think i've shared my screen, maybe once it's it's like nerve wracking I have to do.

305

00:32:33.570 --> 00:32:36.720

Lily McKnight: It like really makes me nervous and also.

306

00:32:36.750 --> 00:32:38.610

Lily McKnight: I used to have a folder on my.

307

00:32:38.850 --> 00:32:52.050

Lily McKnight: Like laptop just called shit because that's where I put all my stuff I didn't need anymore $I$ just threw it in there and then, finally, I was like sharing my screen and I was like oh my God like do people think i'm like aggressive.

308

00:32:56.370 --> 00:33:05.010

Lily McKnight: Okay, let me see okay guys i'm going to be honest, I don't know how to do this, so thank you corbin for sending the tech talk.

309

00:33:06.570 --> 00:33:09.810

Participant: Everybody can watch it individually it's a watch watch on your own time.

310

00:33:09.810 --> 00:33:10.410

guys.

311

00:33:13.410 --> 00:33:19.410

Lily McKnight: i'm so are there, certain things like Sarah kind of started are there, certain things that would.

312

00:33:21.180 --> 00:33:26.820

Lily McKnight: annoy you especially let's put it let's say a.

313

00:33:29.670 --> 00:33:34.680

Lily McKnight: hockey annoy you when they were asking for a donation. 
00:33:37.710 --> 00:33:39.990

Lily McKnight: And fan anything, maybe, nothing would annoy you.

315

00:33:50.160 --> 00:33:51.150

Lily McKnight: Any idea.

316

00:33:51.510 --> 00:33:53.190

Participant: I missed the question you add.

317

00:33:55.560 --> 00:33:56.610

Participant: me my wife doesn't.

318

00:33:59.910 --> 00:34:00.720

Lily McKnight: want to die.

319

00:34:02.190 --> 00:34:02.670

Lily McKnight: So.

320

00:34:02.760 --> 00:34:05.610

Lily McKnight: Are there certain things that would annoy you.

321

00:34:06.360 --> 00:34:14.280

Lily McKnight: i' $\mathrm{m}$ in the college doing so, like in the college asking you for a donation Are there things that would annoy you.

322

00:34:17.370 --> 00:34:24.990

Participant: I think like corbin said, like the wvu day of giving like that just annoys me so much because it's like.

323

00:34:26.040 --> 00:34:35.160

Participant: You take all my money i'm at a state like I I give you thousands upon thousands of dollars, and now you want my donation like really.

324

00:34:37.830 --> 00:34:40.470

Participant: you're kind of like already sucking me dry. 
325

00:34:44.160 --> 00:34:47.970

Lily McKnight: No totally I mean we pay tuition like it's kind of hard.

326

00:34:49.080 --> 00:34:54.480

Lily McKnight: To justify like i'm sure we're all working to like it's a lot to ask for.

327

00:34:55.350 --> 00:35:10.230

Participant: yeah it's like Oh, most of that fundraising stuff is aimed to mainly like alarms and rich alarms especially but it's hard not to see it all the time and think that they're asking us, even though, like university knows we're not going to get like we're not going to donate ship.

328

00:35:10.260 --> 00:35:10.590

Participant: But.

329

00:35:10.950 --> 00:35:17.190

Participant: If you're tweeting about it all the time, eventually students are going to be like okay guys we get it like you want money we're not going to give it to you.

330

00:35:17.580 --> 00:35:21.900

Participant: But it also if we don't do that then it's such it's like I see everybody.

331

00:35:22.470 --> 00:35:34.290

Participant: who complains about this stuff on Twitter, which is all that literally about everything the university does and a lot of times I like agree with the criticisms is like i'm a student to I just happened to work for the social team, but like sometimes.

332

00:35:35.790 --> 00:35:43.050

Participant: it's it's like it's like both worlds, you know it's like we made a lot of money for the university from the day of giving that will go to good stuff like.

333

00:35:43.470 --> 00:35:55.350

Participant: we're gonna have more scholarships, or better scholarships and we're going to keep building the Business School building and like do all the actually good stuff, but it also makes the university seem like hey give us money. 
00:35:55.770 --> 00:35:56.220

Participant: Although.

335

00:35:56.280 --> 00:35:58.260

You know my like bad good impression so.

336

00:36:00.030 --> 00:36:00.420

Participant: I don't know.

337

00:36:00.930 --> 00:36:02.010

Lily McKnight: Oh, my God I love that.

338

00:36:02.370 --> 00:36:10.050

Participant: yeah it's like it's like a little annoying but it's also necessary and it's annoying that's necessary because if the state, just like gave more money than no one would.

339

00:36:10.200 --> 00:36:11.070

Participant: have to donate but.

340

00:36:11.670 --> 00:36:13.980

Participant: uh huh i'm not an accountant, so I don't know.

341

00:36:14.610 -->00:36:16.260

Lily McKnight: uh huh guys.

342

00:36:16.740 --> 00:36:22.080

Lily McKnight: i've worked at the foundation now like, since he came to college and it's it's so hard on people are like.

343

00:36:22.500 --> 00:36:27.810

Lily McKnight: Oh, my gosh like my tuition is like going to the football locker room and i'm like well like it's not.

344

00:36:28.170 --> 00:36:35.820

Lily McKnight: As like you know, like you're helping like keep the lights on, like I know it is a lot of money, like you know, like tuition it's it's too much. 
345

$00: 36: 36.120$--> 00:36:47.580

Lily McKnight: But it's almost like where can those problems be like solved elsewhere, so I think you made a really good point corbin when if the state would maybe there was just more money there.

346

00:36:49.020 --> 00:36:50.460

Lily McKnight: could really help a lot.

347

00:36:51.600 --> 00:37:10.230

Lily McKnight: And thanks for sharing um so on to our next question so think back to those pictures you guys put up with our sticky notes and which stewardship dimensions should the College be prioritizing in your relationship.

348

00:37:11.940 --> 00:37:16.350

Lily McKnight: With them do you think in why which one, do you think is the most important.

349

00:37:17.430 --> 00:37:20.550

Lily McKnight: For your relationship with the reed college.

350

00:37:32.040 --> 00:37:35.280

Participant: Out of the ones on the sheet probably probably regard.

\section{1}

00:37:35.760 --> 00:37:36.840

Participant: I think everything is like.

352

00:37:37.500 --> 00:37:47.040

Participant: Like if you're going to give anything money you should like probably expect something back now they're like you're going to give money to a charity and like okay like give me something now but.

353

00:37:47.430 --> 00:37:57.750

Participant: If, like if the College wants donations and someone gives a donation they shouldn't just be like okay thanks for your money i'm going to not talk to you again, there should be like some back and forth I don't know what that would look like, but. 
354

00:38:01.800 --> 00:38:02.340

Lily McKnight: Does anyone else.

355

00:38:03.360 --> 00:38:12.060

Participant: i'm gonna piggyback off corbin I agree with regard because I feel like you know it's a two way relationship between the College and the students so.

356

00:38:12.600 --> 00:38:20.670

Participant: it's like the students give the College a bunch and then the the College gives students back at lunch so it's just a good balance between the two.

357

00:38:23.700 --> 00:38:26.340

Lily McKnight: Is there anyone that has a different opinion.

358

00:38:32.340 --> 00:38:35.160

Participant: I think mines responsibility $\mathbf{m m ~ h m m . ~}$

359

00:38:37.080 --> 00:38:40.590

Participant: I don't actually really know why, but I think that, like.

360

00:38:41.910 --> 00:38:48.090

Participant: If an organization isn't showing responsibility or like doing the right thing then you're like not going to be inclined to.

361

00:38:48.660 --> 00:38:51.690

Lily McKnight: $\mathrm{mm}$ hmm pay them anything $\mathrm{mm}$ hmm.

362

00:38:54.150 --> 00:38:55.740

Participant: Also i'm gonna go off camera.

363

00:38:58.980 --> 00:39:01.020

Lily McKnight: it's fine eat your prize.

364

00:39:03.750 --> 00:39:11.700 
Participant: So I agree with both regard and responsibility, and I also think relationship nurturing is important, I mean I could think.

365

00:39:12.270 --> 00:39:32.520

Participant: Like us, in the the journalism master's program like I think that the College could have done a little bit better with maintaining that relationships and I only get like having regard for us but continuing that, especially through coven times and recognizing that you know.

366

00:39:33.630 --> 00:39:49.110

Participant: we're getting our masters during coven and the biggest cohort that they've ever had in the Masters journalism program, we need a little extra from you and we need more guidance so that's what I would say in regards to the College itself.

367

00:39:49.530 --> 00:39:51.330

Lily McKnight: $\mathbf{m m}$ hmm absolutely.

368

00:39:52.680 --> 00:39:57.750

Participant: we're like any sort of like like they should have shown responsibility in that.

369

00:39:59.070 --> 00:40:06.240

Participant: Like showing regard like they should have taken responsibility for the fact that they gave us absolutely no information I almost feel like.

370

00:40:07.920 --> 00:40:15.510

Participant: They like know that we're at the end of our schooling, so they don't need to put in any effort in children responsibility or gourd.

371

00:40:16.050 --> 00:40:21.480

Participant: uh huh because they got us and we're hooked him we're almost done so they're like yeah okay bye.

372

00:40:21.960 --> 00:40:22.290

Lily McKnight: uh huh.

373

00:40:22.920 --> 00:40:25.290

Participant: sounds like fun class of $\mathbf{2 0 2 5}$. 
374

00:40:27.480 --> 00:40:32.070

Participant: yeah I completely agree with literally said, like it's like they almost like just.

375

00:40:33.090 --> 00:40:40.950

Participant: Like I understand Grad school is like a different thing like a different game than undergrad or you know your previous schooling, but.

376

00:40:41.730 --> 00:40:59.550

Participant: it's like you know the mom or just kick the baby out of the nest day one didn't even know like didn't have any wings that grown or whatever, and just said how fun like that you're not for yourself like don't really want you back kind of thing like I don't know it just.

377

00:41:00.870 --> 00:41:08.790

Participant: yeah but that that's more of a personal level that's just me speaking of my grievances masters journalism program but.

378

00:41:09.630 --> 00:41:20.280

Lily McKnight: applicable, you know, like if you're ready to give a donation to somebody and they were you know so nice and so informative at the beginning, just like the imagery Program.

379

00:41:20.700 --> 00:41:31.080

Lily McKnight: um and then you know, once they have you in well, then they don't feel like they have to do anything anymore and it's like how would they get another donation from me like I would think.

380

00:41:31.590 --> 00:41:38.100

Lily McKnight: Those are the people you would want to have a better relationship, because you already know that they are inclined.

381

00:41:39.180 --> 00:41:46.680

Lily McKnight: to donate or in the College, you know say good things about the College, you know, citing as a very, very applicable.

382

$00: 41: 47.430-->00: 41: 48.060$ 
Lily McKnight: I compare it.

383

00:41:48.780 --> 00:41:54.630

Participant: Again example that was like the first like week or so like this is because of.

384

00:41:55.200 --> 00:42:07.470

Participant: trisha petty but I love the Grad program I was like this is great like this is like such a great program and everything and I told savant about it likes Yvonne join the program because I was like preaching about how great it was, but then.

385

00:42:07.920 --> 00:42:19.560

Participant: You know, it took a turn for the worst and it's like okay well somebody's gonna like go and continue that and say $\mathrm{Oh}$, this is a great program or is she not because that relationship wasn't nurtured.

386

00:42:19.860 --> 00:42:20.430

Participant: So.

387

00:42:20.520 --> 00:42:23.010

Participant: I don't know I feel like that kind of applies there to.

388

00:42:23.610 --> 00:42:29.250

Lily McKnight: No absolutely no for sure that's a really good grasp on the material go kaylee.

389

00:42:30.810 --> 00:42:42.780

Participant: I also feel like like nurturing relationships goes along with like them, putting in what they expect us to put in, like the organization in general, like.

390

00:42:43.230 --> 00:42:51.330

Participant: Like regardless of our grievances towards the MSG program like if they don't put in the organization doesn't put in enough, then we're not going to put in.

391

00:42:52.380 --> 00:42:52.710

Lily McKnight: $\mathbf{m m}$ hmm. 
392

00:42:53.340 --> 00:42:55.800

Lily McKnight: Absolutely, I think you could say the same thing.

393

00:42:56.070 --> 00:43:08.700

Lily McKnight: About donating to an organization to especially one that you're already you know so a part of like a college university setting absolutely you know you, you want your energy to be matched.

394

00:43:11.370 --> 00:43:13.980

Lily McKnight: Absolutely that's really good discussion guys.

395

00:43:15.180 --> 00:43:26.550

Lily McKnight: Okay, so let's shift gears a little bit um so I know we were we were just a little we're just a little heated there for a second that's fine um that when thinking about graduating.

396

00:43:30.660 --> 00:43:36.990

Lily McKnight: college are some things you'll miss of your media family did I break up sorry.

397

00:43:37.920 --> 00:43:40.800

Participant: There we go a real robot really for like three seconds or.

398

00:43:40.860 --> 00:43:42.660

Lily McKnight: Okay, let me repeat sorry.

399

00:43:43.170 --> 00:43:49.650

Lily McKnight: i'm at least sitting in my roommates room because, like the wi fi or apartment has not been agreed with me recently.

400

00:43:50.880 --> 00:43:59.190

Lily McKnight: But when thinking about graduating from the reed college what are some things that you'll miss of your media family.

401

00:44:01.560 --> 00:44:03.360

Participant: Like besides Omega or. 
402

00:44:04.290 --> 00:44:06.840

Lily McKnight: Well, I mean she's obviously at the top of all of our list.

403

00:44:06.840 --> 00:44:07.560

So.

404

00:44:12.300 --> 00:44:12.930

Participant: I think.

405

00:44:14.430 --> 00:44:17.850

Participant: So, like I worked for the DEA for obviously three and a half years and.

406

00:44:17.910 --> 00:44:19.320

Participant: corbin work there and.

407

00:44:19.500 --> 00:44:33.150

Participant: Mark work there, and you know they might sell work there, I don't know but that's like my experience from the media, family and i've already stepped away from it, so I feel like i'm kind of like already departing from that like life but.

408

00:44:34.020 --> 00:44:37.500

Participant: that's something that I do miss like I do miss the da.

409

00:44:38.640 --> 00:44:45.180

Participant: Not for the work, but for the relationships that were formed and honestly just for our Sunday meetings when we would sit there.

410

00:44:45.510 --> 00:44:57.510

Participant: We would get our meeting done within 30 minutes, then we talked for like an hour and like I missed those relationships and those connections so and that wouldn't have been possible without the media college so.

411

00:44:58.470 --> 00:45:03.750

Participant: i've never felt more hung over than I did at some of those Sunday morning meetings I mean it was really. 
412

00:45:04.710 --> 00:45:13.350

Participant: But for my actual answer that question, I say it's the sense of community and the spontaneity that comes with being in college and.

413

00:45:13.860 --> 00:45:19.140

Participant: I know it's not just a college in general thing because I have friends from home that.

\section{4}

00:45:19.830 --> 00:45:29.250

Participant: I go to other schools and when they talk about what their college experiences like it's not at all like what mine has been like here and like what most of my friends has been like here.

415

00:45:29.760 --> 00:45:40.470

Participant: So, like the spontaneity things like I can be maybe not as much now, but like I can like walk through Martin hall and see a bunch of people that I know and then within 10 minutes, we can have plans to go do something later that day.

416

00:45:41.880 --> 00:45:51.360

Participant: I think that's part of it's really cool and that like sense of community, where I feel like I am a part of a group of people that share like similar like goals and ideas and like.

417

00:45:52.020 --> 00:45:59.370

Participant: You know, just like the same type of vibe I don't really know how you're supposed to get that as like an adult in the real world and, like it's a little scary because.

418

00:45:59.700 --> 00:46:04.650

Participant: Even if I think about like where I want to live and like what I want to do, I don't I can't like picture that.

419

00:46:05.130 --> 00:46:12.810

Participant: sense of community being a part of like, even if, like if you work somewhere right, even if you work for like a company that's considered like a great employer like.

420

00:46:13.350 --> 00:46:24.510 
Participant: Like if you die though upload your job posting the next day and just like get on with it that's just like how it works, so I don't know that sounds a community and in college and $\mathbf{a} w$ in the recalls was pretty great.

421

00:46:25.950 -->00:46:27.420

Lily McKnight: Absolutely that's really good answer.

422

00:46:32.790 --> 00:46:33.870

Lily McKnight: coming year, very good.

423

00:46:33.870 --> 00:46:34.620

speaker.

424

00:46:36.810 --> 00:46:50.550

Participant: Thank you um there's I feel like it may be because of my tour giving experience and did I ever tell you about the time that the dad was with the kidney asked about what was in the filing cabinets in Martin hall.

425

00:46:50.790 --> 00:46:59.460

Participant: No okay I don't want to derail for too long, but I was giving a Martin hall to were to his kid who was like a prospective student and his dad and Whitney was like.

426

00:46:59.880 --> 00:47:06.810

Participant: She was like OK they're in the Office like they're a little like weird but you know just go with it, I was like Okay, whatever like I was awkward in high school too, so I want to talk to them.

427

00:47:07.350 --> 00:47:16.770

Participant: And they just like didn't like talk to me like they like barely responded and the one time that the data ask the questions are the whole tour we're in like the TV edit lab on the second floor.

428

00:47:17.520 --> 00:47:25.080

Participant: third floor which everyone, and he, like points at the filing cabinets and he goes what's in those cabinets I swear to God and I was like.

429

$00: 47: 25.950-->00: 47: 33.870$ 
Participant: I was like speeches for a second I didn't know what to say so honestly, no matter what public speaking or private speaking or anytime I open my mouth, it will never be.

430

00:47:34.350 --> 00:47:43.350

Participant: more confusing than that moment, so from there on out, it was just like smooth sailing when he asked me what was in the filing cabinet, I told Whitney about that, after and she just looked at me and she was like do what.

431

00:47:44.190 --> 00:47:45.390

Lily McKnight: What is going on here.

432

00:47:47.040 --> 00:47:48.120

Lily McKnight: Do you know if the kid came.

433

00:47:49.110 --> 00:47:51.870

Participant: I don't know if he did I answer your question.

434

00:47:52.140 --> 00:47:53.160

Participant: that's numbers know.

435

00:47:53.250 --> 00:47:54.270

Lily McKnight: Larry it.

436

00:47:54.300 --> 00:48:01.560

Participant: was so weird the guy asked me was in the filing cabinets problem I don't know what does that even matter, even if I didn't know what do you like, what do you like files.

437

00:48:01.620 --> 00:48:04.830

Lily McKnight: Okay it's not that big of a deal like.

438

00:48:06.690 --> 00:48:19.770

Lily McKnight: guys one thing i'm glad I didn't have to do, I didn't have to do any of those with Whitney because they're not doing tours right now, because, like if some if somebody asked me, I was in the filing cabinet like probably would have cried so. 
439

00:48:21.570 --> 00:48:22.350

Lily McKnight: i'm international.

440

00:48:22.410 --> 00:48:28.710

Participant: I generally like the tours because, like $70 \%$ of the time you'll get a family that's like Nice and they're excited and they're like.

441

00:48:28.710 --> 00:48:32.880

Participant: curious like I remember, I was really excited on my tour, so, if I can give those things like.

442

00:48:32.910 --> 00:48:36.960

Participant: Good vibes to them it's good, but then you, you know everyone smile you get the filing cabinet dad that's.

443

00:48:38.010 --> 00:48:38.310

Participant: Where.

444

00:48:39.210 --> 00:48:42.570

Lily McKnight: I think later i'm just gonna text Whitney and be like filing cabinet see.

445

00:48:42.570 --> 00:48:44.850

Lily McKnight: What she says or what's in the filing cabinet.

446

00:48:45.420 --> 00:48:49.110

Participant: If she doesn't remember it off the top of her head, if you bring up the tour thing she definitely will.

447

00:48:50.790 --> 00:48:55.860

Lily McKnight: So funny i'm so sorry that happened to you God costly cry.

448

00:48:57.990 --> 00:49:08.700

Lily McKnight: So um where these things nice relationship, you know things you would want future students to experience as well. 
00:49:15.330 --> 00:49:22.740

Participant: yeah I mean like even after leaving the da like just because it came time for me to leave because there's nothing left for me there.

450

00:49:23.070 --> 00:49:26.100

Participant: It doesn't mean that it wasn't like a great experience and like.

451

00:49:26.850 --> 00:49:39.240

Participant: that's where all my friends came from was from the da and that's where I met all these media people who were involved in every college where they weren't and I definitely think that that environment there is.

452

00:49:40.380 --> 00:49:46.920

Participant: Great for incoming freshmen and our I think is like I said I was a volunteer photographer there for two years and.

453

00:49:47.400 --> 00:50:03.630

Participant: that's where my friends were so it was it was all I had with my friends there so it's definitely something that I, I always I still recommend to anybody that I talked to is that john da because it's just it's easy friends that you can make.

454

00:50:05.400 --> 00:50:06.450

Lily McKnight: Absolutely, thank you for.

455

00:50:06.450 --> 00:50:10.110

Lily McKnight: Sharing and so, in the next couple of years.

456

00:50:11.190 --> 00:50:27.150

Lily McKnight: In what ways, do you see yourselves being active alumni so like, for example, would you see yourself like hoping Whitney with like an alumni social media initiative for something like that.

457

00:50:30.870 --> 00:50:33.480

Lily McKnight: I mean we do anything for Whitney let's be honest, but it's.

458

00:50:34.620 --> 00:50:43.860 
Participant: Not that i'd want to be like the like the fifth year guy that like hangs around too much, but i'd love to be they do that comes back when he's 13 it was like oh that's cool, but what a cool guy like I remember him when he was here.

459

00:50:45.030 --> 00:50:54.120

Participant: Now, like I would definitely help out and if I ever like make a lot of money which I won't because I want to do, social media stuff I feel like I would donate but that's not that's not gonna happen so.

460

00:50:57.810 --> 00:51:03.660

Lily McKnight: Absolutely any other ways that you see yourself, being an active alumnus.

461

00:51:06.750 --> 00:51:24.150

Participant: I think, just like you know going on to doing bigger things than what you did in college and say, like, I will do you gave me the start like I think that's always just like you always hyping it up and telling your story about your experience here uh huh.

462

00:51:25.170 --> 00:51:30.750

Lily McKnight: Absolutely That was really well said that was really well side marks a freshman to aren't show.

463

00:51:32.070 --> 00:51:34.620

Participant: that's a blurry line yeah.

464

00:51:37.410 --> 00:51:49.440

Lily McKnight: awesome well in what ways, could you guys see yourselves, providing the College with financial or voluntary support.

465

00:51:53.220 --> 00:51:56.760

Lily McKnight: And also, you cannot see yourself doing that too that's fine that's an answer.

466

00:51:57.300 --> 00:52:03.390

Participant: One of the most helpful and like reassuring things that happened to me was before coven last year I was looking for internships in New York.

467

00:52:03.840 --> 00:52:07.710 
Participant: In anything to do with advertising or media or creative stuff or whatever.

468

00:52:08.160 --> 00:52:13.560

Participant: and New York is like the most competitive market for that, so I go into linkedin and i'd find the Agency, I want to look for.

469

00:52:13.800 --> 00:52:18.960

Participant: And then i'd see their strategy internship position and it would be like 600 applicants just something insane like one spot.

470

00:52:19.500 --> 00:52:28.560

Participant: So what I did is I went on linkedin and I found every single w or specifically like every single reed college alumni that lived in New York that worked for agencies.

471

00:52:28.950 --> 00:52:37.740

Participant: And I literally message, like every single one of them I probably sent like 20 3040 times over the course of like a couple weeks in like February 2020.

472

00:52:38.100 --> 00:52:46.620

Participant: And I got so many responses from people that were even like pretty like one guy was like the chief growth officer at an agency that was like you know, one of the.

473

00:52:47.070 --> 00:52:49.620

Participant: big ones, and was, like all they had all these like great clients.

474

00:52:49.920 --> 00:53:01.170

Participant: And I just sent him a cold DM and I was like hey man like i'm a w student I see you're an alumni like, would you be willing to like help me out or give me an advisor and he was like yeah man, some of your resume i'll get you connected with our HR people bought he didn't have to do that.

475

00:53:01.200 --> 00:53:01.800

Participant: You just took like.

476

00:53:02.250 --> 00:53:05.550

Participant: You know, a couple minutes out of his day to do something nice for a current student. 
477

00:53:06.120 --> 00:53:13.140

Participant: and none of it worked out because all the positions got canceled because of the pandemic, but I feel like I could have gotten a job through someone that went to $\mathrm{w}$.

478

00:53:13.620 --> 00:53:20.190

Participant: So if I could provide that same type of resource down the line for current w students, because it was it was super Nice and like reassuring.

479

00:53:20.610 --> 00:53:22.530

Participant: So if i' $m$ in a position to do that later I definitely.

480

00:53:22.530 --> 00:53:24.360

Participant: Will and doesn't cost any money so.

481

00:53:25.860 --> 00:53:27.030

that's really sweet answer.

482

00:53:31.350 --> 00:53:31.680

Lily McKnight: Now.

483

00:53:32.460 --> 00:53:33.720

Lily McKnight: yeah I definitely think, just like.

484

00:53:33.930 --> 00:53:36.750

Participant: Helping future students so um.

485

00:53:38.130 --> 00:53:46.590

Participant: So I talking to you know future like one example, I have, I know somebody who's going into the Masters journalism Program.

486

00:53:47.100 --> 00:53:57.180

Participant: used in the first year for four plus one program so like advocating for her and like helping her and telling her everything that we've already experienced and telling you exactly what not to do. 
487

00:53:57.600 --> 00:54:13.740

Participant: And like who exactly to talk to, and like I think that's important is like talking to like reaching out to current students and stuff like that, after the fact, and like I would definitely be willing to talk to students and kind of be like a mentor and that way.

488

00:54:17.010 --> 00:54:18.540

Lily McKnight: You guys are still Nice.

489

00:54:20.460 --> 00:54:27.390

Participant: i'm still like super close with a lot of my high school journalism friends like from your book and mass comm and stuff like that.

490

00:54:27.780 --> 00:54:41.340

Participant: So i'm always reaching out and texting them like hey you know what are you doing after college or and I have a feeling they're actually going to come to the College so i'm always like hey if you have any questions or you know need help getting started just let me know.

491

00:54:43.770 --> 00:54:47.280

Lily McKnight: that's super cool it's nice yeah you guys are so nice.

492

00:54:48.960 --> 00:55:02.640

Lily McKnight: So, in what ways um, this is an interesting question in what ways would your possible student debt impact your willingness to donate back to the reed college.

493

00:55:06.390 --> 00:55:11.280

Participant: Based on the fact my net worth will be like negative like $\$ 20,000$ in like a year and a half.

494

00:55:12.300 --> 00:55:15.750

Participant: Significantly impact my financial well being for anything so.

495

00:55:17.040 --> 00:55:22.980

Participant: I feel like Tony until i'm like not out of debt until I am out of debt.

496

00:55:24.600 --> 00:55:24.990 
Participant: yeah.

497

00:55:28.830 --> 00:55:35.790

Participant: I feel like are you talking about like financial or like my mental well being like which one, are you talking.

498

00:55:35.790 --> 00:55:37.590

Lily McKnight: About honestly both.

499

00:55:38.820 --> 00:55:43.080

Participant: Because I will never forgive wvu for ruining my mental health.

500

00:55:43.170 --> 00:55:50.130

Participant: So if that's the case, I will not be doing anything anytime soon unless they're paying for my therapist.

501

00:55:51.960 --> 00:55:52.860

Lily McKnight: And that's a fair.

502

00:55:52.890 --> 00:55:56.670

Lily McKnight: that's a fair argument, especially after this past year.

503

00:55:57.810 --> 00:55:58.950

Lily McKnight: My goodness.

504

00:56:00.270 --> 00:56:21.930

Lily McKnight: So are there, certain things pertaining to the College that you'd like to donate your time or money to like over others like so, for example, would you rather volunteer to speak on like one of whitney's alumni panels, or would you rather dhoni to read college scholarship fund.

505

00:56:25.260 --> 00:56:32.970

Participant: So I think just in terms of financial stability, like we were just talking about I definitely be more willing to donate my time and people.

506

00:56:35.580 --> 00:56:43.560 
Participant: down the line, maybe for the donating towards scholarships and stuff but, like in the now it'd be more time based.

507

00:56:43.650 --> 00:56:43.980

Lily McKnight: $\mathbf{m m}$ hmm.

508

00:56:45.180 --> 00:56:45.450

Lily McKnight: um I.

509

00:56:46.290 --> 00:56:57.900

Participant: feel like it's more impactful to to give you time because then you can actually like see the impact that you're having rather than if you just giving money you don't really know what's coming up that.

510

00:56:59.520 --> 00:57:01.680

Lily McKnight: Absolutely, I think that's a really good point mark.

511

00:57:04.230 --> 00:57:05.160

Participant: I know you're.

512

00:57:06.330 --> 00:57:06.540

Participant: Very.

513

00:57:06.600 --> 00:57:07.470

Lily McKnight: Good you.

514

00:57:08.820 --> 00:57:15.450

Participant: are just gonna say I feel like i'm so much more inclined to like don't obviously don't eat time than money but.

515

00:57:15.990 --> 00:57:24.930

Participant: I would much rather do something, maybe in like writing then be on a panel, or like have to talk to people like in person like.

516

00:57:25.260 --> 00:57:42.120 
Participant: You can write an article about me all day and i'll say like thanks wvu thanks reed college like you gave me this opportunity but i'm much like i'd much rather it be in writing or like a social posts then have to like do the panel.

517

00:57:42.930 --> 00:57:47.100

Participant: But that's just that's just me because i'm like lazy and busy and i'm like.

518

00:57:47.730 --> 00:57:48.330

Participant: still have.

519

00:57:52.440 --> 00:57:53.190

Lily McKnight: I think that's.

520

00:57:53.310 --> 00:58:06.810

Lily McKnight: It it's completely like, especially with our age range now and, like, I know, really like you just started a job, like i'm on here, having no idea what i'm doing and it's like in no way right now, like what I be.

521

00:58:07.380 --> 00:58:15.780

Lily McKnight: In a position where I could like give someone even just like partially a scholarship like a can you uncover myself right now.

522

00:58:17.430 --> 00:58:20.160

Lily McKnight: So now, I completely get where you guys are coming from.

523

00:58:21.870 --> 00:58:23.220

Lily McKnight: Technology fun stuff.

524

00:58:24.450 --> 00:58:28.860

Lily McKnight: And so you can think about the discussions we've had, I think a lot.

525

00:58:33.360 --> 00:58:50.040

Lily McKnight: Definitely brought up, and I think a lot of you guys had the same opinions on things to um so like last time we can go through, and I know core corbin Sarah, mark you were here last time. 
00:58:50.790 --> 00:59:01.590

Lily McKnight: But Lillian kaylee super fun super easy we'll go through, and you can kind of look through the pictures and you guys can see if you see any themes.

527

00:59:02.820 --> 00:59:04.920

Lily McKnight: Throughout the pictures that you guys.

528

00:59:06.120 --> 00:59:13.290

Lily McKnight: chose so, for example, with the part one actually think it was corbin that came up with the idea but.

529

00:59:14.340 --> 00:59:25.560

Lily McKnight: They chose the themes people and environment, so you can have their can be as any themes, as you want, but take a look through and see if you guys see anything.

530

01:00:09.540 --> 01:00:12.930

Lily McKnight: Does anyone have any ideas any suggestions.

531

01:00:13.500 --> 01:00:15.960

Participant: I feel like one of the themes could be like teamwork.

532

01:00:17.040 --> 01:00:17.520

Lily McKnight: uh huh.

533

01:00:17.910 --> 01:00:20.580

Participant: there's a few for those that are kind of resemble that.

534

01:00:21.480 --> 01:00:22.830

Lily McKnight: uh huh teamwork.

535

01:00:22.860 --> 01:00:23.610

Lily McKnight: that's a good one.

536

01:00:26.280 --> 01:00:29.790

Lily McKnight: Just like corbin said it takes it day giving takes a team. 
537

01:00:35.130 --> 01:00:36.570

Lily McKnight: Anyone see another one.

538

01:00:37.320 --> 01:00:44.040

Participant: In one that is very specific but it's among the ones where there's multiple people in frame is eye contact.

539

01:00:45.180 --> 01:00:45.660

Participant: A lot of.

540

01:00:45.840 --> 01:00:47.700

Participant: people that are in the frames.

541

01:00:47.730 --> 01:00:49.020

Participant: That are like actually photos are not.

542

01:00:49.020 --> 01:01:00.240

Participant: Just like screenshots they are either making eye contact with someone who's in the frame or someone who is out of the frame like maybe that's because we've like think of stuff to be more like.

543

01:01:01.320 --> 01:01:04.830

Participant: I don't know like more relationship based if you're like actually looking at someone.

544

01:01:05.730 --> 01:01:07.650

Lily McKnight: hmm absolutely I like thought.

545

01:01:08.130 --> 01:01:09.960

Lily McKnight: See teamwork and eye contact.

546

01:01:10.020 --> 01:01:13.560

Lily McKnight: I like that that's a good thing to notice corbin.

547

01:01:15.270 --> 01:01:20.070 
Lily McKnight: And we can stop there, or we can keep going whatever you guys think or feel.

548

01:01:23.250 --> 01:01:28.740

Participant: feel like there's a lot of pictures that are like making a difference or change related to.

549

01:01:30.510 --> 01:01:31.710

Lily McKnight: I think that's another good one.

550

01:01:32.760 --> 01:01:38.400

Lily McKnight: Absolutely, so we have teamwork eye contact and change.

551

01:01:40.980 --> 01:01:46.710

Lily McKnight: that's a pretty good it's a pretty good handle on things does anyone have any other suggestions.

552

01:01:48.780 --> 01:01:49.260

Lily McKnight: yeah.

553

01:01:52.050 --> 01:01:53.280

Participant: I love your cat.

554

01:01:54.540 --> 01:01:55.800

Participant: Oh, my God.

555

01:01:59.250 --> 01:01:59.880

he's huge.

556

01:02:02.610 --> 01:02:03.750

Lily McKnight: Oh, my gosh.

557

01:02:07.710 --> 01:02:10.500

Participant: Sorry, that was me driving home and eating. 
01:02:12.300 --> 01:02:14.550

Lily McKnight: I spiked it What did she get from are obese.

559

01:02:15.270 --> 01:02:21.870

Participant: I got curly Fries and then I also stopped at a gas station and got those like sour shells.

560

01:02:22.500 --> 01:02:26.610

Lily McKnight: Ah, oh, those are so good at those like make my teeth hurt they're so good.

561

01:02:29.490 --> 01:02:32.370

Participant: But I agree, I feel like a lot of us have people in them.

562

01:02:33.000 --> 01:02:35.130

Lily McKnight: uh huh absolutely.

563

01:02:36.810 --> 01:02:45.930

Lily McKnight: How do you want to split it up, then, do you wanna do you want to make an needs, do you want to combine any or do you want to keep all, for we can add people in there.

564

01:02:46.890 --> 01:02:48.630

Participant: No, I mean, I think that people's like.

565

01:02:48.840 --> 01:02:49.470

Lily McKnight: Too generic.

566

01:02:49.560 --> 01:02:54.600

Participant: I feel like your guys's teams are better, but like a lot of them do have like I think only to.

567

01:02:55.920 --> 01:02:58.170

Lily McKnight: Like don't yeah uh huh.

568

01:02:59.850 --> 01:03:07.740 
Lily McKnight: Okay, so i'll go ahead and write these things down on some slides so we had teamwork.

569

01:03:14.640 --> 01:03:17.520

Lily McKnight: teamwork, we have eye contact.

570

01:03:34.860 --> 01:03:43.980

Lily McKnight: Okay, so if everyone wants to go on the jam board, we can go one by one and kind of split these pictures up.

571

01:03:45.300 --> 01:03:49.230

Lily McKnight: In under into the theme that you think they belong under.

572

01:03:51.060 --> 01:03:56.280

Lily McKnight: So firstly have and if if I click it you guys can see which one i'm highlighting right.

573

01:04:01.020 --> 01:04:01.560

Lily McKnight: yeah.

574

01:04:02.910 --> 01:04:10.170

Lily McKnight: Maybe not cool So what do we think this, what do we think lily's picture falls under.

575

01:04:20.640 --> 01:04:22.980

Lily McKnight: I feel like this one could fall under change.

576

01:04:27.030 --> 01:04:28.110

Lily McKnight: yeah okay.

577

01:04:29.160 --> 01:04:29.640

Participant: I agree.

578

01:04:29.730 --> 01:04:31.800

Participant: Sorry, I was flipping back and forth to like look. 
579

01:04:31.800 --> 01:04:32.790

Participant: At what the words word.

580

01:04:35.940 --> 01:04:38.400

Participant: was taking me a second but yeah I definitely agree with that.

581

01:04:43.830 --> 01:04:48.510

Lily McKnight: Do you see any others on this first slide that we want to put under a theme.

582

01:04:50.280 --> 01:04:52.200

Lily McKnight: And our responsibility slide.

583

01:04:56.910 --> 01:04:59.340

Participant: I feel like carbons would be changed to.

584

01:04:59.970 --> 01:05:00.750

corbin.

585

01:05:03.000 --> 01:05:03.780

Participant: And then really.

586

01:05:03.810 --> 01:05:09.750

Participant: Like I guess if you knew the context behind like kaylee's and.

587

01:05:10.410 --> 01:05:11.460

Lily McKnight: Is this one sarah's.

588

01:05:12.930 --> 01:05:15.750

Participant: Like couldn't they technically be.

589

01:05:16.920 --> 01:05:21.630

Lily McKnight: uh huh change, where you guys think they fall.

590

01:05:22.470 --> 01:05:25.860 
Participant: Because they get moving one could be teamwork that's getting moving isn't it.

591

01:05:27.060 --> 01:05:28.920

Participant: But like I feel like you'd have to know that.

592

01:05:29.670 --> 01:05:30.120

Lily McKnight: uh huh.

593

01:05:30.660 --> 01:05:32.550

Participant: you to know that it was change.

594

01:05:33.420 --> 01:05:34.110

Lily McKnight: Kelly, I don't know.

595

01:05:34.410 --> 01:05:37.290

Participant: This but i'm assuming that they're talking about something important.

596

01:05:40.110 --> 01:05:49.590

Participant: yeah they're like talking about like the issues for whatever or which

Conference, it was, but whatever mission that they're launching but yes.

597

01:05:49.950 --> 01:05:52.650

Participant: Be teamwork and shaming.

598

01:05:54.090 --> 01:05:56.160

Lily McKnight: Guy and we could put them under both to.

599

01:05:59.010 --> 01:06:01.410

Lily McKnight: Now put that on under bed.

600

01:06:05.670 --> 01:06:11.010

Lily McKnight: Do you feel like are they looking at each other it's like Donald could go under eye contact to yeah.

601

01:06:13.650 --> 01:06:14.160 
Lily McKnight: Okay.

602

01:06:14.910 --> 01:06:19.290

Participant: marks if you if you thought really deeply yours can be changed to.

603

01:06:20.610 --> 01:06:24.180

Participant: Like the tides of balance.

604

01:06:29.730 -->01:06:31.500

Participant: is not like the last thing.

605

01:06:32.280 --> 01:06:35.910

Participant: I was trying to look for a given take but.

606

01:06:36.690 --> 01:06:38.370

Lily McKnight: Oh that's clever.

607

01:06:38.700 --> 01:06:42.060

Participant: You can't really express that with people so.

608

01:06:44.070 --> 01:06:45.510

Lily McKnight: Where do you want to put that one mark.

609

01:06:47.640 --> 01:06:49.920

Participant: You can leave that one off you want it's okay.

610

01:06:53.370 --> 01:06:53.520

Participant: I.

611

01:06:53.670 --> 01:06:54.060

Participant: like that.

612

01:06:56.010 --> 01:06:56.610

Lily McKnight: Change. 
613

01:06:57.210 --> 01:06:57.600

yeah.

614

01:06:59.100 --> 01:07:00.030

Participant: Like give or take.

615

01:07:01.320 --> 01:07:01.740

Participant: don't.

616

01:07:02.310 --> 01:07:03.270

Lily McKnight: I like that.

617

01:07:06.300 --> 01:07:06.810

Lily McKnight: Okay.

618

01:07:07.410 --> 01:07:09.180

Participant: Wait what's the other one change to work.

619

01:07:10.050 --> 01:07:10.620

Lily McKnight: I mean I.

620

01:07:13.050 --> 01:07:17.850

Lily McKnight: think everything on the first slide is under at least one category.

621

01:07:19.380 --> 01:07:21.180

Lily McKnight: So move on to the next one.

622

01:07:22.890 --> 01:07:24.210

Lily McKnight: Anything jump out.

623

01:07:29.430 --> 01:07:31.920

Participant: kaylee's people are making eye contact.

624

01:07:33.090 --> 01:07:33.240 
or.

625

01:07:34.680 --> 01:07:35.760

Participant: Looking on me joey.

626

01:07:36.600 --> 01:07:37.230

Lily McKnight: I see it.

627

01:07:42.300 --> 01:07:49.230

Participant: I think like sarah's could be under eye contact as well, especially with the camera because it's like perception and focus.

628

01:07:51.750 --> 01:07:53.220

Lily McKnight: Which one is your SAP.

629

01:07:54.720 --> 01:07:58.620

Participant: The one of tammy you're making mine so deep I appreciate it.

630

01:07:58.710 --> 01:08:00.180

Participant: I just found these.

631

01:08:01.320 --> 01:08:02.310

Lily McKnight: Here, for it.

632

01:08:03.720 --> 01:08:07.560

Participant: I like orange can be changed again guys.

633

01:08:08.100 --> 01:08:08.700

Participant: you're like.

634

01:08:10.170 --> 01:08:11.340

Lily McKnight: Change.

635

01:08:12.090 --> 01:08:15.030

Participant: Market maybe yours is I contact to. 
636

01:08:16.830 --> 01:08:21.270

Participant: or it's teamwork because there's like a film crew plus.

637

01:08:24.630 --> 01:08:26.010

Lily McKnight: And we can do both to.

638

01:08:27.450 --> 01:08:31.980

Participant: yeah I think Well, this is teamwork I don't know if you guys don't know yet if i'm just sold out or what.

639

01:08:34.020 --> 01:08:34.680

Participant: Well, but.

640

01:08:37.500 --> 01:08:42.000

Lily McKnight: now listen guys i'm so i'm so appreciative you guys are here, I know this is like.

641

01:08:43.650 --> 01:08:44.100

Lily McKnight: Okay, wait.

642

01:08:45.270 --> 01:08:47.520

Lily McKnight: reporter one what did we say on that one.

643

01:08:49.530 --> 01:08:50.190

Participant: teamwork, and I.

644

01:08:51.720 --> 01:08:52.140

Lily McKnight: agree more.

645

01:08:52.890 --> 01:08:53.910

decisions for the group.

646

01:09:01.980 --> 01:09:02.160

Lily McKnight: cool. 
01:09:03.600 --> 01:09:06.150

Lily McKnight: Okay well on to the next one.

648

01:09:07.800 --> 01:09:08.580

Lily McKnight: regard.

649

01:09:11.400 --> 01:09:14.130

Participant: Definitely I talk in teamwork.

650

01:09:21.120 --> 01:09:22.770

Participant: More she's definitely teamwork.

651

01:09:24.870 --> 01:09:25.890

Lily McKnight: What did you say sorry.

652

01:09:26.490 --> 01:09:32.640

Participant: Mark says definitely teamwork teamwork, I feel like corbin does change again.

653

01:09:36.780 --> 01:09:37.830

Lily McKnight: Change.

654

01:09:39.450 --> 01:09:42.600

Participant: And then, Sarah will be team or.

655

01:09:46.020 --> 01:09:46.530

Participant: Someone else.

656

01:09:50.340 --> 01:09:54.210

Participant: I feel like I don't want to like assume kaylee.

657

01:09:55.290 --> 01:09:56.730

Participant: What do yours be teamwork. 
01:09:59.310 --> 01:10:02.490

Participant: And maybe I contact because he's looking at or she's looking at him.

659

01:10:03.660 --> 01:10:08.220

Participant: yeah I don't know I feel like it could be any of them, obviously.

660

01:10:09.960 --> 01:10:10.290

Participant: Okay.

661

01:10:11.550 --> 01:10:15.360

Participant: teamwork, and I contact all yeah it's all that.

662

01:10:16.950 -->01:10:18.960

Lily McKnight: Okay, so you want to put that one under all of them.

663

01:10:19.980 --> 01:10:21.480

Lily McKnight: I mean yeah.

664

01:10:22.320 --> 01:10:23.370

Participant: everybody else agrees.

665

01:10:24.420 --> 01:10:25.290

Participant: yeah I think that works.

666

01:10:25.950 --> 01:10:26.430

yeah.

667

01:10:28.590 --> 01:10:28.980

Participant: corbin yeah.

668

01:10:33.360 --> 01:10:33.540

Participant: Your.

669

01:10:34.200 --> 01:10:39.240

Participant: Name you're wearing like a wvu sure you have the let's go fly behind you. 
670

01:10:40.590 --> 01:10:41.520

Participant: i'm on the brand.

671

01:10:42.120 --> 01:10:42.420

Participant: you're like.

672

01:10:42.780 --> 01:10:44.430

Participant: You are team for a reason.

673

01:10:47.190 --> 01:10:48.090

Participant: i'm on brand.

674

01:10:49.980 --> 01:10:52.590

Lily McKnight: In the plan to love it.

675

01:10:54.360 --> 01:10:57.600

Participant: This is not, this is not branded However, this is this is.

676

01:10:59.100 --> 01:11:00.630

Participant: Another plan to he doesn't see you.

677

01:11:01.230 --> 01:11:03.210

Participant: In the Web you.

678

01:11:05.580 --> 01:11:07.980

Participant: Know web branding on those just plant.

679

01:11:08.040 --> 01:11:09.420

Lily McKnight: I don't believe it carbon.

680

01:11:09.510 --> 01:11:11.550

Participant: rob's yeah sorry no flying wv on the planet.

681 
01:11:15.930 --> 01:11:18.720

Lily McKnight: Alright, so next we have recognition.

682

01:11:24.360 --> 01:11:25.770

Lily McKnight: And you jump out at you guys.

683

01:11:31.530 --> 01:11:36.090

Participant: Mars is definitely teamwork that's like the epitome of teamwork.

684

01:11:36.960 --> 01:11:37.710

Participant: That picture.

685

01:11:38.160 --> 01:11:38.520

True.

686

01:11:41.010 --> 01:11:42.000

Participant: But like did the whole.

687

01:11:42.060 --> 01:11:43.920

Participant: gotta get that award bro.

688

01:11:44.190 --> 01:11:45.330

Participant: That was the whole point.

689

01:11:47.220 --> 01:11:49.380

Participant: Did the whole team get the trophy or did.

690

01:11:49.380 --> 01:11:50.910

Participant: A whole team.

691

01:11:52.680 --> 01:11:54.720

Participant: Is there one person with a trophy.

692

01:11:57.960 --> 01:12:07.620 
Participant: that's the goal to give the quote unquote war and whatever award is to that's the angle this way it's you gotta have a teamwork.

693

01:12:09.840 --> 01:12:15.570

Participant: So I feel like kaylee's could be teamwork, because I don't really think they're like tag teaming the what is that.

694

01:12:17.070 --> 01:12:17.520

Participant: Good.

695

01:12:18.570 --> 01:12:19.230

Participant: or whatever.

696

01:12:19.620 --> 01:12:23.820

Participant: No, no, a what is it called Nobel Peace Prize.

697

01:12:28.020 --> 01:12:28.920

Participant: i'm not that dumb.

698

01:12:33.240 --> 01:12:34.830

Lily McKnight: Okay, so that one's teamwork.

699

01:12:43.680 --> 01:12:44.520

Participant: So knows the answer.

700

01:12:45.900 --> 01:12:50.760

Participant: i'd say yeah because it's like the two of them they're getting awarded for their foundation.

701

01:12:51.000 --> 01:12:52.770

Participant: and work together on it so.

702

01:12:53.310 --> 01:12:54.000

that's really. 
01:12:55.110 --> 01:12:55.500

Lily McKnight: Where my.

704

01:12:55.650 --> 01:12:56.340

Participant: Mind lines.

705

01:12:58.890 --> 01:12:59.490

Lily McKnight: This done.

706

01:13:02.370 --> 01:13:03.840

Lily McKnight: Which one mine yeah.

707

01:13:05.970 --> 01:13:11.190

Participant: um would it be I contact because i'm sure they're looking at you over there clapping for.

708

01:13:11.760 --> 01:13:13.410

Lily McKnight: guys like oh perfect.

709

01:13:18.420 --> 01:13:19.290

Lily McKnight: Okay.

710

01:13:19.800 --> 01:13:22.260

Participant: I feel like share, as is dirty but that in one.

711

01:13:23.940 --> 01:13:26.580

Participant: eye contact eye contact.

712

01:13:37.080 --> 01:13:40.320

Lily McKnight: And I think the last one, we have is corbett's for recognition.

713

01:13:41.880 --> 01:13:44.520

Participant: What his be change I don't know what that says, but.

714

01:13:45.480 --> 01:13:47.400 
Lily McKnight: guys like change perfect.

715

01:13:48.840 --> 01:13:50.520

Participant: is definitely no eye contact so.

716

01:13:51.300 --> 01:13:53.010

Lily McKnight: Just probably throw that one out.

717

01:13:53.100 --> 01:13:54.000

Participant: The Twitter screenshot.

718

01:13:56.730 --> 01:14:00.900

Lily McKnight: Okay, so last category relationship nurturing.

719

01:14:04.320 --> 01:14:05.580

Lily McKnight: Last slide of this.

720

01:14:09.300 --> 01:14:11.520

Participant: I think mine is teamwork an icon.

721

01:14:12.480 --> 01:14:14.190

Lily McKnight: teamwork an eye contact.

722

01:14:15.240 --> 01:14:17.610

Participant: And I think marks is teamwork.

723

01:14:19.380 --> 01:14:26.460

Participant: And maybe change because maybe they decided that they were going to change something really big so they do a really big like.

724

01:14:28.860 --> 01:14:29.130

say.

725

01:14:33.420 --> 01:14:34.290

And then. 
726

01:14:35.340 --> 01:14:38.220

Participant: gordon's looks like change again.

727

01:14:38.880 --> 01:14:39.930

Participant: Mr Todd corbin.

728

01:14:40.440 --> 01:14:41.040

Lily McKnight: corman's in.

729

01:14:41.580 --> 01:14:42.750

Participant: The general theme.

730

01:14:45.930 --> 01:14:51.630

Participant: And there was, I think teamwork, and I can talk again.

731

01:14:54.540 --> 01:14:58.290

Lily McKnight: Okay, Sarah teamwork and contact.

732

01:14:59.490 --> 01:15:08.400

Participant: And I feel like kaylee's could be all three because teamwork because there's two people change because i'm sure that means something important.

733

01:15:08.460 --> 01:15:09.030

And then.

734

01:15:11.280 --> 01:15:12.690

Participant: I contact with executive.

735

01:15:14.040 --> 01:15:14.640

Lily McKnight: and love it.

736

01:15:15.270 --> 01:15:18.060

Lily McKnight: Incredible absolutely amazing. 
737

01:15:19.980 --> 01:15:22.290

Participant: He brought that actually sounds.

738

01:15:22.680 --> 01:15:22.920

cool.

739

01:15:24.510 --> 01:15:28.650

Participant: The audacious run the audacity, or like the audacious.

740

01:15:30.150 --> 01:15:32.910

Participant: If I had a podcast I would call it the audacity.

741

01:15:35.220 --> 01:15:36.090

Lily McKnight: I love that.

742

01:15:37.230 --> 01:15:51.690

Lily McKnight: Okay Cindy now you guys can go through, and so this whole process is human centered design with which is just like a creative way to problem solve.

743

01:15:52.710 --> 01:15:56.880

Lily McKnight: and part of that process is is doing just this.

744

01:15:58.680 --> 01:16:11.130

Lily McKnight: With photos and stuff like that, and in getting responses from people that would be deeper than just a traditional interview so for the next part, now that we've organized them.

745

01:16:11.670 -->01:16:21.810

Lily McKnight: You can all go through and pick one picture that you really feel like connects with you or speaks to you in any kind of way, and this is called your gem.

746

01:16:22.200 --> 01:16:40.170

Lily McKnight: To you can all go through and pick your jam it doesn't have to be your own picture, it can be any picture and you can go through and use the sticky note feature it's on the left, right there in that little bar and you can put your name on it and claim your gem. 
01:16:42.720 -->01:16:45.750

Participant: 01 for each category just one overall.

748

01:16:46.590 --> 01:16:49.860

Lily McKnight: What when one overall so you all can pick one picture.

749

01:16:50.820 --> 01:16:54.870

Participant: and could it be like in the categories that we chose, or should it be like.

750

01:16:56.010 --> 01:16:56.730

Participant: prompts.

751

01:16:57.450 --> 01:17:00.420

Lily McKnight: Oh yeah you can go over to the theme park.

752

01:17:01.440 --> 01:17:02.940

Lily McKnight: and yellow sticky on it.

753

01:17:05.100 --> 01:17:08.280

Participant: Right well, no one choose mine, because I don't know what it is yet.

754

01:17:09.630 --> 01:17:11.430

Lily McKnight: It done i'll fight okay.

755

01:17:25.980 --> 01:17:27.420

Participant: changed the name of the theme.

756

01:17:28.620 --> 01:17:28.920

Participant: tonight.

757

01:17:32.220 -->01:17:35.670

Lily McKnight: Oh, my gosh trying to steal the show. 
01:17:35.790 --> 01:17:38.550

Participant: I just did the same thing you could probably click and drag it.

759

01:17:39.450 --> 01:17:41.250

Participant: Okay, and I think it's over top.

760

01:17:41.250 --> 01:17:43.590

Participant: Because that's what mine was, and I was like oh crap.

761

01:17:46.950 --> 01:17:49.320

Lily McKnight: Oh i'm letting your guys's jams.

762

01:17:59.490 --> 01:18:01.260

Participant: kaylee picking her own photo.

763

01:18:02.460 --> 01:18:03.120

Lily McKnight: wow.

764

01:18:04.680 --> 01:18:06.720

Lily McKnight: All right, who wants to talk about the gem.

765

01:18:09.150 --> 01:18:10.800

Participant: Oh, Sarah picked her own photo too.

766

01:18:11.460 --> 01:18:14.370

Participant: wow I didn't I was just move it.

767

01:18:15.360 --> 01:18:16.920

Lily McKnight: give her a second lily.

768

01:18:17.820 --> 01:18:19.170

Participant: Okay got it.

769

01:18:21.180 --> 01:18:23.370

Participant: whoo kaylee and Sarah pick the same one. 
770

01:18:27.450 -->01:18:29.550

Lily McKnight: That means works.

771

01:18:32.820 --> 01:18:33.210

yay.

772

01:18:36.330 --> 01:18:45.420

Lily McKnight: sticky note oh there it is wow that's so much fun okay so i'm going to go copy the gems and put them on their own side, so you mean on second.

773

01:18:52.260 --> 01:18:54.330

Participant: Oscar do that yeah.

774

01:18:55.320 --> 01:18:56.430

Lily McKnight: gem gems.

775

01:18:59.130 --> 01:19:03.420

Lily McKnight: Okay there's kaylee's jam and sarah's JAMA.

776

01:19:03.840 --> 01:19:05.040

Yes, ma'am.

777

01:19:08.160 --> 01:19:10.830

Lily McKnight: Okay, about works jam.

778

01:19:20.940 --> 01:19:21.720

Participant: Obvious here.

779

01:19:38.040 --> 01:19:38.430

I know.

780

01:19:42.870 --> 01:19:47.310

Participant: It and Paul he does Paul but he's mad at me right now. 
781

01:19:53.280 --> 01:19:54.690

Lily McKnight: Hello my fridge lily.

782

01:19:56.490 --> 01:19:58.020

Participant: I put his picture and everyone's.

783

01:20:00.510 --> 01:20:14.910

Participant: Like where is a little sweater and then this year really I don't know if I gave you one he did like a snow globe and he, like sat in this like glass bowl and then I like added little snow to it, and he was just like looking around he was so.

784

01:20:15.510 --> 01:20:19.020

Lily McKnight: Oh, my gosh I love him, he said, your.

785

01:20:21.300 --> 01:20:22.050

Participant: dog cat.

786

01:20:22.830 --> 01:20:23.190

Participant: Okay.

787

01:20:23.790 --> 01:20:25.140

Lily McKnight: i'm sure why you are living now.

788

01:20:30.930 --> 01:20:31.290

Participant: alright.

789

01:20:31.680 --> 01:20:33.540

Lily McKnight: So now.

790

01:20:34.920 --> 01:20:37.380

Lily McKnight: i'm we are going to write.

791

01:20:38.400 --> 01:20:57.630

Lily McKnight: Creative statements, so these a little insights of each of our gems so we'll have to we'll come up with for because we have four gems um so you can kind of think of 
the creative statement as almost like if you are going to post this like kind of like what would be the caption for it.

792

01:21:00.240 --> 01:21:01.950

Lily McKnight: So brainstorm first that.

793

01:21:02.880 --> 01:21:03.870

Participant: See if it'll have.

794

01:21:06.210 --> 01:21:08.130

Participant: The brain capacity to do this right now.

795

01:21:11.190 --> 01:21:12.420

Participant: it's been a long day $I$.

796

01:21:12.750 --> 01:21:13.590

Lily McKnight: really had.

797

01:21:15.810 - > 01:21:20.730

Lily McKnight: This is our last thing for the for the meeting, now that gets you guys through this our last.

798

01:21:21.480 --> 01:21:22.650

Lily McKnight: Our last bullet.

799

01:21:23.790 --> 01:21:26.100

Participant: was then I have mind, because I.

800

01:21:27.450 --> 01:21:34.440

Participant: So mine, if I were to like post it on, I would say something cheesy at first and be like teamwork makes the dream work.

801

01:21:34.830 --> 01:21:36.120

Participant: And then, like this.

802 
01:21:36.420 --> 01:21:48.300

Participant: This picture that one's mine like it's the one that I think I think mark put that on there um It reminds me a wvu like that's like trust the climb like.

803

01:21:48.780 --> 01:21:51.750

Participant: Well i'm home blah blah blah so.

804

01:21:51.840 --> 01:21:57.120

Participant: And i'm like sell me something even though it's like kind of a cheesy photo.

805

01:21:58.140 --> 01:22:01.410

Participant: still be like I would totally buy something from them.

806

01:22:01.710 --> 01:22:02.280

Lily McKnight: uh huh.

807

01:22:02.520 --> 01:22:05.670

Participant: And the fact that, like the sunset is in the background, so.

808

01:22:05.970 --> 01:22:08.760

Participant: uh huh something like that would be my creative senior.

809

01:22:09.000 --> 01:22:21.210

Lily McKnight: We love that we love that okay so let's let's pick on then lily let's let's do a creative statement for your PIC i'll give you here's a little text box.

810

01:22:22.800 --> 01:22:25.530

Participant: Well, I can't put teamwork makes the dream work because that's not creative.

811

01:22:26.160 --> 01:22:29.160

Lily McKnight: You totally can say whatever you want to say.

812

01:22:29.640 --> 01:22:31.200

Participant: You just say trust the climb.

813 
01:22:31.590 --> 01:22:33.240

Participant: Should I say trust the glide.

814

01:22:35.520 --> 01:22:37.080

Participant: Fine, but the view is great.

815

$01: 22: 38.010-->01: 22: 38.220$

I.

816

01:22:39.300 --> 01:22:39.990

Lily McKnight: love that.

817

01:22:40.410 --> 01:22:44.340

Participant: This guy listen that's what like MSG teaches you guys.

818

01:22:45.630 --> 01:22:47.010

Lily McKnight: As what you pay for guys.

819

01:22:49.560 --> 01:22:51.450

Trust the corn there we go.

820

01:22:52.770 --> 01:22:55.800

Participant: it's a new era, I never understood that one but.

821

01:22:58.650 --> 01:23:01.920

Lily McKnight: As we want to make this on trust the climb I love that.

822

01:23:05.520 --> 01:23:07.920

Lily McKnight: Alright, so one done three to go.

823

01:23:10.560 --> 01:23:12.240

Lily McKnight: let's do kaylee and sarah's.

824

$01: 23: 14.760-->01: 23: 15.480$

Participant: i'm. 
825

01:23:19.620 --> 01:23:27.600

Participant: The only thing that comes to mind like is like just something about change so sorry my dogs are wrestling.

826

01:23:28.260 --> 01:23:32.910

Participant: Around um but yeah just something about just you know.

827

01:23:35.070 --> 01:23:39.540

Participant: hands on work I don't know I don't know what the statement should be but.

828

01:23:40.470 --> 01:23:43.320

Participant: yeah i'll get this and i'm like I It makes me think of.

829

01:23:43.470 --> 01:23:50.670

Participant: Like when our parents, you say like someone always has it worse than you like never take what you got for granted, like.

830

01:23:50.910 --> 01:23:51.180

Some.

831

01:23:52.200 --> 01:23:53.940

Participant: Like that's what mission trips make me think of.

832

01:23:55.410 --> 01:23:58.020

Participant: Live laugh love.

833

01:24:00.630 --> 01:24:01.560

Participant: Better yet.

834

01:24:01.710 --> 01:24:03.570

Participant: alive hahaha.

835

01:24:08.850 --> 01:24:10.980

Participant: I think that should be, it should be it. 
836

01:24:15.750 --> 01:24:17.220

Participant: Not right on your.

837

01:24:20.250 --> 01:24:24.630

Participant: hey here's Bill Gates in an impoverished village somewhere live laugh love.

838

01:24:27.060 --> 01:24:27.360

Lily McKnight: guys.

839

01:24:28.500 --> 01:24:38.790

Lily McKnight: So traumatic and this just happened recently, so my my boyfriend's family and my family man he's from New Jersey and i'm from here, since.

840

01:24:39.060 --> 01:24:41.820

Participant: i'm so sorry i'm so sorry that you're doing so after New Jersey.

841

01:24:41.850 --> 01:24:42.390

Lily McKnight: I know.

842

01:24:42.420 --> 01:24:43.440

Participant: I know what's that supposed.

843

01:24:46.200 --> 01:24:46.560

Participant: To mean.

844

01:24:46.890 --> 01:24:49.080

Participant: Coming from long island, I understand, but.

845

01:24:51.030 --> 01:25:01.860

Lily McKnight: But, so we are sitting there talking and it's me my boyfriend's mom and my mom and my mom says she sees some commercial and she was like oh my God.

846

01:25:02.550 --> 01:25:19.170 
Lily McKnight: Literally lily I would never let you buy a sign for your apartment That said, live laugh love and let me tell you why I wanted to die in this moment, because my boyfriend's mom loves that quote it has it tattooed.

847

01:25:20.190 --> 01:25:45.780

Lily McKnight: On her leg and their meeting, for the first time in my mom goes oh my gosh lily I would never let you buy something with a stupid quote like live laugh love and literally I was like oh my God and then my boyfriend's mom is like Oh well, I actually really love that well I haven't.

848

01:25:51.030 --> 01:25:51.450

Lily McKnight: yeah.

849

01:25:52.530 --> 01:25:54.540

Lily McKnight: It was absolutely traumatic.

850

01:25:54.870 --> 01:26:01.980

Participant: I have never heard something worse than that ever in my entire life and I never will again that's The worst thing i've ever heard.

851

01:26:02.310 --> 01:26:03.270

Lily McKnight: $\mathbf{m m}$ hmm it was.

852

01:26:03.360 --> 01:26:06.720

Lily McKnight: It was so it was as bad as it sounds.

853

01:26:07.170 --> 01:26:14.040

Lily McKnight: Totally real and they just it just cannot have my mom's mouth like so quickly that there was no.

854

01:26:14.370 --> 01:26:18.060

Lily McKnight: There was no like stopping her or rescuing her from that.

855

01:26:19.080 --> 01:26:21.540

Lily McKnight: uh huh yeah so. 
01:26:23.250 --> 01:26:25.020

Lily McKnight: there's a lot to unpack there.

857

01:26:25.530 --> 01:26:29.070

Participant: girl i'm so sorry, you had to bring all of them no i'm sorry.

858

$01: 26: 29.400-->01: 26: 30.450$

Lily McKnight: I know i'm like.

859

01:26:31.860 --> 01:26:45.120

Lily McKnight: Like How is this worth it at home, no Okay, let me i'm so bad, let me tell you her other tattoo it's right here in his family and the why goes into the infinity sign.

860

01:26:48.120 --> 01:26:50.130

Participant: Listen you wanna bang or let's go.

861

01:26:50.700 --> 01:26:54.810

Participant: I got this patio it's like the scorpio thing I sent it to lily.

862

01:26:54.870 --> 01:27:03.750

Participant: She goes is that an $\mathrm{m}$ for a maverick like that's my cat's name I was like yes lily I got my cat initial tattooed on my wrist.

863

01:27:04.230 --> 01:27:06.570

Lily McKnight: it's like oh my gosh em for math.

864

01:27:08.880 --> 01:27:10.140

Lily McKnight: I just an idiot.

865

01:27:11.940 --> 01:27:12.240

Lily McKnight: yeah.

866

01:27:12.750 --> 01:27:14.490

Participant: How was your mom his relationship. 
01:27:14.490 --> 01:27:16.470

Participant: With his mom now are they are they.

868

01:27:17.310 --> 01:27:34.740

Lily McKnight: They actually did recover so after like a minute of like you know the shock value um my boyfriend's mom her name's amy she did start to laugh, and she was like my family makes fun of me all the time for loving that quote and i'm like oh my God.

869

01:27:36.060 --> 01:27:39.060

Lily McKnight: yeah yeah so.

870

01:27:40.890 --> 01:27:42.750

Lily McKnight: there's my take with live laugh love.

871

01:27:44.790 --> 01:27:48.750

Participant: Wait, so I think this one with the girl should be like fight like a girl.

872

01:27:50.310 --> 01:27:52.650

Lily McKnight: Oh Look how cute she is.

873

01:27:55.590 --> 01:27:57.930

Participant: And then, this one should be take the photo.

874

01:27:59.310 --> 01:28:00.390

Take the photo.

875

01:28:01.650 --> 01:28:02.790

Lily McKnight: Right, like a girl.

876

01:28:03.510 --> 01:28:09.810

Participant: Actually, these are kind of like really cheesy that all I have is like all it's in my brain right now is just like really cheesy quotes.

877

01:28:10.710 --> 01:28:13.890

Lily McKnight: i'm here for it, these are going anywhere people. 
878

01:28:13.920 --> 01:28:18.450

Participant: Make Dr press growth be like wow you guys shareware creative in your workshop.

879

01:28:20.190 --> 01:28:21.600

Participant: folder that I came up with them.

880

01:28:22.890 --> 01:28:25.410

Lily McKnight: i'll be like these are all at the hands of lily hates.

881

01:28:26.010 --> 01:28:29.370

Participant: I think the the wings of the woman and the man like come on.

882

01:28:29.370 --> 01:28:33.360

Participant: Like laughing or whatever to just be the handshaking emoji.

883

01:28:37.950 --> 01:28:39.210

Participant: And then she made a handshake and.

884

01:28:39.480 --> 01:28:43.140

Participant: We had the one last time, where the mojo was literally just as a hat emoji and I was.

885

01:28:43.140 --> 01:28:43.350

It.

886

01:28:44.670 --> 01:28:48.900

Lily McKnight: Press girls loved that she thought that was such art.

887

01:28:51.900 --> 01:28:52.950

Participant: I agree.

888

01:28:53.910 --> 01:28:55.380

Participant: yeah really just speak really. 
889

01:28:59.910 --> 01:29:00.540

Participant: What we're doing.

890

01:29:01.050 --> 01:29:01.260

Participant: Like.

891

01:29:01.350 --> 01:29:05.880

Participant: A praying man you guys are religious but that's what I think of mission trips so.

892

01:29:08.490 --> 01:29:12.210

Participant: All right, oh okay good good handshake handshake emoji.

893

01:29:14.340 --> 01:29:15.330

And then, like raising.

894

01:29:16.380 --> 01:29:20.730

Participant: her hand emoji okay amazing incredible.

895

01:29:22.320 --> 01:29:25.080

Lily McKnight: Oh, we love that she's in thing we're so cool again.

896

01:29:26.610 --> 01:29:27.480

Lily McKnight: It really is.

897

01:29:29.760 --> 01:29:31.710

Participant: it's like shaking hands with the Lord.

898

01:29:34.890 --> 01:29:37.770

Participant: Be oh yeah if God was Bill Gates.

899

01:29:40.860 --> 01:29:43.440

Participant: think he is gone so like words.

900 
01:29:45.210 --> 01:29:46.590

Participant: My computer parts guys.

901

01:29:48.720 --> 01:29:51.000

Participant: Are all injected with Bill Gates anyway so.

902

01:29:51.450 --> 01:29:53.430

Participant: I have been vaccinated.

903

01:29:54.930 --> 01:29:55.620

Participant: implanted.

904

01:29:55.710 --> 01:30:02.370

Participant: I don't know if you guys started your Microsoft Office free trial, yet, but when I got my vaccine card it came with a little Microsoft Office code.

905

01:30:02.670 --> 01:30:12.360

Participant: code unless in mine is like the extended warranty like I like I already had the free Microsoft trial, so when I got the vaccine, they just said, oh now you have like a lifetime.

906

01:30:12.630 --> 01:30:24.600

Participant: lifetime lifetime wow all right, but it is funny thing right a for like university stuff will have like clay marsh tweet something that's like obviously pro vaccine.

907

01:30:25.020 --> 01:30:32.820

Participant: And then someone will like quote it or reply to it, or like tweet something else be like yeah I just got my microchip and it's like them like smiling when it's like clearly a joke.

908

01:30:33.150 --> 01:30:44.790

Participant: And then there's always somebody was like oh my God you're just admitting to it now, all of this is horrible how could you possibly do that to your body and it's like the like users like dub the Republican 304.

909

01:30:48.750 --> 01:30:50.340

Participant: i'm doing this, a vaccine. 
910

01:30:50.460 --> 01:30:56.820

Participant: Like campaign and literally it's exactly the same thing, but like on a government scale so they're literally like.

911

01:30:57.330 --> 01:31:09.420

Participant: I don't know we probably shouldn't put okay anyway they're just like a few Jim justice like you're making I thought you were like a one of my bros but you're just like just like everyone else crazy.

912

01:31:09.480 --> 01:31:11.850

Participant: So me out to the friggin live is oh my God.

913

01:31:17.190 --> 01:31:20.130

Participant: Okay, now that we've hijacked your project lily.

914

01:31:20.310 --> 01:31:23.850

Lily McKnight: Know i'm here for it it's getting me through it honestly.

915

01:31:27.450 --> 01:31:29.910

Lily McKnight: So we're halfway down, we have these $T$ left.

916

01:31:36.690 --> 01:31:38.700

Participant: clue make the other one live laugh love.

917

01:31:39.420 --> 01:31:41.070

Participant: or something along the lines of.

918

01:31:41.760 --> 01:31:42.300

Like.

919

01:31:43.650 --> 01:31:44.520

Participant: live.

920

01:31:45.900 --> 01:31:48.930 
Participant: laugh play or something because it's the day of play.

921

01:31:49.200 --> 01:31:52.020

Participant: Oh that's a way to sneak it in there and still be.

922

01:31:52.020 --> 01:31:53.220

Participant: Safe and cheesy but.

923

01:31:53.760 --> 01:31:55.170

Lily McKnight: let's laugh play.

924

01:31:55.530 --> 01:32:00.750

Participant: Now, I think I think I think it works specifically since it's like maybe day playing like.

925

01:32:02.010 --> 01:32:02.310

Participant: yeah.

926

01:32:02.340 --> 01:32:07.020

Participant: My dad drives what we need is the worst caption you'll ever hear that's it yeah.

927

01:32:08.130 --> 01:32:08.370

Participant: that's.

928

01:32:08.640 --> 01:32:14.070

Participant: Good and I think the one with the camera should be worth a shot and then that can go in your like.

929

01:32:14.160 -->01:32:20.130

Participant: interior like finance campaign like raising money because it's like worth a shot.

930

01:32:20.790 --> 01:32:22.110

Lily McKnight: Okay, good. 
931

01:32:22.590 --> 01:32:24.720

Participant: deal itself is worth a shot.

932

01:32:25.140 -->01:32:26.160

Lily McKnight: I love it.

933

01:32:27.510 --> 01:32:28.410

Lily McKnight: Added in.

934

01:32:29.520 --> 01:32:34.440

Lily McKnight: Do I have to write it do you want to type it you get to do the honors.

935

01:32:36.270 --> 01:32:38.040

Okay, if I have to.

936

01:32:39.390 --> 01:32:39.570

Wait.

937

01:32:40.800 --> 01:32:41.250

Participant: For.

938

01:32:42.390 --> 01:32:42.870

Participant: A.

939

01:32:44.670 --> 01:32:45.300

Participant: All caps.

940

01:32:46.620 --> 01:32:47.670

first letter caps.

941

01:32:51.000 --> 01:32:51.990

Participant: Or we could do like.

942

01:33:01.980 --> 01:33:02.790 
Lily McKnight: You want it lily.

943

01:33:09.390 --> 01:33:14.850

Lily McKnight: It add some flavor obviously we'll see there was some like there is some meaning behind that.

944

01:33:16.200 --> 01:33:18.480

Participant: far as hey.

945

01:33:20.550 --> 01:33:22.290

Participant: i'm 13, and this is deep.

946

01:33:26.340 --> 01:33:28.470

Participant: The camera the lens of the camera.

947

01:33:31.080 --> 01:33:32.460

Participant: wait to see you all know.

948

01:33:33.930 --> 01:33:39.630

Participant: I can't remember the exact thing, but you guys, are you guys know, like the copy pasta, where it's like it was like.

949

01:33:41.760 --> 01:33:46.950

Participant: Oh, my God what is, what is the exact thing where it's like the some letters are capitalizing some or lowercase.

950

01:33:47.400 --> 01:33:56.970

Participant: And the one was like oh yeah I think I remember now, it was like the lowercase were ones was like she believed in like the upper case ones were like he lied and it's like oh yeah so deep.

951

01:33:57.330 --> 01:33:58.020

Participant: Listen, I.

952

01:33:58.350 --> 01:34:01.980 
Participant: really thought that this stem from like sponge Bob because of the sponge Bob mean.

953

01:34:02.100 --> 01:34:03.570

Lily McKnight: Like on the sound thing.

954

01:34:06.480 --> 01:34:08.790

Lily McKnight: that's hilarious.

955

01:34:10.020 --> 01:34:21.780

Lily McKnight: All right, well, thank you guys, for your lovely work and i'll ask you one last question you're free to go um so one two down here.

956

01:34:22.980 --> 01:34:34.110

Lily McKnight: If you could have a magic wand and when a bajillion dollars um and it had to go to the recall to media wet What would you do with that.

957

01:34:37.320 --> 01:34:38.700

Participant: I will make a new.

958

01:34:39.870 --> 01:34:41.130

Participant: Media innovation Center.

959

01:34:41.610 --> 01:34:41.970

Lily McKnight: yeah.

960

01:34:42.000 --> 01:34:43.650

Participant: pimping the shadow Martin hall.

961

01:34:43.740 --> 01:34:44.190

Participant: we're.

962

01:34:44.610 --> 01:34:45.780

Participant: gonna fly by the. 
01:34:45.780 --> 01:34:45.990

Time.

964

01:34:47.940 --> 01:34:50.430

Participant: we're gonna have a Martin hall prt station.

965

01:34:51.360 -->01:34:51.960

Lily McKnight: Oh.

966

01:34:52.230 --> 01:34:58.050

Participant: we're gonna have Omega is consciousness uploaded into a robot dog body so she can live forever.

967

01:35:00.330 --> 01:35:03.480

Participant: it's gonna be crazy we're going to be like look like what kinda.

968

01:35:10.770 --> 01:35:11.610

Lily McKnight: I love that.

969

01:35:12.840 --> 01:35:17.070

Lily McKnight: sounds great So is there anything else anyone would want to add.

970

01:35:21.870 --> 01:35:24.090

Participant: I don't I don't know if we can top that I think.

971

01:35:26.040 --> 01:35:27.510

Participant: Their corporate set the bar pretty high.

972

01:35:27.840 --> 01:35:29.010

Lily McKnight: $\mathbf{m m}$ hmm.

973

01:35:30.030 --> 01:35:45.150

Lily McKnight: Well, thank you guys so much for taking time out of your night to do this, I really appreciate it um maybe you're going to leave feeling really inspired to volunteer or donate or something i'm. 
974

01:35:46.290 --> 01:35:48.810

Lily McKnight: Maybe i'm not feeling inspired i'm tired.

975

01:35:50.940 --> 01:35:51.900

Participant: of money to donate.

976

01:35:53.340 --> 01:36:03.720

Participant: Like if I ever have enough money where i'm in the financial situation like like yeah i'll give on come on boys to college media like that'll be good, but I don't I don't foresee that happening for a long time so.

977

01:36:04.710 --> 01:36:09.600

Lily McKnight: we're gonna we're gonna wave a magic wand and you're gonna win a bajillion dollars.

978

01:36:12.000 --> 01:36:12.360

Lily McKnight: yeah.

979

01:36:12.480 -->01:36:13.260

Participant: I like the sound of them.

980

01:36:14.100 -->01:36:23.280

Lily McKnight: Well, thank you guys so much, I really appreciate it, this is the last thing we had so thanks for your help throughout the Semester and.

981

01:36:23.790 --> 01:36:24.240

I hope.

982

01:36:25.260 --> 01:36:25.740

Lily McKnight: You say.

983

01:36:26.340 --> 01:36:31.650

Lily McKnight: Hope you graduate me to sister I run keep a great that i'm.

984

01:36:32.730 -->01:36:40.260 
Lily McKnight: If I don't defend it on the 28th all I have to stay in school, so we don't want that, and we don't need that.

985

01:36:41.160 -->01:36:46.200

Participant: You got if Dr press grove What if you're defending is she attacking Is that how it works.

986

01:36:48.420 --> 01:36:52.140

Participant: to capture these hands if it doesn't go through options or fire.

987

01:36:52.350 --> 01:36:55.380

Lily McKnight: It they don't put me through i'm sending them straight to you corbin.

988

01:36:56.730 --> 01:36:58.620

Participant: yeah i'll i'll handle it.

989

01:36:59.100 --> 01:37:06.600

Lily McKnight: Thank you, thank you, thank you alright well have a good night everyone Thank you again like times a billion.

990

01:37:08.910 --> 01:37:09.540

Lily McKnight: Right.

991

01:37:10.260 --> 01:37:12.690

Participant: Now it says by I don't hear him but he's screaming.

992

01:37:13.290 --> 01:37:14.430

Participant: I thought I heard something.

993

01:37:16.380 --> 01:37:18.180

Lily McKnight: He wants to he's looking for you.

994

01:37:18.570 --> 01:37:20.130

Participant: He is literally right here, he says.

995 
01:37:21.330 --> 01:37:21.930

Lily McKnight: Oh.

996

01:37:29.880 --> 01:37:30.720

Lily McKnight: My gosh.

997

01:37:32.250 --> 01:37:33.510

Lily McKnight: Easter buddy.

998

01:37:36.540 --> 01:37:38.220

Lily McKnight: Alright, see you guys.

999

01:37:38.310 --> 01:37:38.730

Participant: bye oh.

1000

01:37:39.570 --> 01:37:40.170

yeah. 